\title{
Administrative professionals in New \\ Zealand: their professional development opportunities and career pathways
}

\author{
Ethelwyn Eva Lloyd
}

A thesis submitted in partial fulfilment of the requirements for the

Master of Education

Victoria University of Wellington 
I wish to dedicate this thesis to my Mother, who graduated from Victoria University of Wellington in 1935 with a Bachelor of Arts, but who sadly died when I was only 17.

I particularly note here, for those of you who wondered why I have taken this on, it is primarily because I can when for the majority of my life I never believed I could. 


\section{Acknowledgements}

I wish to sincerely thank my supervisors, Dr Liz Jones and Margaret Lamont, for patiently and politely keeping me on track, curbing my passion when required and ensuring that I kept my objectivity to produce an academic thesis. They kept me in tune with what was required and supported me through the many times that were challenging - thank you.

In addition, my thanks and deep appreciation go to Dr Deborah Laurs, my Learning Support Tutor, for keeping me going at all times, listening to me when the going got tough and never ever allowing me to sink to the level of giving up. Thank you for believing in me when I began to doubt and for always finding something positive and constructive in whatever I had done.

My appreciation goes to the survey participants (including the trial group) for taking the time to both respond to the survey and when requested, forward the survey to their own personal networks. Your involvement provided essential data for this research.

To all focus group participants (including the trial group), your commitment and the distances some of you travelled were appreciated. You gave so warmly and willingly, sharing your stories and insights into your profession which were central to the data gathered in this study. In particular I thank the participants who provided me with on-site support in each area, ensuring I and my facilitator had everything we required. You showed the true value of all administrative professionals taking everything in your stride. I acknowledge the difference it made to me having that type of support - thank you so much.

My friend, colleague and focus group facilitator, Wendy Rapana; arohanui and thank you for giving of your time, sharing your thoughts with me after each focus group and providing me with support throughout. In particular thank you for managing the facilitation process with skill and empathy. It was very comforting to place this crucial part of my research in your safe hands, thank you so very much.

Appreciation goes to Tricia Caughley for the final preparation of this document - your patience and understanding were legend. We have been friends for a long time, have worked together many times before and for me those same synergies were there when we 
took on this task. To Lynn O'Shea for the graphics in the model and a poster, your flair and knowledge were appreciated. Thank you both for your support and work to help me produce the best document possible.

My loving appreciation to my husband Charles, who is so relieved now this process is over and we can return to something approaching normal conversations which don't start with "I am struggling with ..." This has been a 6 year journey with only a little break in the middle, his support has been essential and provided without too many murmurs.

To my daughter, son and their spouses, "How's the thesis going?" is no longer the first question you need to ask. Thank you for understanding my single minded approach to life, especially over the past 18 months. I would also like to thank my cousin Jane in particular, who has provided support since I started this process in 2004. Your statements after reading things I wrote of "Now tell me what you are trying to say?" followed, after I obliged, with "Now go away and write that", will always stay with me.

My colleagues, friends, neighbours, clients and those who knowingly and unknowingly became my "external motivating force"; thank you for being there and providing me with the impetus to go on. In the future, you will no longer need to provide support and encouragement to me - it will be about you from now on!

I would finally like to thank my examiners for their thoughtful and valuable comments. Their input at the end of this process was the bit that convinced me that I had made a contribution and did have something of value to add. 


\section{Abstract}

This descriptive study to investigate the perceptions of administrative professionals of their professional development opportunities and career pathways was conducted mid-2009. The study used an on-line survey and focus groups. One hundred and ninety-three responded to the survey from throughout New Zealand. Fifteen of those respondents participated in the focus groups, held in both the North and South Islands.

The majority of participants were from larger organisations who perceived that training and professional development was available for them and supported. However, the professional development available was often ad hoc, with no specific goal.

Many participants perceive themselves as undervalued within the business world and noted that even where support for professional development was available there were significant barriers. These barriers, impacting on the availability and the uptake of professional development opportunities and career pathways, were both internal (value of self) and external.

A conceptual framework is presented of the relationship between the key elements from the research, value of self and value of the role, and the impacts of those on professional development opportunities and career pathways. 


\section{Table of Contents}

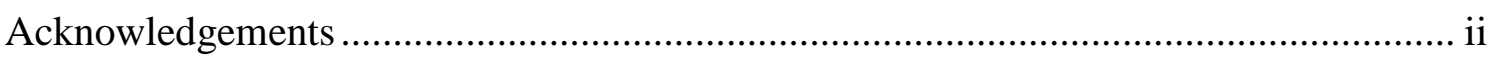

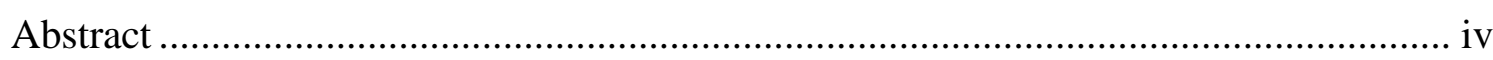

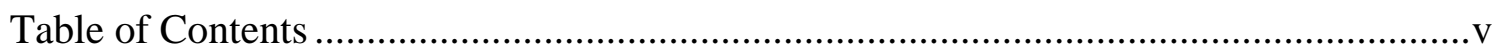

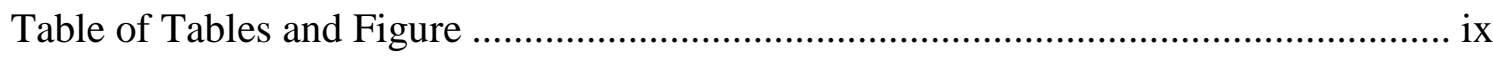

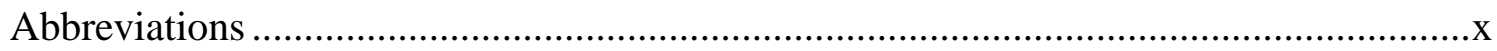

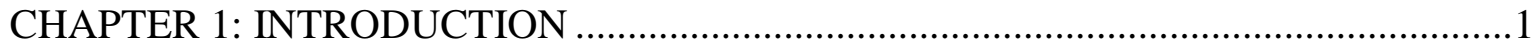

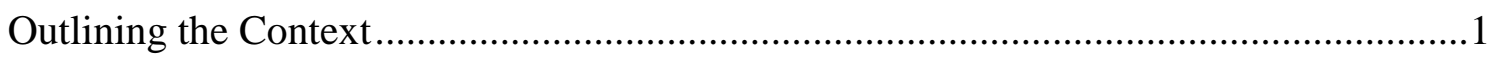

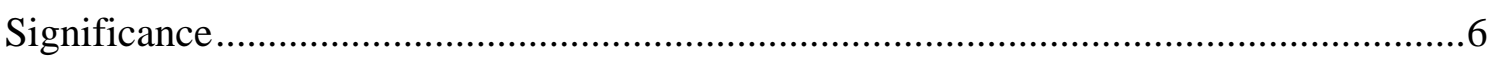

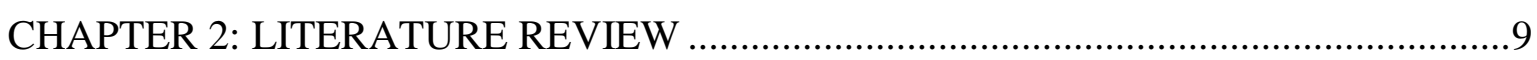

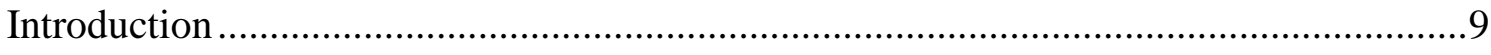

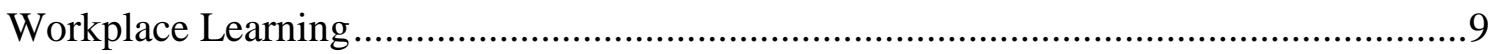

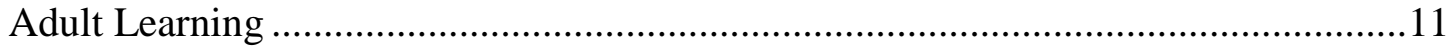

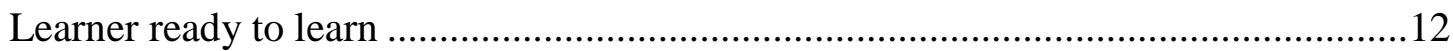

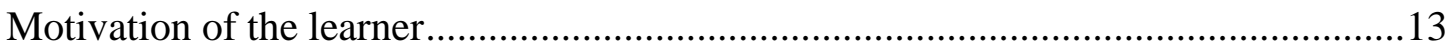

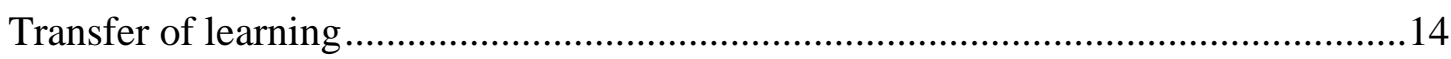

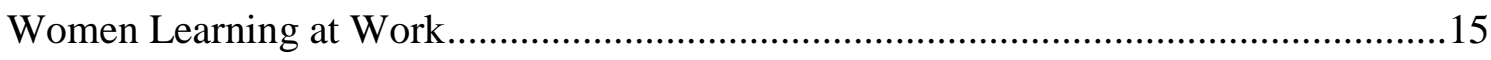

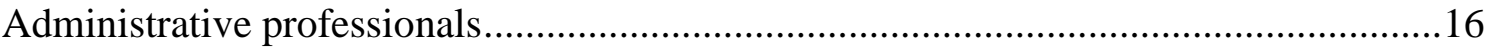

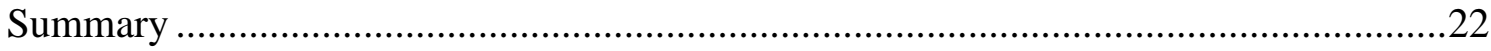

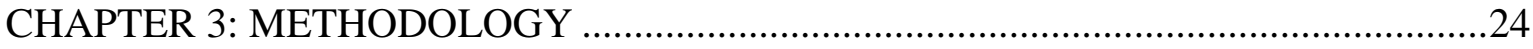

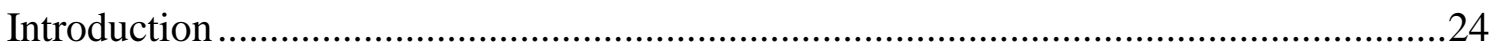

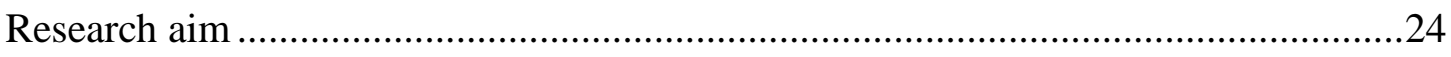

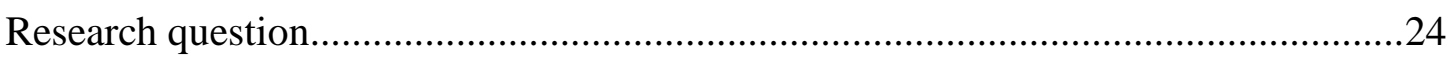

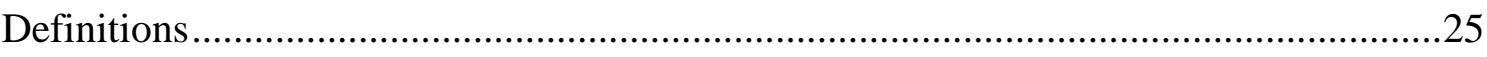

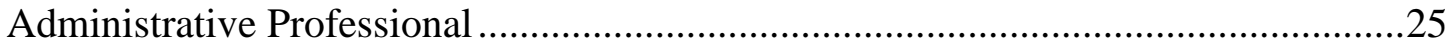

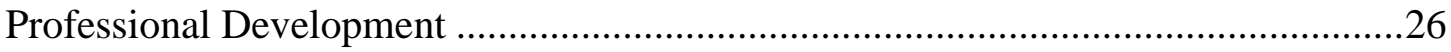

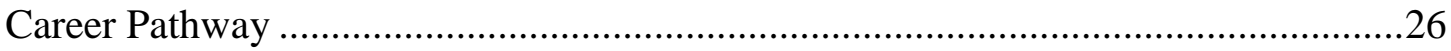

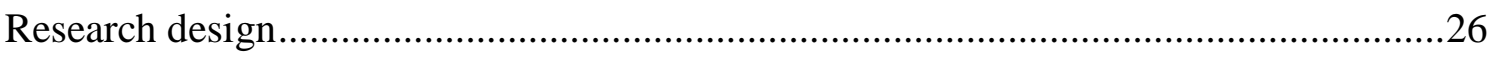

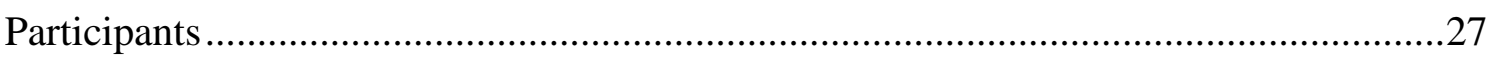

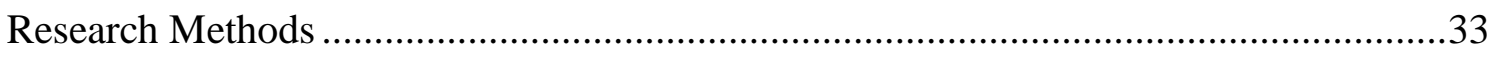

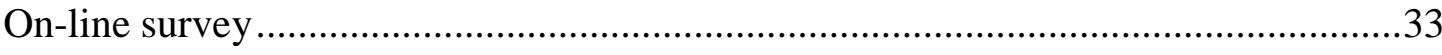

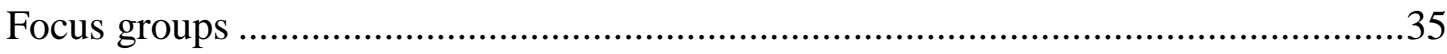

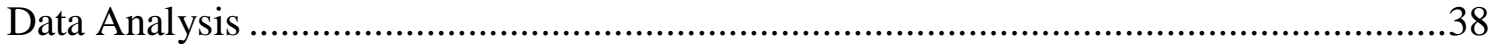

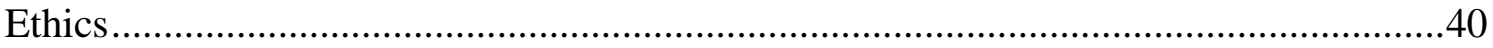




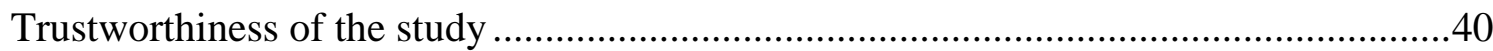

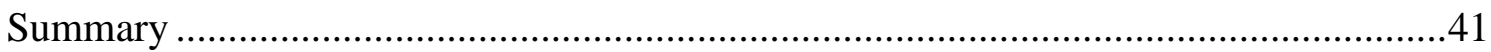

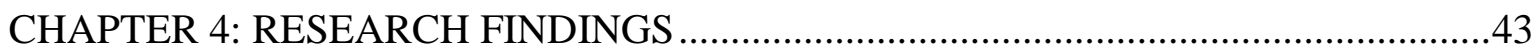

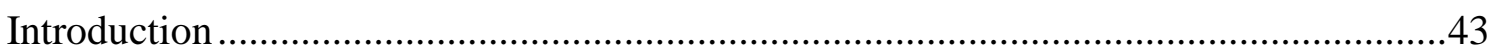

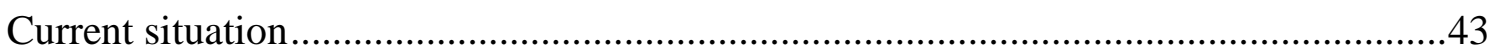

Knowledge of professional development opportunities............................................44

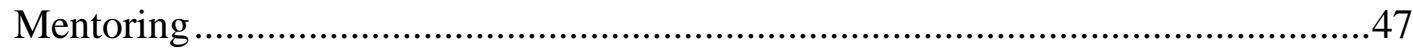

Access to Professional Development ...................................................................48

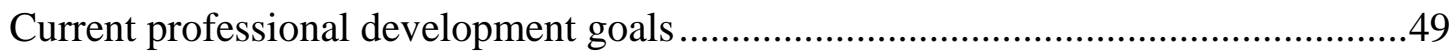

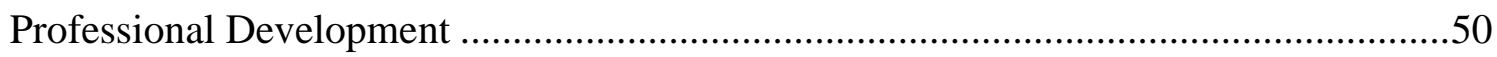

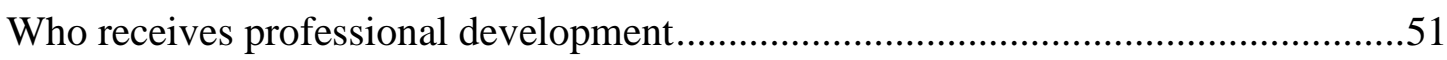

Importance of professional development …......................................................... 51

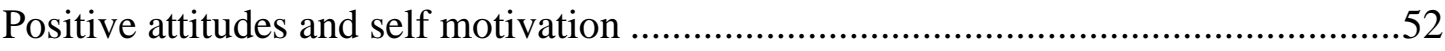

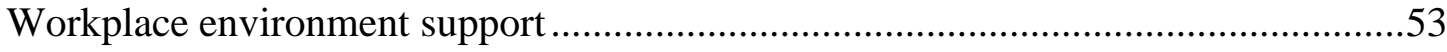

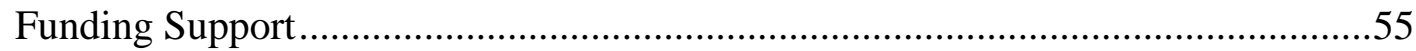

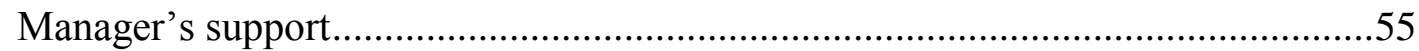

Providing a professional development pathway ..................................................56

Administrative professionals concerns ............................................................56

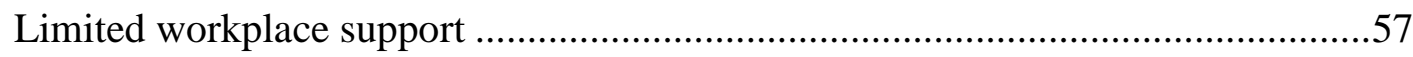

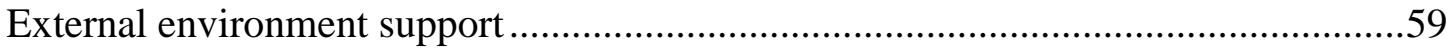

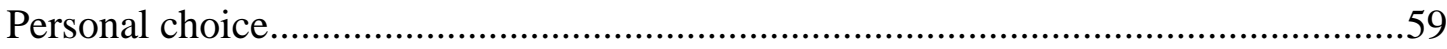

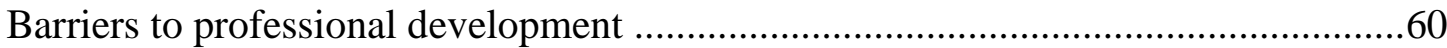

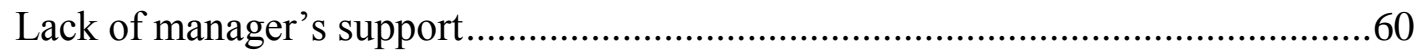

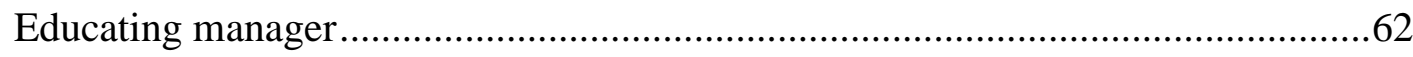

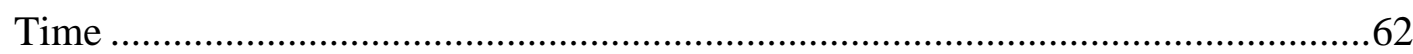

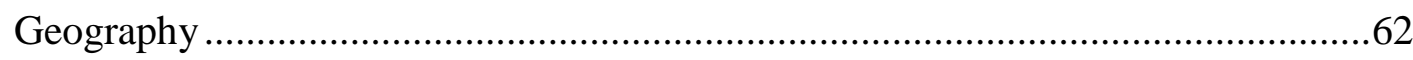

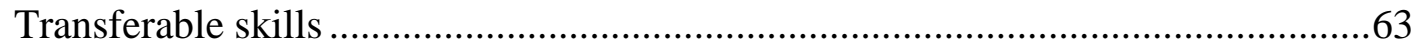

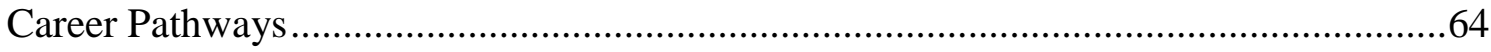

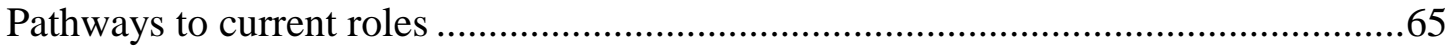

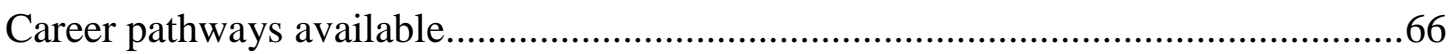

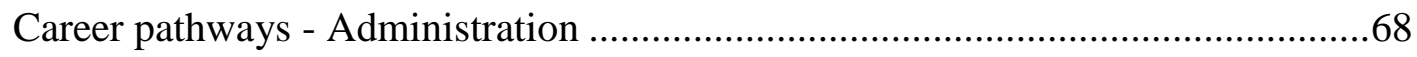

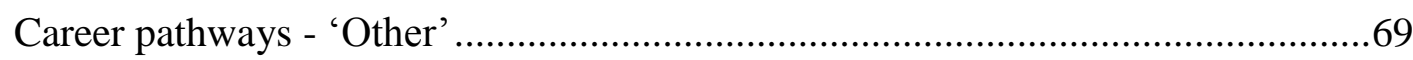

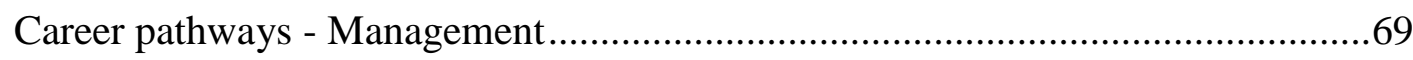

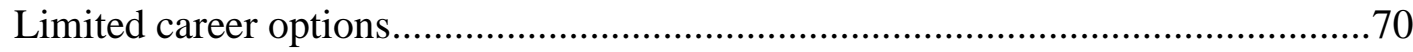


Personal choice - age and stage in life .71

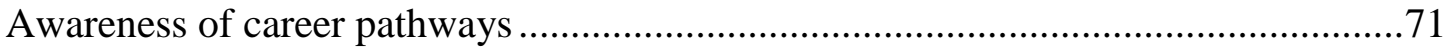

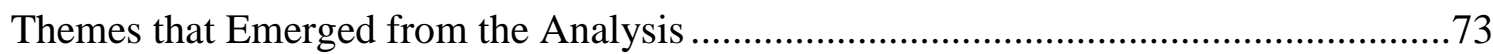

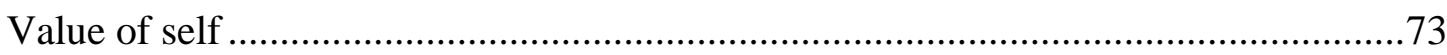

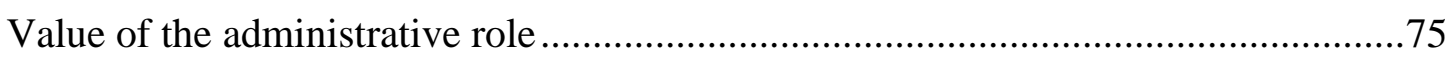

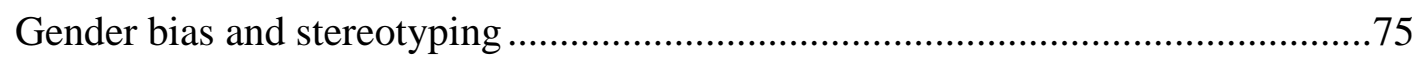

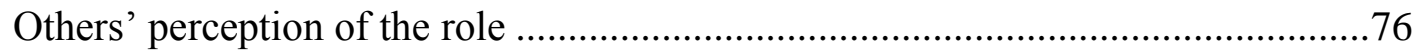

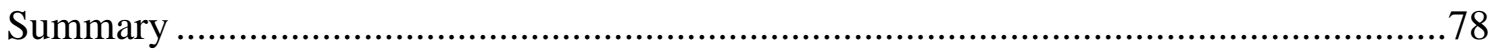

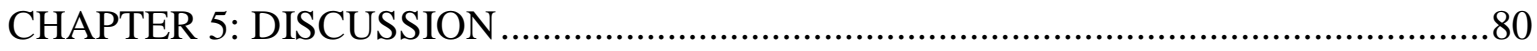

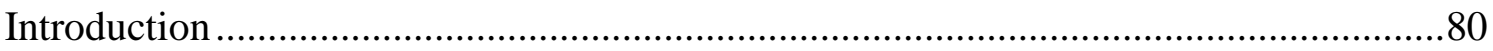

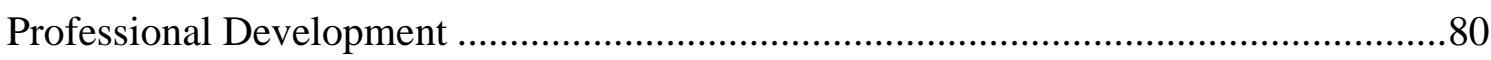

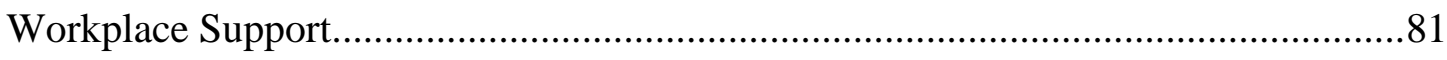

Informal learning - on the job, ad hoc and just-in-time........................................... 84

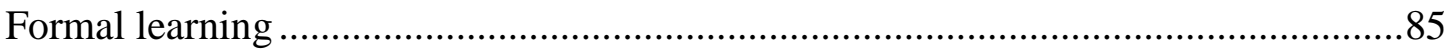

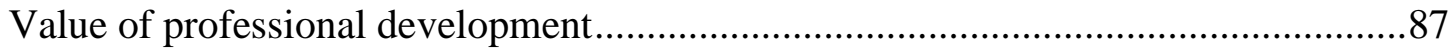

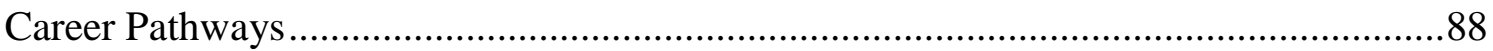

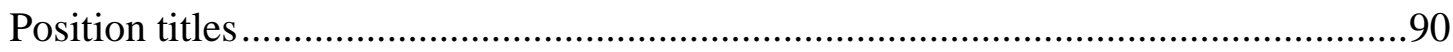

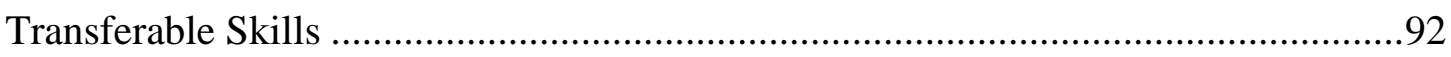

Value of Self/Value of Role - Conceptual Framework ..............................................92

External environment - home, social, work, geographical .......................................94

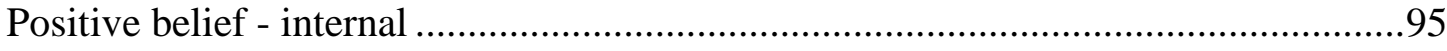

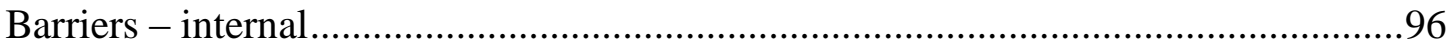

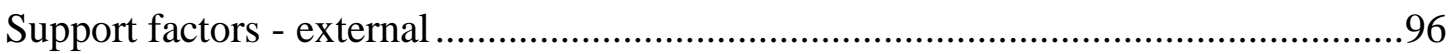

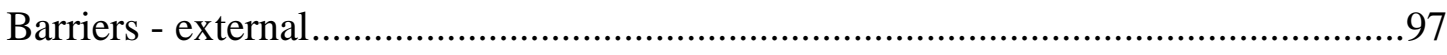

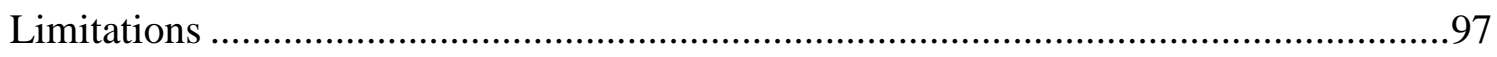

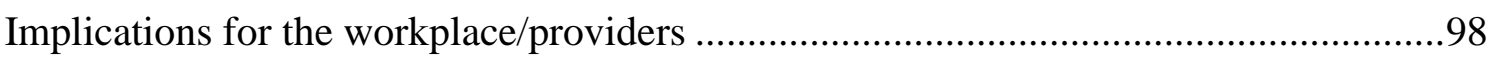

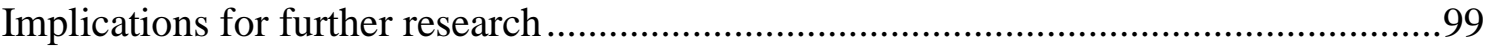

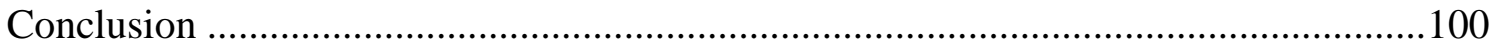

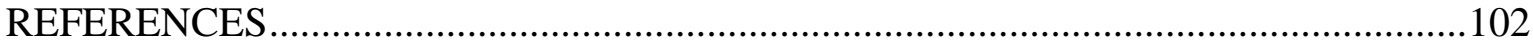

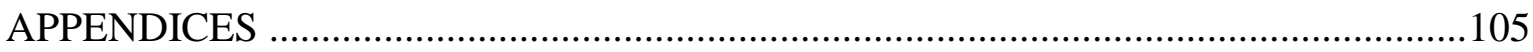

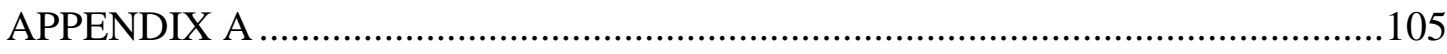

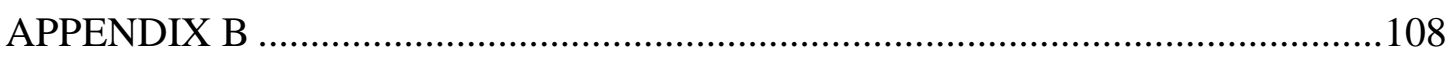

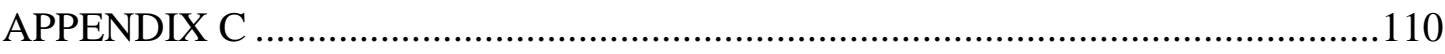

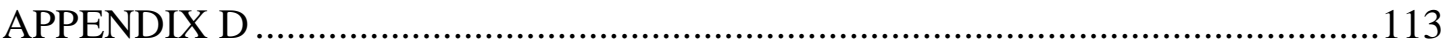




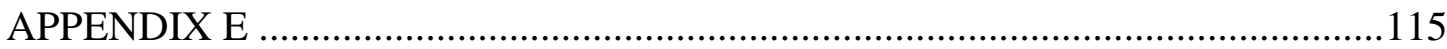

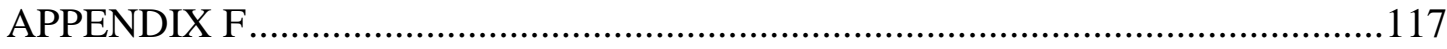

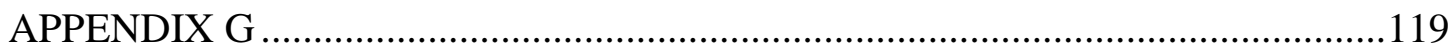

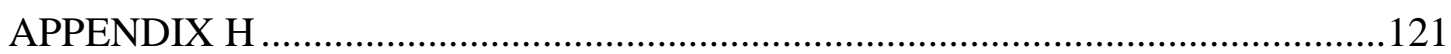

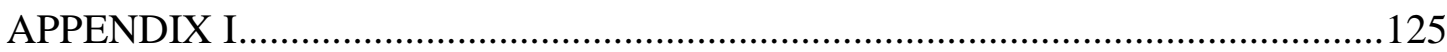

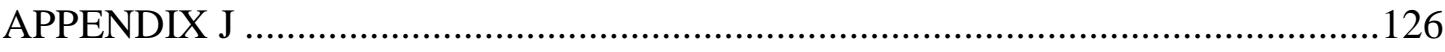

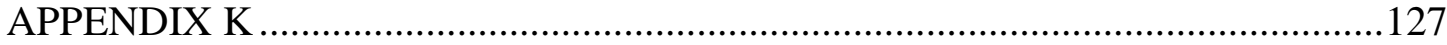

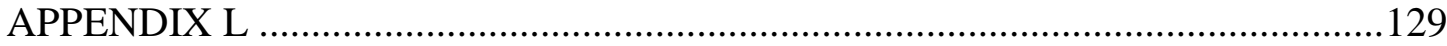

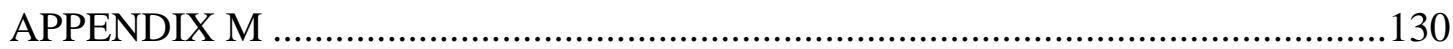

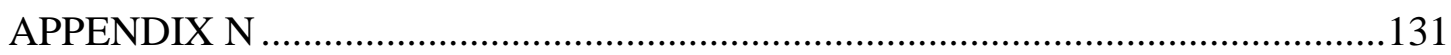

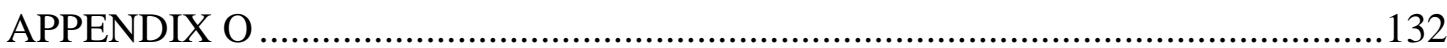




\section{Table of Tables and Figure}

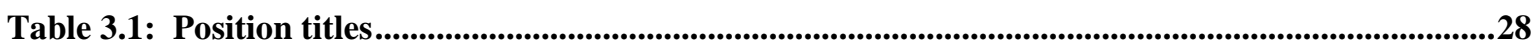

Table 3.2: Location of place of work ........................................................................................................................29

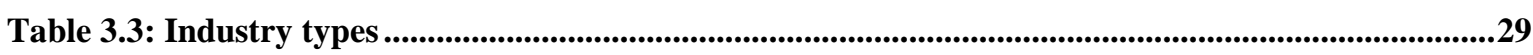

Table 3.4: Years working as an administrative professional................................................................30

Table 3.5: Number of people employed in own organisation ..............................................................................30

Table 3.6: Number of employees in own office ............................................................................................31

Table 3.7: Make up of Focus Groups ........................................................................................................................32

Table 3.8: Make up of additional Feedback Group ..............................................................................................33

Table 4.1: Professional development support available for administrative professionals .......................44

Table 4.2: Professional development opportunities available ...............................................................................45

Table 4.3: Types of professional development ................................................................................................45

Table 4.4: Professional development goals................................................................................................50

Table 4.5: Employees who receive professional development ............................................................................51

Table 4.6: Importance of professional development ......................................................................................52

Table 4.7: Employer support............................................................................................................................54

Table 4.8: Career pathways....................................................................................................................................67

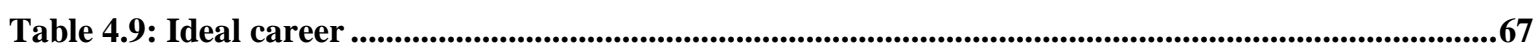

Figure 1: Conceptual framework of the interrelationship between value of self/value of role, professional development and career pathways.................................................................................................93 


\section{Abbreviations}

NZ

NZQA

AAPNZ

NEC

IAAP

SOLGM

BOP

MIT

CEO or CE

HR

PD

PA

EA

DHB

CV

Kiwi Quals

NZDipBus

NDBusAdmin

UK
New Zealand

New Zealand Qualifications Authority

Association of Administrative Professionals New Zealand Inc

AAPNZ's National Executive Committee

International Association of Administrative Professionals

New Zealand Society of Local Government Managers

Bay of Plenty

Manukau Institute of Technology

Chief Executive Officer or Chief Executive

Human Resources

Professional Development

Personal Assistant

Executive Assistant

District Health Board

Curriculum Vitae

NZQA's website which holds the register of qualifications in New

Zealand

New Zealand Diploma in Business

National Diploma in Business Administration

United Kingdom 


\section{CHAPTER 1: INTRODUCTION}

\section{Outlining the Context}

The nature and quality of professional development and career pathway prospects of administrative professionals became particularly interesting to me during my 13-year involvement with the Association of Administrative Professionals New Zealand Inc (AAPNZ) and my own personal history of 35 years as an administrative professional in a wide variety of roles and industries in several countries.

The classification Clerical-Administrative covers the wide variety of titles used in the workplace for employees who work in the many varied administration positions (Statistics New Zealand, 2010a) (see Appendix A). Of the total population in New Zealand, 1,985,778 are listed as employed. Of those 240,816 are listed as working in ClericalAdministrative roles. Of these Clerical-Administrative workers, four-fifths $(189,561)$ are women (Statistics New Zealand, 2010b). To explain the workplace roles covered by the overarching title of 'administrative professional', I have used the Australia New Zealand Standard Classifications of Occupations (ANZSCO) Classification 5: ClericalAdministrative (Statistics New Zealand, 2010c). As a representative body for the administrative workforce in New Zealand, AAPNZ has approximately 650 members (of which only three are male) from 15 groups throughout the country.

AAPNZ is the professional body for all administrative professionals. It is a not-for-profit incorporated society which was initially formed in 1972. AAPNZ's mission statement reads Our Association encourages personal and professional administrative excellence within a global network (AAPNZ, 2010d). I held the position of AAPNZ National President from 2002 - 2004 and am currently Co-chairman of their national Professional Development Sub-committee.

An important part of AAPNZ's benefits to its members is the provision of scholarships to achieve qualifications and opportunities for professional development. As National President for AAPNZ, I was instrumental in developing a certification process, launched in 2004 (Lloyd, 2004). While certification is a voluntary credentialing process for administrative professionals, its requirements are similar to those of recruitment consultants, teachers or chartered accountants. This programme has been widely 
promulgated to members and is listed on their website for non-members to be informed as well (AAPNZ, 2010b).

AAPNZ certification incorporates holding a formal qualification (NZQA Kiwi Quals registered) at level 5 or above with $120+$ credits, as one of its requirements. As a result of the certification process administrative professionals become informed of the qualifications that are available for them, either through a training provider or, through workplace assessment of skills and competencies they already hold. The AAPNZ certification process provides a professional development goal for administrative professionals.

Those AAPNZ members who have achieved their certification are listed on the website (AAPNZ, 2010c) and their citations list their formal qualification(s). The qualifications already held by AAPNZ members at Level 5 or above, range from the New Zealand Diploma in Business, the National Diploma in Business Administration through to a variety of academic degrees. However to date, only 7\% of AAPNZ members have achieved certification which suggests that few members hold formal qualifications. My interest in the availability and accessibility of professional development opportunities for administrative professionals has deepened over the past six years, as I have worked to assist them to gain national qualifications in the workplace.

In my role as an assessor, I often hear stories relating to the work environment. This anecdotal evidence seems to suggest that there is a lack of progression and limited opportunities to develop and advance professionally. Professional development or training is explained as being mostly available to develop skills for a specific task, however, this is usually informal, 'just-in-time' and 'ad hoc' training. These stories largely echoed my own experiences, further raising my interest in the experiences of professional development for administrative professionals and whether professional development includes planning that will lead to progression or career pathways in other areas, either individually or within the organisation.

The historical role of a secretary was as an exclusively male profession with considerable prestige, until its feminisation during and immediately after the First World War (Golding, 1986). The role of secretary, now incorporated under the wider 
title of administrative professional, has a more recent history of being under-valued and stereotyped as 'work that women do' which is a significant change from its beginnings. The impact of being under-valued and stereotyped may create a feeling of powerlessness for administrative professionals with regard to the ability to direct their development and change their status.

The limited research which has been undertaken suggests that administrative professionals often do not value their own role or see themselves as belonging to a valued profession and have no career expectations. In the past this may have been explained by women's assumption that their working life was limited to the 'before children' years. However, it does not explain the current situation for many women where working and care-giving roles often take place side by side and they remain in the workforce for the majority of their working life. This change in the roles of women may mean that a career pathway now has more relevance to the administrative professional.

Research in Australia in the late 1980s looked at the role of the secretary from a sociological perspective and the term "office wife" (Golding, 1986, p. 97; Pringle, 1988) was used to describe the types of tasks and the gendered nature of the role. The duties requested of the secretary, of providing support to the manager, were equated with those of a wife providing support to her husband. This similarity led to blurring of the tasks that were asked of the administrative professional. While there have been some changes to this perception there are still expectations today for many in the role that they will perform what are often referred to as personal tasks for managers (Truss, Rosewarne, Alfes \& Parr, 2009). The performing of personal tasks may be considered part of the highly gendered nature of the administrative role.

The under-valuing and stereotyping of the administrative role may result in an assumption that administrative skills are intrinsic to women. It may also be due in part to an expectation by the employer that administrative professionals do not require formal qualifications. These factors all may contribute to a lack of understanding of the professional development needs of administrative professionals. In my work with administrative professionals I became interested in whether this lack of understanding by employers becomes reflected in the way administrative professionals view themselves, therefore limiting their awareness of and drive for professional development. 
Employment in an administrative role does not require formal qualifications (see Appendix B), therefore many administrative professionals do not hold a formal qualification.

However, there are difficulties for administrative professionals moving out of the administrative role into other positions (Pringle, 1988; Truss, et al., 2009) and one of these difficulties is perhaps due to the lack of a formal qualification (Maguire, 1996). This difficulty of no formal qualification raised another area of interest for me - the effect of a lack of qualification on career pathways. It is important to recognise however, that not holding a qualification is a difficulty that administrative professionals can change if they wish, so I am also interested in whether there may be barriers preventing them doing so.

The following Dilbert cartoon provides a social comment on the perception of a lack of recognition for a secretary achieving a qualification. The cartoon strip also comments on performing personal tasks for the senior person and a perception that administrative professionals may be trapped in their roles.
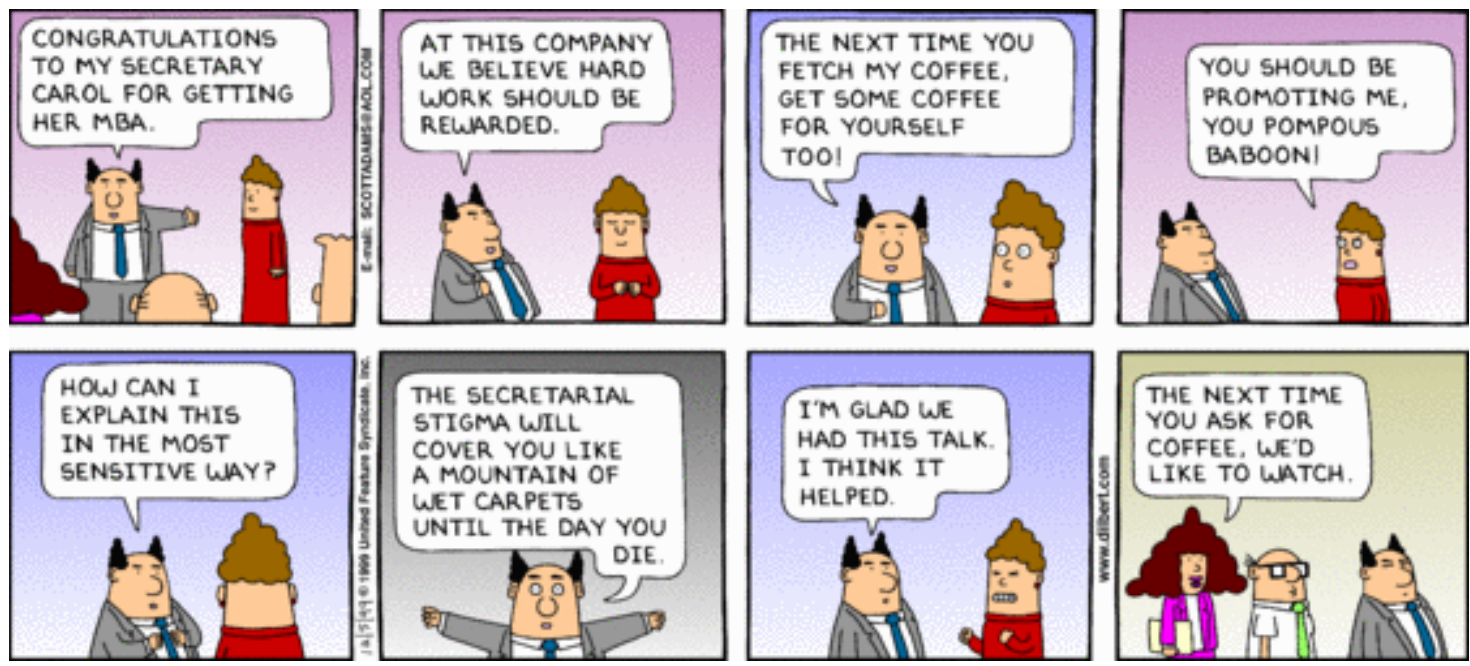

DILBERT: (C Scott Adams / Dist. by United Feature Syndicate, Inc. (Dilbert, 1999)

The development, almost 20 years ago, of the New Zealand Qualifications Authority's (NZQA) 'fit for purpose' business administration qualifications on the competency framework was positive for administrative professionals wishing to gain a relevant qualification. In the past there had been secretarial qualifications available but only through polytechnics. However the unit standards, developed under the competency framework were based on the work that administrative professionals actually do in the workplace recognising the skills they require (see Appendix C) or have. In addition these unit standards, and the qualifications they contribute to, are not solely available through 
polytechnics; they are able to be assessed in the workplace through recognition of current competency (RCC) using the day to day work that an administrative professional undertakes. The business administration qualifications available include: Certificates at Levels 2 and 3 in Business Administration and Computing, a Certificate at Level 4 in Business Administration and a Diploma at Level 5 in Business Administration (NZQA, 2010b).

A significant factor influencing the opportunities for administrative professionals gaining qualifications in the workplace is the structure of the Industry Training Organisations (ITOs). These bodies were grouped on industry lines and are a mechanism for providing funding and support to up-skill sections of the New Zealand workforce. ITOs are funded through the Tertiary Education Commission (TEC) and member industry subscriptions. Administrative professionals and/or clerical/office workers were seen, during the development of the ITOs, to be covered through all industry groups and were therefore not defined as a separate industry. ITOs provide a reporting mechanism of unit standards and whole qualifications achieved, to NZQA.

To undertake reporting, an ITO has to apply to NZQA and be accredited with the range of unit standards and qualifications (referred to as 'scope') they expect to report. For example, the building ITO would have applied for the scope to report to NZQA unit standards and qualifications relating to the building industry. However, business administration does not appear to be well covered throughout the ITO system. To date on the Industry Training Federation website only one ITO actually lists 'administration' under 'Work that they cover' and one more has 'public sector services' which may be presumed to include administration (Industry Training Federation, 2010). On the NZQA website, of the 38 ITOs listed, 22 have scope to report some business administration unit standards and 16 appear to not have applied for scope in business administration (NZQA, 2010a). However, over all 38 ITOs only five have a sufficiently comprehensive business administration scope to report a qualification at Level 5 and a further three for a qualification only at Level 4. Therefore, 30 ITOs at this stage cannot report business administration as a whole qualification above Level 3 and half of those cannot report business administration at all. This suggests that there may be within the ITOs, a lack of understanding of the level at which administrative professionals work and perhaps a lack of value of the work they undertake. 
Gaining a national qualification can be undertaken through three processes: through a tertiary provider gaining new skills, through workplace assessment recognising their current competency, or a combination of the two. Workplace assessment, while recognising current competency, may also identify gaps in their knowledge where they could up-skill, providing a professional development plan and goal. Of further interest to me therefore was whether administrative professionals had knowledge or awareness of the various ways to gain a qualification and the relevance of that qualification in formally recognising the work they do.

In summary the administrative professional role in New Zealand is primarily a female occupation. Their professional development is seen as being largely informal and while there are formal qualifications available, these are not required which may contribute to a perception of limited career pathways. These observations have come from my involvement with administrative professionals and are anecdotal. They have however, raised my interest in undertaking a systematic investigation of the situation for administrative professionals' professional development opportunities and career pathways.

\section{Significance}

To date only a very few research reports have been found and these specifically investigate secretarial staff only. The title 'secretary' has largely been incorporated under the overarching title of administrative professional in New Zealand (AAPNZ, 2010a) and internationally by the International Association of Administrative Professionals (IAAP) (IAAP, 2008). The most recent research investigates the professional development opportunities for Australian legal auxiliary (administrative) staff (Cavanagh, 2007) and secretarial work, skills and careers in the United Kingdom (Truss, et. al., 2009).

Cavanagh's (2007) work, while significant, has some limitations. It is focused on only one segment of the administrative work force (legal) and was carried out in Australia. Truss et al's (2009) research has similar limitations as it was based in the United Kingdom and is focused primarily on secretaries. The title secretary is one which is disappearing and was "used by just $4 \%$ of respondents" (Truss, et. al, 2009, p. 16). This change in position title from secretary and clerical to administrative professional, which is an overarching title covering both the others, has led to some lack of clarity over the roles, titles and tasks carried out within the role. 
The recent report by Truss followed on from her earlier research (Truss, 1993) which compared secretarial staff in three European countries. Truss looked at limitations placed on those who worked in this profession which may have 'ghettoized' it. This earlier work now 18 years old, investigates a workforce that has today changed significantly. Some of these changes involve significant changes in technology, organisational restructuring, and blurring of job titles and roles.

An understanding of what factors impact on the professional development opportunities of administrative professionals in New Zealand could significantly contribute to the current knowledge base and would be helpful for understanding the career pathways available to them. In addition, the limited international research and the lack of New Zealand based research on this specific group of workers, makes this research project significant. This lack of research has contributed to the limited understanding of the professional development opportunities and career pathways of administrative professionals in New Zealand.

The purpose of this descriptive study is to explore administrative professionals' experiences of, and opportunities for, professional development and how these affect their career pathways. It will provide a background to develop understanding of the current situation and a platform for future studies into the professional development needs and career pathways of this group of primarily female workers. The research will be conducted under aspects of feminist and participatory research methodologies and its primary aim is to give a voice to those in the administrative professional field, of their experiences.

The research will also provide a foundation from which to determine any differences between the professional development opportunities and career pathways for administrative professionals in New Zealand. It will perhaps begin the process of formal recognition of the skills and capabilities held by this highly gendered section of the workforce and encourage development of their career pathways.

The following chapters will examine the literature relating to administrative professionals, explain the methodology used in this research and outline the research findings. The research findings will then be discussed in relation to relevant literature and the conceptual framework 
will be presented. Finally, limitations of the study and implications for future development and research opportunities will be outlined. 


\section{CHAPTER 2: LITERATURE REVIEW}

\section{Introduction}

We live in an age in which adults, particularly those in or seeking employment, are expected to engage in education, training or learning throughout their lives. Such learning is believed to make individuals more productive, more adaptable and better citizens, and thus promote both the national economy and social well-being. (Hughes \& Tight, cited in Blaxter, Hughes, \& Tight, 1998, p. 69)

This chapter will provide an overview of theoretical and research literature that is relevant to the professional and career development of administrative professionals. As the workplace is the context within which professional development (education, training or learning) occurs and career pathways for administrative professionals are developed, this chapter will begin with an overview of workplace learning. As most administrative professionals are female, the different needs for some women learning at work are discussed, and finally the current situation with regard to administrative professionals and their workplace learning is reviewed.

\section{Workplace Learning}

There has been considerable change within the workplace, with a changing make-up of the workforce influenced by the retirement of the baby boomers, more women in the workforce, organisational restructuring including downsizing, layoffs and early retirements plus the technological advances leading to an information explosion (MacDonald, Gabriel, \& Cousins, 2000). The shift in demographics is demonstrated in the United States where in the early $20^{\text {th }}$ century half the population was under 16 where today only a quarter are under 16. The changes in society and the workplace are also evident in changing knowledge requirements. It is important for organisations to recognise these changes and to keep up with changing demands through developing the skills of their employees "the knowledge age is driving the need for continuous improvement within organisations" (Kostos, 2006, p. 79). The shift in focus to adult learners in our society (Merriam, Caffarella, \& Baumgartner, 2007) has led to a recognition of the learning needs of adult learners and a requirement for more, and more effective adult education and training. 
The workplace is an environment which provides learning for adults on a daily basis as they continually gain and improve the skills required to perform their work tasks (Lave \& Wenger, 1991). Billett (2001) states that learning in the workplace enables the learner to gain deeper knowledge while undertaking the task required.

Workers learn through a variety of processes that include formal and informal learning. Informal learning is a common process in the workplace to develop the skills required to perform a role, often through communities of practice (Wenger, 1998). For example, an administrative professional may be involved with others in similar roles forming a community of practice for those in administrative work where sharing and gaining knowledge of administrative skills occurs. The administrative professional may also be involved in other communities of practice - specific work groups or departments - where other more specific skills and knowledge may be gained and shared.

However, there is often a general lack of value placed on informal and experience-based learning (Lave \& Wenger, 1991). This is supported by Billett when he discusses that there is still a belief that learning undertaken in the workplace is not of the quality required to be a professional "Workplace experiences are viewed by key advocates (the trades, professions and educators) principally as ... inherently less valuable than those in educational institutions" (Billett, 2001, p. 4) and that learning occurs best in a formal environment.

One recognised and valued process for workplace learning is that used for apprenticeships where the outcome is a qualification to practise their trade. This is an integrated approach to gaining knowledge in the workplace and combines theoretical and tertiary learning with workplace experience (Billett, 2001). This integrated approach is consistent with the learning undertaken by administrative professionals where they combine informal learning in the workplace through communities of practice and 'doing the work' with participating in targeted training courses. In addition, study of theoretical knowledge underpinning those applied skills could be undertaken through formal learning at a tertiary provider and may lead to achieving a formal qualification. Due to recognition of current competence it is, however, possible for a qualification to be gained without further training or formal learning. 
An understanding of adult learning theories should increase the effectiveness of professional development experiences as they take account of the needs of adult learners.

\section{Adult Learning}

Knowles (1973), in his ground-breaking work, adopted the term andragogy for adult learning, recognising that adults learn in very different and less controlled situations than children (pedagogy). His description of the requirements of adults in learning encompassed the following four assumptions:

1. Changes in self concept which describes the development of the individual from being dependent to being self-directed. Lack of recognition of being self-directed can be perceived as being treated as a child, which produces resentment in the adult.

2. The role of experience acknowledges that the individual's experiences formulate what he or she knows and their recognition of 'who they are'. Importantly, where their "experience is being devalued or ignored, the adult perceives this as not rejecting just his experience but rejecting him as a person" (p. 46). This lack of recognition of an individual's experience gained will negatively impact the learning being undertaken.

3. Readiness to learn recognises that adults learn when they 'need' to know, as opposed to children where the assumption is made that they learn when they 'ought' to, due to their developmental stage. The adult learners' 'need' however is influenced not solely by their natural development but also by their environment, for example the workplace.

4. Orientation to learning acknowledges that unlike the situation for children where their learning is focussed on what they need for their future (e.g., primary school learning leads to secondary school), adults seek learning to resolve a problem or inadequacy they have encountered in the present (Knowles, 1973).

Although Knowles' theory is nearly 40 years old and there have been challenges to his assumptions, I believe these assumptions still have direct implications for professional 
development and in particular for the professional development of administrative professionals.

The complexity of education theories is further explored by Fenwick and Tennant (2004) who describe four adult learning processes. Of these four learning processes, the most relevant to this study is the practice-based community process due to the perception that 'learning-on-the-job' is undertaken by many administrative professionals. Learning as a practice-based community process takes place within the environment and situation in which the learner is involved; not solely as an intellectual process through reflection (Fenwick \& Tennant, 2004). It has its roots in social and situated learning theories. Social learning is learning that occurs from modelling the behaviour of others (Bandura, 1977). Situated learning is, simplistically, learning that occurs in the same context (situation and environment or community of practice) in which it is applied (Lave \& Wenger, 1991).

The effectiveness of the professional development experience is demonstrated when consideration has been taken of specific criteria which learners must meet (Noe \& Colquitt, 2002). Since the focus of this research is the learner, and not the delivery of training, the most relevant of Noe and Colquitt's criteria to this study are: the learner being ready to learn; the motivation of the learner; and transfer of learning to the workplace.

\section{Learner ready to learn}

There are various conditions that influence adult learners' readiness to learn. For those many adult learners who have had a negative educational background their approach and attitudes to learning are influenced by this background (Wlodkowski, 1999). It is important to ensure that adult learners have choice in their learning, that the training has relevance to the learner and their work and has meaning so they can see the value of the training. Wlodkowski suggests that even with a positive attitude and feelings of inclusion; without meaning and relevance, the value of the learning is reduced.

For those adults who have had a negative educational background, learning-to-learn as a pre-training technique may be required. Learning-to-learn supports improved learning through recognising and accommodating the different learning needs of individual learners (Burns, cited in Kostos, 2006). 
Other factors which support the adult learner in being ready to learn are involving them in the design of the learning and in the learning process, thereby creating a feeling of ownership. In addition Noe and Colquitt (2002) raise the importance of self efficacy; which is a learner's belief that they have the ability to learn the content of the training, which in turn influences the learner being ready to learn. Self efficacy plays a significant part in the motivation of the learner.

\section{Motivation of the learner}

The value of motivation in adult learning is highlighted by Blanchard and Thacker (2004) who state "if motivation is lacking no learning is likely" (p. 196). Motivation of adult learners comes from four conditions "inclusion, attitudes, meaning and competence" (Wlodkowski, 1999, p. 69). The social environment the learner is in may foster a feeling of inclusion. This environment may, for example, be the culture of where one works or the environment created by a trainer. Attitudes come from within, strongly affecting behaviour and learning and providing a framework within which to respond to situations (Wlodkowski, 1999). Motivation is also aligned with value or relevance in the training and learners' belief in their ability to succeed in it.

The competency of the learner positively impacts upon self-confidence and self efficacy which in turn promotes learning. "To feel assured that one's talents and effort can lead to new learning and achievement is a powerful and lasting motivational resource" (Wlodkowski, 1999, p. 79). There would seem to be an interrelationship between identity or sense of self, self efficacy and learning and that identity is shaped by the individual's intentions and their actions. Experiences in social environments, such as the workplace, promote changes in the individual's knowledge and their sense of self or identity (Billett \& Somerville, 2004) which, if positive, will enhance the learning experience.

Several other factors which affect a learner's ability to learn include: an individual's involvement with and reaction to the social world; the processes of thinking, doing and learning at work; how life experiences shape the understanding of the practice of their work; and changes in the workplace which may evolve from the way an individual redefines their work practices (Billett $\&$ Somerville, 2004). In addition there are underlying but strong influences from the way the social world sees a work role and the individual 
working in it, which the individual can choose to buy into or ignore (Billett \& Somerville, 2004).

The effectiveness of adult learning in professional development experiences is best demonstrated through transference of learning into the workplace.

\section{Transfer of learning}

Research shows that the recognition of adult learning theories in any style of training or learning will greatly enhance the learner's ability to learn and assist in transferring the learning back to their workplace, which demonstrates the effectiveness of training (Cheetham \& Chivers, 2001). There are various tools or techniques which support this transfer. One technique is to create a partnership between the trainer and the adult learner, rather than the more formal teacher/student relationship (Bowerman \& Peters, 1999).

Central to the transfer of learning is support in the workplace from supervisors (or managers), peers and subordinates (Analoui, 1993; Blanchard \& Thacker, 2004; Noe \& Colquitt, 2002) and this is further supported by Facteau et al., and Tracey et al., (cited in Salas \& Cannon-Bowers, 2001). However, as there is often insufficient support in the workplace to ensure transfer of learning occurs, support for the learner through selfmanaged learning is important to facilitate the transfer (Noe \& Colquitt, 2002).

Another training tool or technique is simulation, where work scenarios are used as part of the learning process, making the learning 'real' and relevant, supporting the transfer of that learning to the workplace (Bowerman \& Peters, 1999). Simulation is a process common within tertiary institutes delivering business administration unit standards. A functioning 'business centre' is set up to practise the foundational skills learned by the students, mimicking those situations that may be encountered when they join the workplace.

In summary, changes in the workplace and the make-up of the workforce have led to an increased need for more effective adult learning in the workplace. Professional development is provided from different sources ranging from informal learning in the workplace to attendance at industry conferences through to formal training with an educational provider. Professional development experiences are greatly enhanced through 
trainers having an understanding of adult learning theories. Also, for learners to best engage in learning, readiness to learn, motivation and support for the transfer of learning into the workplace are important criteria. In addition feelings of competency, confidence and self efficacy in the learner promote a sense of self worth which impacts positively on an adult learners' ability to learn in the workplace.

\section{Women Learning at Work}

While the application of adult learning theories enhances adult learning experiences, it is also important to take account of some specific needs of female adult learners. Studies into the training and development of women in the workforce have shown there may be some specific issues to be addressed. For example, some women's preferred learning approaches involve relationships, interactions and support (Hayes \& Flannery, cited in Bierema, 2001). On-line learning provides an example of how the requirements of the learner may not be adequately addressed and outlines a conflict between the preferences of the manager and the potential requirements of the learner in this situation. A preference is expressed by some managers for on-line learning because it enables administrative professionals to learn without leaving their desks, but it may not support women's preferred learning needs due to the absence of a human instructor (Martin, 2000, 2002).

The power structures within the workforce (Bierema, 2001), plus the lack of a sense of self where women undervalue what they do (Fenwick, 1998), may negatively impact on learning opportunities for women. The value of the workplace as a source of learning and development and development of self is raised by Fenwick (1998). She notes the complexity of this for women where family and other commitments have a significant impact upon their learning and sense of self. Fenwick (2002) further raises issues of sense of self for women in the workplace in that "women's businesses don't count or aren't important or serious ... these images are internalized by some women, who may unconsciously participate in their own diminishment. ... 'We [women] have a tendency to undervalue what we do"” (p. 225). These findings by Fenwick are reflected by those expressed in relation to the administrative professionals' lack of value of self and their role (Lloyd, 2003). This lack of value of self may also be promoted by the role women have in society generally. 
The same power structures that are in society are reflected in the workplace (Bierema, 2001) and these power structures can provide an inequitable situation for women in the workplace. Cavanagh (2007) discusses how the overall workplace experiences of many female workers are affected by the learning they are able to undertake and the variety of conditions which impact on their learning. These conditions include: richness of the learning opportunities, the effects of equity and ethics, the impact of discriminatory language, and the economic needs of an organisation in terms of worker development. Cavanagh (2007) also notes that "It is through their learning that women's opportunities will be expanded, yet women's access to support and affordances for learning are set within the very structures which inhibit women's progress" (p. 11) which further supports Bierema's 2001 research.

In summary women's needs in relation to professional development may not always be adequately addressed due to some different requirements for female adult learners. These different requirements include: preferred learning approaches, the impact of learning on their sense of self, power structures in the workplace replicating those in society, the learning women can access, and the quality of the learning opportunities.

\section{Administrative professionals}

Administrative professionals, as adult learners in the workplace, need to engage in professional development in order to keep up to date with their skills and to progress within their field. However there is little known about how this occurs for administrative professionals or what effect such professional development has on their career pathways.

Internationally, prior to 1992, there has been a limited amount of research into secretarial staff (Truss, 1993). There has been little research undertaken in New Zealand into this specific group of workers other than a study by Maguire (1996) which focused on the changing roles of secretarial staff in Australia and New Zealand. Three recent international studies also focus on secretarial staff and are based in the United States of America (Kennelly, 2006), Australia (Cavanagh, 2007), and the United Kingdom (Truss, et al., 2009). This lack of research is a significant gap in the knowledge of a large group of primarily female workers. 
The employment classification of Clerical-Administrative workers in New Zealand lists 240,816 working in this field, of these four-fifths $(189,561)$ are women (Statistics New Zealand, 2010b). The highly gendered nature of administrative work is a situation which has changed little since the 1940s (Truss, 1993). This is confirmed by Maguire (1996) with $99.5 \%$ of respondents being female, and Truss et al (2009) in their recent study, where only $1 \%$ of their respondents were male. However, these studies all focused on secretarial staff and the following two paragraphs will outline the situation with regard to role titles within this group of workers.

Most researchers over the past thirty years (Golding, 1989; Kennelly, 2006; Maguire, 1996; Pringle, 1988; Truss, 1993; Truss, Goffee, \& Jones, 1995) have focused primarily on secretarial workers. Today, the changes in the workplace have blurred role definitions and titles as demonstrated by the wide variety of position titles listed on the Career Services website (Career Services, $2007^{1}$ ), tasks (see Appendix D) and in the New Zealand Census information (Statistics New Zealand, 2010a) (see Appendix A).

This blurring of role definitions and titles is further demonstrated by the change of titles internationally for the professional associations which were formerly based around secretaries and which now encompass administrative professionals (AAPNZ, 2010a; IAAP, 2008). It is also shown by the small number (11\% of 1011 respondents) who had the word secretary in their job title in the recent United Kingdom study by Truss et al. (2009). Another recent example of blurring of roles and titles is provided by the variety of titles used in the recent workplace survey involving 3,177 North American respondents (IAAP, 2009), where nine job titles were listed, but 26\% (826) indicated they had 'other' titles.

The research over recent decades has outlined some expectations for those working in the administrative field. This research indicated that there appeared to be a perception that women had inherent skills in nurturing which made them specifically suited to the roles providing administrative support. Therefore many of the skills required for administrative work were assumed to be intrinsic and contributed to the use of the term "office wife" (Pringle, 1988, p. 5). The term "office wife" was frequently used in relation to secretarial tasks during the period 1950 - 2000 (Golding, 1989; Pringle, 1988; Truss, 1993; Truss, et al., 1995). These implications are also raised by Maguire (1996) where she discusses

\footnotetext{
${ }^{1}$ Career Services are currently (2010) reviewing these position titles and tasks; this will be the first review since accessing this site in 2007. The previous review was in 2005.
} 
"peripheral tasks such as office house-keeping" (p. 37) and further "the highly personalized, 'office-wife' nature of many relationships between secretary and superior" (p. 42). A submission from the Public Sector Association to the Department of Women's Affairs Pay Equity document ${ }^{2}$ states, "Lower pay could be a result of their occupation being female dominated ... and being seen as technical rather than professional; or as an extension of women's domestic role" (2003, p. 17), showing a continuation of women's roles being seen in the light of their perceived intrinsic skills.

Truss et al. (2009) discusses performing personal tasks as part of the administrative role perpetuating negative perceptions where they; "serve in part to perpetuate the gender segregation of the role and negative perceptions of secretarial work and its status" (Henson \& Rogers, cited in Truss et al. 2009, p. 34). The column in the Times On-Line, commenting on Truss et al.'s report, indicated that the negative perceptions of the administrative role are still present: "it [secretarial work] is essentially menial. And if secretaries can't cope with this, then it probably means they are overqualified" (Sanghera, 2009).

An alternative perspective on the use of nurturing skills in this service provision role is that these skills are used by men and women based on a desire to provide a public service; a time honoured role in the work force. However, their use in secretarial work is perhaps not recognised as providing a public service:

Since secretarial work is one of the few paid labor market options available to many women who desire a career of public service, and since so many women do enact their ethic of service in their secretarial jobs, it is important that organizations recognize and compensate the public service work that secretaries do. When we, as a society, attribute valor to individuals who commit their lives to public service occupations, we must not overlook the ethic of service that guides so many secretaries and compels them to contribute to the society's greater good (Kennelly, 2006, p. 188)

\footnotetext{
${ }^{2}$ This document is about pay equity for women generally. I, as AAPNZ National President, put forward a submission to this document from the perspective of administrative professionals. The quoted comment relates to the service roles that women generally are in, not specifically about administrative professionals. However administrative professionals provide a service so are part of the service industry.
} 
It is, perhaps, the negative perceptions about the role that contribute to this lack of recognition of secretarial work as a public service; a provision of service which can be seen as being of value. Kennelly's research does however highlight the earlier perceptions that the technical skills required for the administrative role were seen as being intrinsic in women: "As one secretary put it 'typing is seen as something every woman can do - like washing up!'” (Pringle, 1988, p. 3).

The degree of competence in technical skills such as typing and shorthand previously required for the secretarial role would often determine the level of role undertaken. However, there was no recognition of qualifications held (Maguire, 1996) and no requirement for a specific qualification. For example in New Zealand, while there are qualifications available (NZQA, 2010b) which may be recommended, they are not a requirement for employment in an administrative position. Statistics New Zealand (2010c) indicates an acceptable alternative is noted as having 'a specific number of years relevant experience' (see Appendix B).

Many administrative professionals gain the skills and experience required for their role within the workplace through social interaction with others in similar roles or communities of practice (on-the-job), self tuition and, 'just-in-time' or 'ad-hoc' informal training when required. While these are acceptable methods of learning task specific skills, they do not lead to a qualification or identify a career pathway; however this informal learning appears to be the predominant mode of professional development available to most administrative professionals (Truss et al., 2009).

The IAAP website industry articles identified that administrative professionals have a need for increased skills. These skills are largely in areas that have traditionally been considered management, such as leadership, project management, team building, multi-tasking, communication, public speaking and Board interaction (IAAP, 2010).

Cavanagh's (2007) research conducted in Australia shows there is still a continuation of separation between professional staff and auxiliary staff (administrative professionals) in the legal field, especially in relation to professional development. Truss et al. (2009) in the United Kingdom reported on a lack of, or limited professional development received by their survey respondents. Training received was primarily in technical, time management, 
interpersonal and staff management skills. Strong interest was expressed in receiving more training primarily in project and event management, presentation skills, HR, negotiation, management skills and personal image. Fewer than half of those surveyed felt they were encouraged to undertake training and development. However "four-fifths [of those surveyed] believe a recognised professional secretarial qualification would raise the status of secretaries" (Truss et al., 2009, p. 15). This finding reflects the interest expressed by administrative professionals in AAPNZ Certification since 2004 (AAPNZ, 2010c).

The lack of a required qualification and a subsequent lack of clear career pathways contribute to the perception held by both employers and employees that administrative work is work 'that anyone can do'. However, not holding a qualification is something that administrative professionals can change. This is highlighted in a report by Maguire (1996, p. 48) where she states that "secretaries themselves need to be proactive not reactive in respect to qualifications".

Many administrative professionals achieve their skills through being involved in informal learning through communities of practice (Wenger, 1998) in the workplace and other social groupings in which they are involved, for example AAPNZ or participating in a school Board of Trustees. Industry commentators advocate that administrative professionals should take advantage of training offered through their employer and through professional and business magazines, or they can pick the skills up on their own through on-the-job learning (Martin, 2002). Other methods of undertaking professional development recommended are self tutorials, joining professional organisations, gaining leadership skills through community work, and taking on internal volunteer projects (Fenner, 2004). However, while valid, these informal training options are often 'ad hoc', do not provide a coherent structure, and do not lead to a recognised qualification or career oriented professional development plan.

During the 1980s there was no career pathway for those working in the administrative field (Pringle, 1988). A lack of qualifications is noted as a barrier for administrative professionals wanting to progress on the career ladder. This continues the perception of aspects of a "ghetto" occupation (Maguire, 1996; Truss, 1993) through a lack of opportunities for progression for those in the administrative field. 
A further limitation impacting on administrative professionals' ability to have a career of their own is where their status is predicated or defined by the status of their manager (Maguire, 1996; Pringle, 1988). This perception of the administrative person's inability to have a career pathway of their own, was discussed in the research by Kennelly (2006) where a participant indicated "[she] feels that her current organization has many opportunities for promotion to other secretarial positions, although there does not seem to be a ladder between these secretarial positions and other professional jobs in the organisation" (p. 182).

The most recent studies in the United Kingdom show that, for those in the administrative field, there is a belief that career pathway options are still limited today: "Perceptions of secretarial career paths are overwhelmingly negative" (Truss, et al., 2009, p. 44). The situation with regard to career pathways for administrative staff therefore has not changed significantly in recent times. A lack of qualifications and lack of encouragement to undertake professional development promotes a "catch-22" situation for many administrative staff.

The factors of inequality in employment, historical divisions between professionals and non-professionals, the status of various roles, and the lack of qualifications or a clear career pathway have been identified. However, it is difficult to establish a causal relationship between the lack of value placed on the role by those undertaking it and the lack of perception of value by those outside it.

From the earlier discussion on competency and sense of self and identity, it can be seen that the potential for an individual to be affected by the way others perceive their work role can impact on how the role is seen by those who work in it. However, there is always the option for an individual to choose to ignore the perceptions of others and undertake the development of the role in a more positive light if administrative staff can take pride in the work they are undertaking (Lloyd, 2003; Maguire, 1996).

In summary, for administrative professionals, professional development opportunities are of value, as they are to all staff. However there has been no research into what the professional development requirements of administrative professionals in New Zealand are, and whether these are being met. Most of the research that has been carried out is 
international and has, in the past, focused on secretarial staff; a title that is today disappearing. This change in job titles has led to a blurring of roles and titles and also to a lack of clarity around the group being researched in relation to today's administrative professionals. Administrative work is highly gendered with the vast majority being female and there are perceptions based around the 'tasks that women do' which have provided some potential limitations on this group of workers.

Recent international research has indicated that there is still today some separation of professional staff from administrative staff with regard to professional development opportunities, and professional development provision is often limited to 'just-in-time' technical skills. It appears from the research that for this group of workers there may be value in a recognised and expected formal qualification (Truss, et al., 2009). There are relevant qualifications available in New Zealand. However, whether administrative professionals are aware of what is available and how they can be achieved has not been researched in New Zealand.

Truss et al. (2009), in their recent study, indicated there is a lack of career pathways for administrative professionals. This lack of pathway may be linked to a lack of required qualifications which; when coupled with a lack of self esteem, a lack of value of the role, and no encouragement within the workplace to undertake qualifications, could lead to a 'catch-22' situation for administrative professionals.

\section{Summary}

The requirement in today's work environment for workers to undertake professional development (education, training and learning) in the workplace, the part played by adult learning theories in enhancing learning experiences, and recognising that there are specific learning needs of female workers, are all factors which contribute to creating an effective and fully functioning workforce. However, there are factors that may limit workplace professional development opportunities and career pathways for those who enter the administrative field. These factors may include: professional development that does not meet the needs of adult learners or female adult learners, a lack of value placed on informal learning in the workplace, difficulties experienced by administrative professionals in accessing professional development or workplace learning, power structures in the workplace reflecting those of society, differing expectations by employers of professional 
development requirements, and the negative perception of administrative roles by those in them and how others perceive them.

There is a lack of understanding of how administrative professionals in New Zealand perceive their professional development opportunities and career pathways due to a lack of research internationally and no New Zealand based research. Previous research was directed primarily at secretarial staff, however, the blurring today of roles and titles means that the group of workers involved is now more diverse. Neither the professional development needs of administrative professionals in New Zealand nor their career pathways are well understood. This is a very significant gap in knowledge of a large group of mostly female workers.

The above factors have informed this descriptive study. The findings from this study will provide a significant contribution to understanding the perceptions of administrative professionals in New Zealand their experiences of professional development opportunities, and how those opportunities affect their career pathways. 


\section{CHAPTER 3: METHODOLOGY}

\section{Introduction}

This chapter outlines the aim of the research and the research question. It explains the research design framework and describes the methods for data collection and analysis.

\section{Research aim}

The research aimed to discover the perceptions of New Zealand administrative professionals about their professional development opportunities and career pathways. It was anticipated that the data gathered would provide some understanding of how these perceptions might affect their potential career pathways.

\section{Research question}

The overall research question was:

How do administrative professionals in New Zealand perceive the effects of their professional development opportunities on their career pathways?

There were three aspects to this question: perceptions of the current situation, professional development and career pathways. In the first point, perceptions of the current situation, the research was looking at the perceptions of administrative professionals of their current access to and support for professional development for them. The second point, professional development, was to look at what professional development was available to them, how the administrative professional perceived their employer supported them and what type of support there was available to them. In the final point, career pathways, the research looked at what career pathways administrative professionals believe they could follow, what career pathways goals they had and how they believed they could achieve those goals.

The following supplementary questions further develop this question.

Current situation

What professional development opportunities are there?

What do administrative professionals know about the professional development opportunities that are available? 
What are their professional development goals?

How can administrative professionals access professional development?

What professional development opportunities do administrative professionals access?

Professional

How do administrative professionals perceive or experience their

Development employing organisation's view of their professional development needs?

What support, organisational or other, is there available for administrative professionals to undertake professional development?

Career Pathways How do the professional development opportunities available impact on administrative professionals' career pathways? What career pathways are there available to administrative professionals?

\section{Definitions}

\section{Administrative Professional}

The classification Clerical-Administrative covers the wide variety of titles used in the workplace for employees who work in the many administration positions (see Appendix A). For further definition I refer to NZQA Unit Standard 21862; Demonstrate knowledge of management administrative services (see Appendix C) which uses the phrase 'management administrative services' for the support provided to management by those in administrative roles generally. This is a foundational unit standard for the National Certificate in Business Administration and the National Diploma in Business Administration. Unit Standard 21862 covers a significant number of the tasks performed by the administrative professional and listed in the examples in Appendix D.

Administrative professional is also the term used internationally to define, in general, the work roles formerly covered by the titles secretary, clerical worker, office worker and receptionist. The use of this title internationally is confirmed by the change of name for relevant professional associations, for example, in the United States in 1998 from Professional Secretaries International to International Association of Administrative 
Professionals (IAAP), and in 2000 from the Society of Executive Secretaries New Zealand Inc. to Association of Administrative Professionals New Zealand Inc. (AAPNZ).

\section{Professional Development}

This is defined as the development of the knowledge, skills and attitudes acquired through education, training or learning, to undertake the work an individual is employed to do. This development may be undertaken formally or informally and either within, or externally to, the working environment. It may be required to improve work practices generally or specifically, due to changes in the requirements of the role; or to widen the scope of work already undertaken.

\section{Career Pathway}

This is defined as the opportunities in the workforce which enable workers to progress in the employment field from the role currently held, either within the same field or into related fields.

\section{Research design}

This is a descriptive study focusing on a specific employment group, administrative professionals who are clearly defined using definitions from Statistics New Zealand. It is also explanatory as it is looking for some explanation of the relationship between professional development opportunities and career pathways for administrative professionals - "descriptive studies answer questions of what, where, when and how; explanatory questions, of why" (Babbie, 2001, p. 93) This study is an exploration of the topic as there has been no, or very limited, research on administrative professionals in New Zealand. It therefore sets the scene for further studies, as "an exploratory report serves to point the way to more refined research on the topic" (Babbie, 2001, p. A18).

The aim was to discover what the current situation is, to provide a basis for understanding the perceptions of professional development for administrative professionals and their career pathways options. This descriptive and explanatory study aims to give administrative professionals a voice (Krueger \& Casey, 2009) through sharing their experiences and perceptions of professional development and career pathways. Consequently those who have participated in this research project are the 
administrative professionals themselves. There has been no attempt to gain the views of their managers, human resource or training personnel.

The intentions above informed the design of the research. It was important to provide an environment conducive to participation. To achieve a suitable environment the research was conducted using research tools from feminist and participatory research, initially using an on-line survey to provide anonymity, a wide industry base and well spread locations, and then involving focus groups to provide interaction with the researcher and others within the administrative field to encourage the sharing of stories.

\section{Participants}

The target group was administrative professionals in New Zealand. Administrative professionals are those workers who provide administrative services and support within an office environment (this environment can be the employers' place of work, home-based or virtual, it can also cover those who work in temporary, casual or part-time positions).

AAPNZ is the only professional body within New Zealand for administrative professionals and its members are predominantly female. AAPNZ has 15 groups throughout New Zealand in three regional areas, Northern, Central and Southern with a membership of approximately 650. The membership database of AAPNZ was the only accessible database of administrative professionals providing a wide cross section geographically and of different industries and organisation size.

This database was accessible due to my own position as a member of AAPNZ. Initial contact was made with the AAPNZ National Executive Committee (NEC) requesting their support for this research and for contacting the AAPNZ membership through their local group presidents and this support was received (see Appendices E and F).

AAPNZ local group presidents were contacted through an email invitation to their members which they were asked to then forward to their own group's email database. This invitation contained information about the research and a link to the on-line survey (see Appendix G). 
The initial response to the on-line survey through the AAPNZ membership was very low (approximately 70 completed survey forms out of a potential 650$)^{3}$. Therefore, after discussion with my supervisors, a second round of on-line survey questionnaires was sent out. This second round survey employed 'snowball' sampling, where those contacted were asked to forward the email and link to the questionnaire to their own networks of administrative professionals. This resulted in a total of 193 completed survey forms.

The survey respondents were asked to provide their current job title and this showed the wide range of titles that apply to administrative professionals (see Table 3.1).

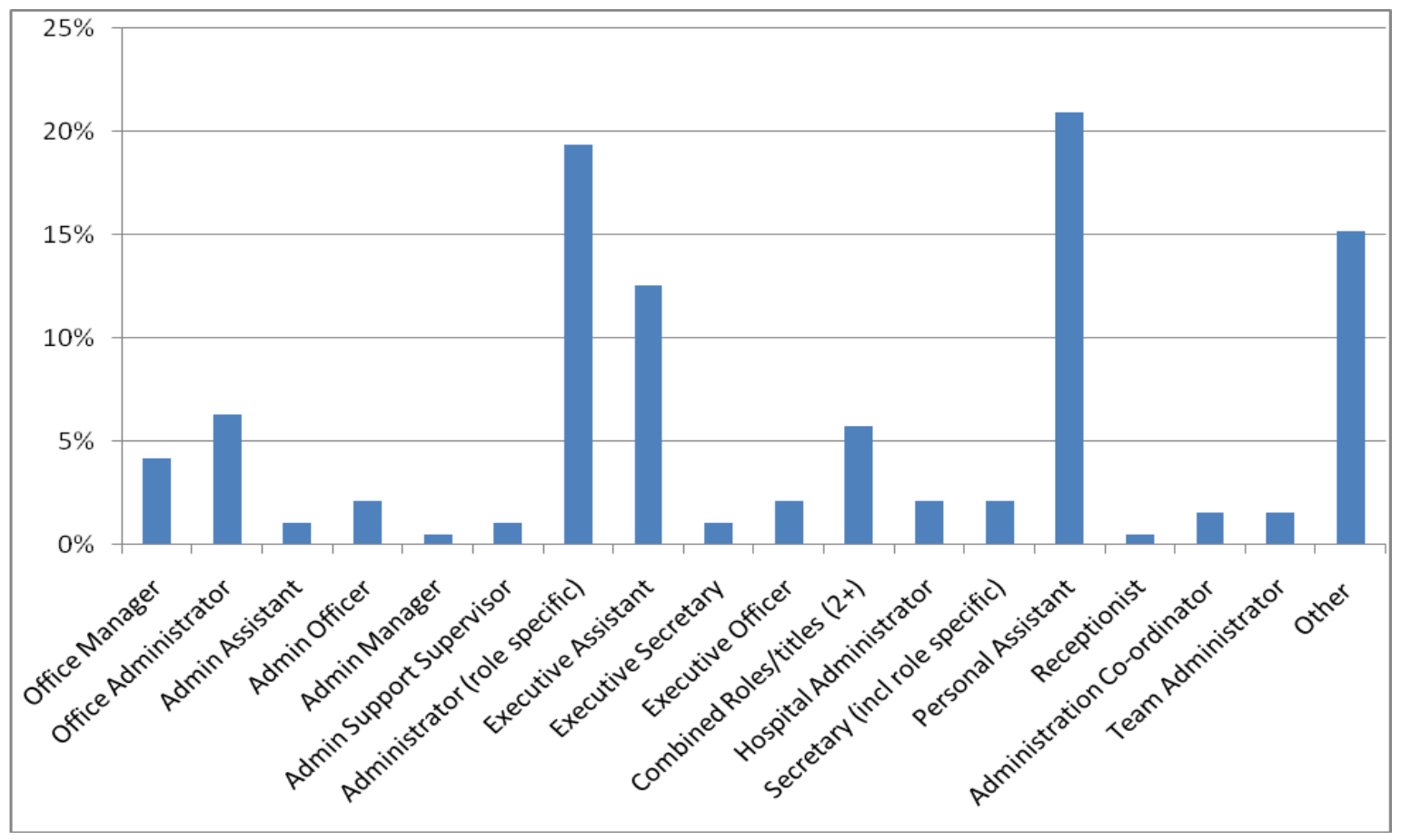

Table 3.1: Position titles

A list of 19 different position titles plus one box for 'other' (see Appendix H Q1.2) were provided for respondents to choose from in the on-line survey. A further 29 position titles were provided by respondents under 'other' (see Appendix I).

Respondents to the on-line survey came from throughout New Zealand, (see Table 3.2) indicating where respondents were located.

\footnotetext{
${ }^{3}$ Of the initial $\sim 650$ AAPNZ members' surveyed 134 forms were returned, however only 70 of those were complete. Incomplete survey forms were deemed to be those that provided only the demographic data but no answers to the questions that related to the research. These incomplete forms were removed from the data.
} 


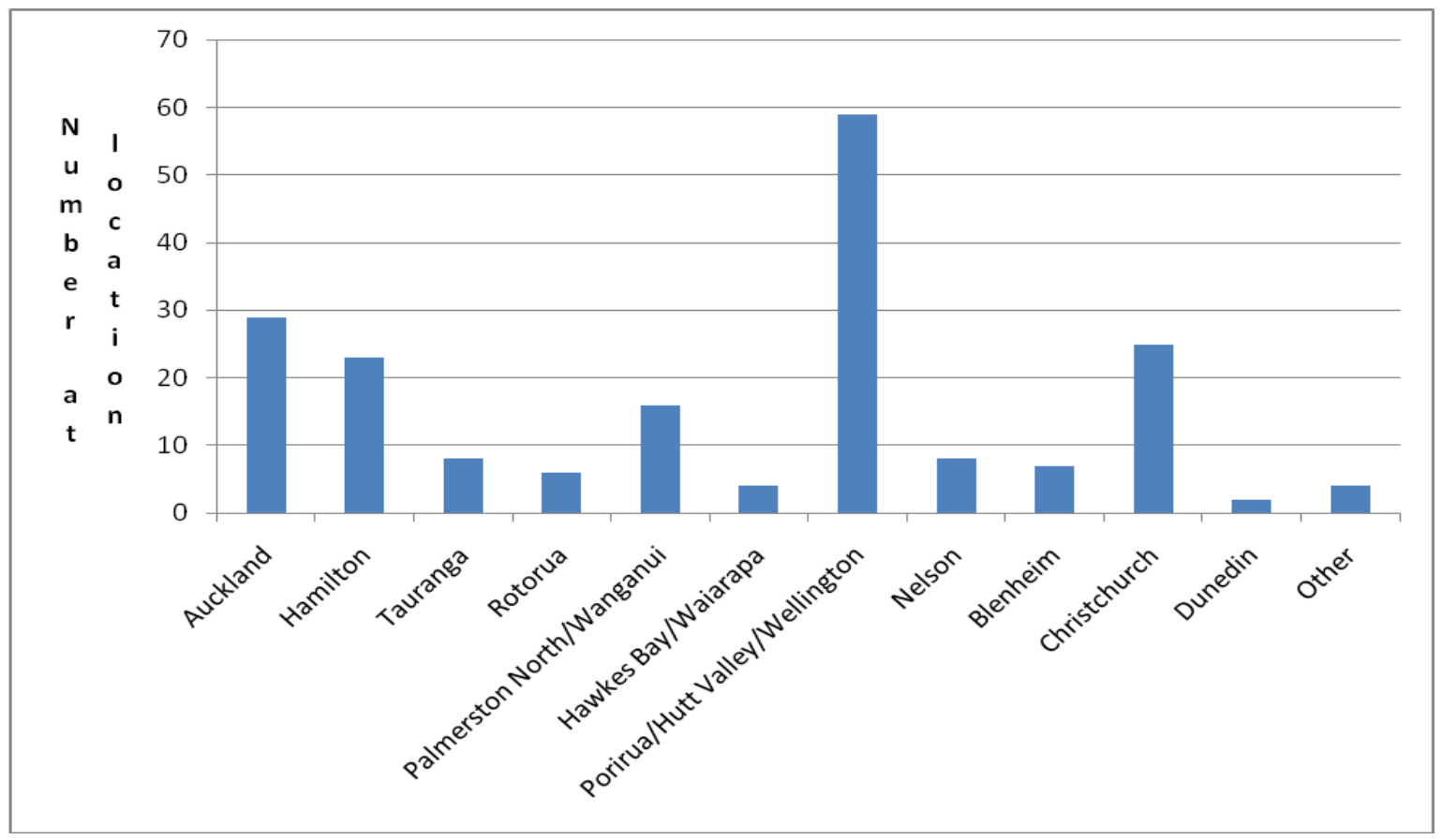

Table 3.2: Location of place of work

A wide range of industries were represented by the respondents to the survey (see Table 3.3). Education, health, government and local government were strongly represented. Industries listed under 'Other' were: recruitment, transport, funeral director, temping, entertainment, business development, tourism, business consultant, utility, manufacturing, petrochemical, media, pharmaceutical, and project management.

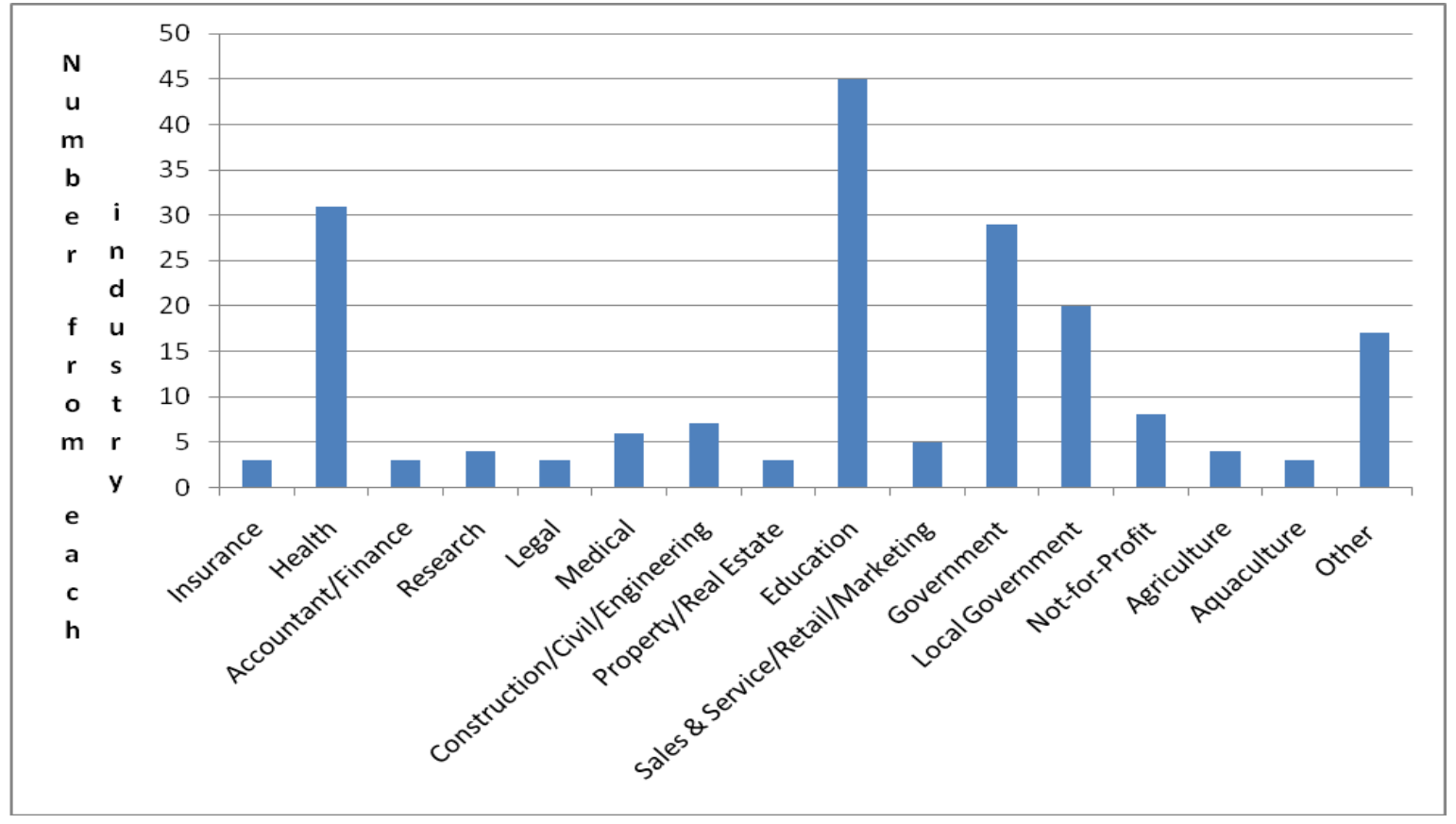

Table 3.3: Industry types 
The majority (75\%) of respondents have worked in the administrative field for $11+$ years and a significant number of those (30\%) for more than 31 years (see Table 3.4).

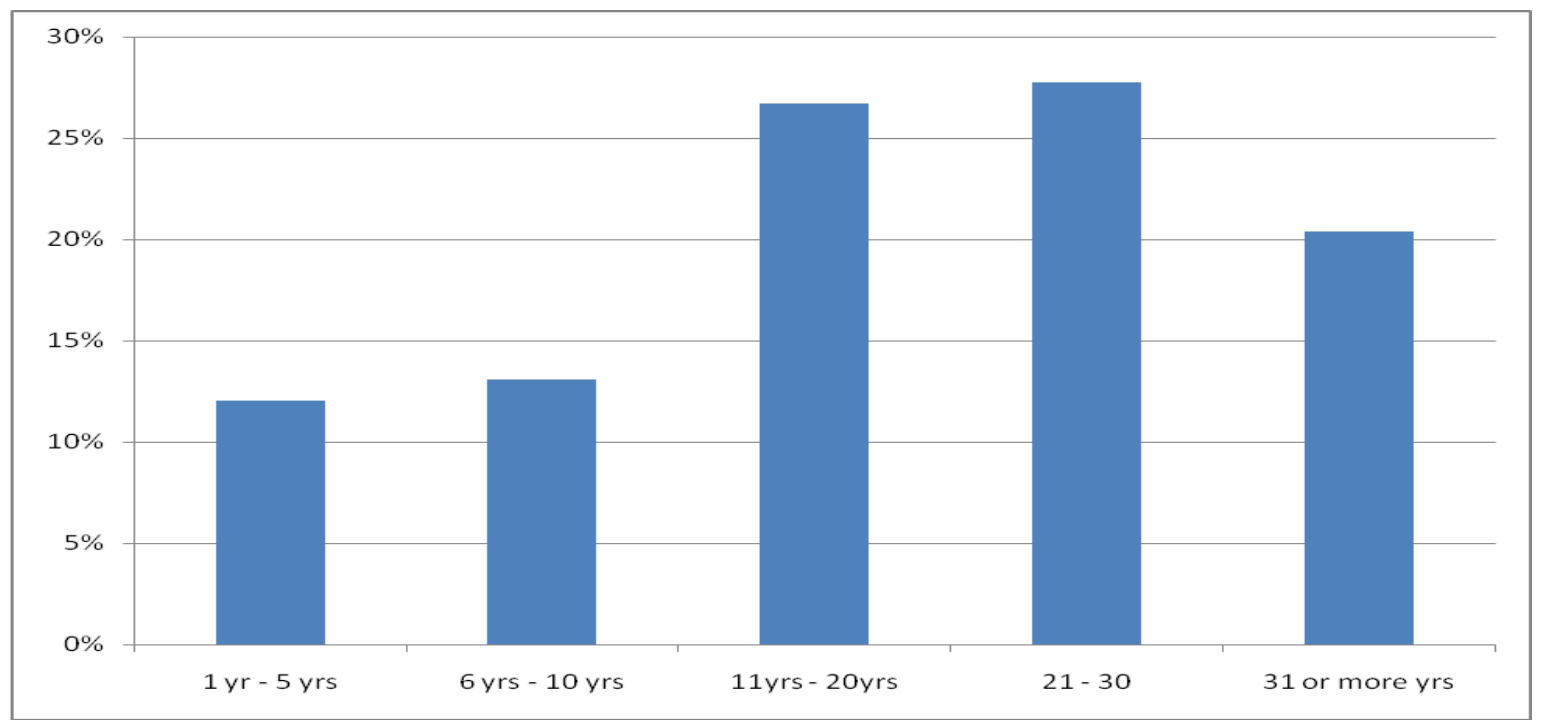

Table 3.4: Years working as an administrative professional

The majority of respondents (51\%) worked for large employers with 500+ employees (see Table 3.5).

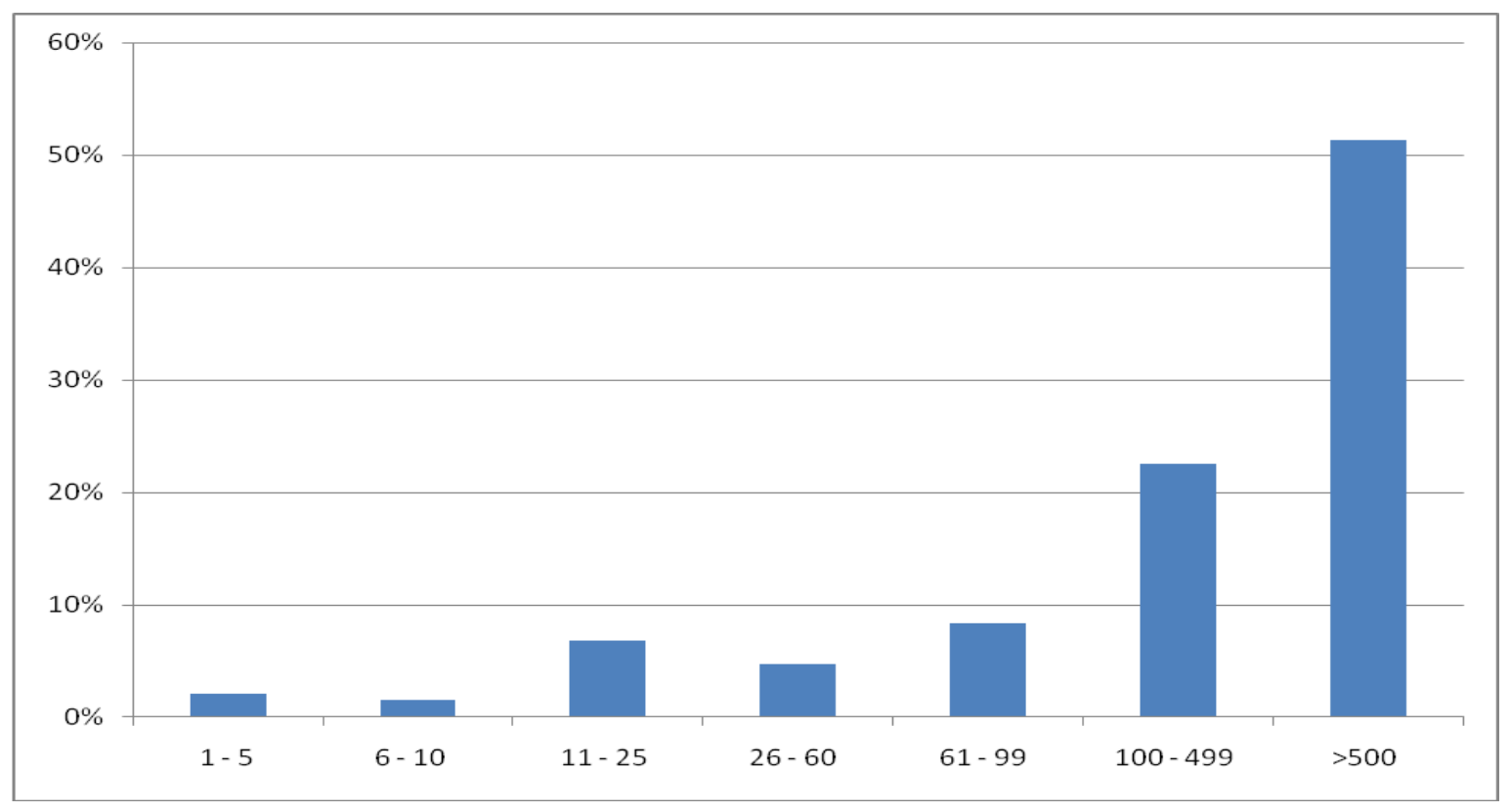

Table 3.5: Number of people employed in own organisation

In this way the research sample is not representative of New Zealand business which is recognised as being primarily a small to medium enterprises (SME's) of less than 100 employees. However, SME's only employ $30 \%$ of those who are in employment. 
A greater number of respondents (80\%) actually work in an office with less than 60 employees even though their employer is large overall (see Table 3.6).

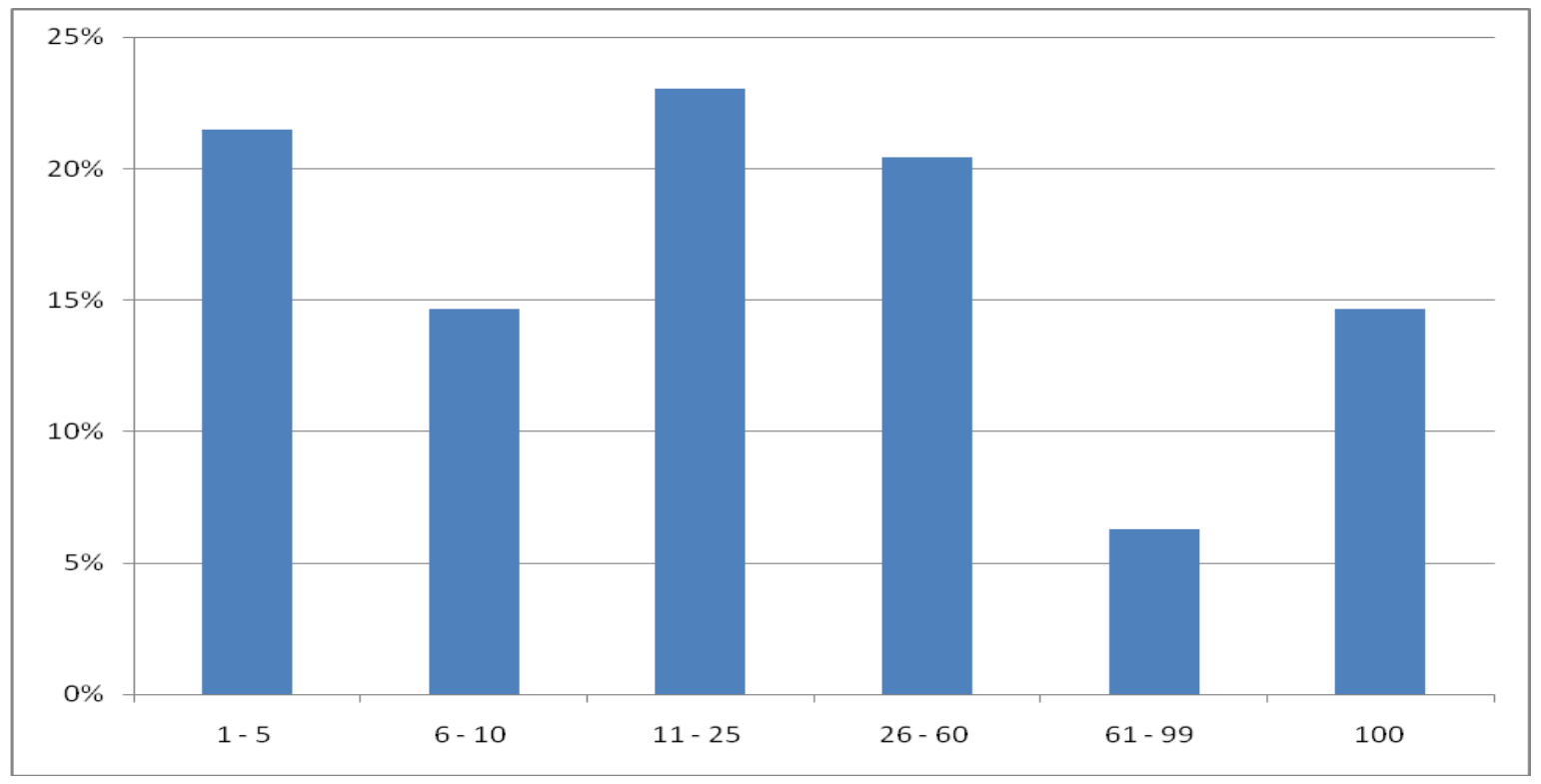

Table 3.6: Number of employees in own office

The two focus groups were made up from the respondents to the survey prior to the snowball sampling, who expressed interest in participating in the next stage of the study. Purposive sampling was used to select participants for the two focus groups to provide the widest range of demographics possible from those respondents to the on-line survey who had volunteered to be involved.

Selection of the focus group participants required the development of a specific process to enhance the credibility of the research by mitigating possible questions of bias based on my personal knowledge of the AAPNZ members. Selection was undertaken by one of my supervisors so that I was not directly involved. The selection process was based on two sets of information.

Firstly the demographic information gathered in the survey was used to select participants. This information included years working in administration, geographical area of work, type of industry in which working, title of current position, professional development opportunities provided and taken, and awareness of career pathway options. 
Secondly, specific criteria for the focus group make-up (see Appendix J) were used in conjunction with the demographic information to create purposive sampling. These criteria covered location, size of business and proportion in the focus group, knowledge of professional development and career pathways. These criteria were identified from the survey questions.

Using the above criteria, of the 31 who indicated interest, 21 participants were selected and sent invitations (see Appendix K) to participate. These invitations contained further information on the type of involvement required, amount of time commitment and consent forms (see Appendix L). Of the 21 invited, acceptances were received from 18 and once final dates were agreed, this number reduced to 15 .

One focus group was held in each of the North (8 participants) and South (7 participants) Islands, providing a geographic cross section. The planned cross section of business types and sizes did not fully eventuate due to the demographics of those who responded (see Table 3.7).

\begin{tabular}{|l|c|c|c|l|l|}
\hline & $\begin{array}{c}\text { No in } \\
\text { Group }\end{array}$ & Location & $\begin{array}{c}\text { Yrs in } \\
\text { Admin }\end{array}$ & Industry type & $\begin{array}{c}\text { Organisation } \\
\text { size }\end{array}$ \\
\hline $\begin{array}{l}\text { Focus } \\
\text { Group 1 }\end{array}$ & 8 & North Island & $1-31+$ & $\begin{array}{l}\text { Education } \\
\text { Health } \\
\text { Consultancy } \\
\text { Forestry }\end{array}$ & $\begin{array}{l}<21-30 \\
100-500+\end{array}$ \\
\hline $\begin{array}{l}\text { Focus } \\
\text { Group 2 }\end{array}$ & 7 & South Island & $1-31+$ & $\begin{array}{l}\text { Not for profit } \\
\text { Admin Services } \\
\text { Retail } \\
\text { Education } \\
\text { Government } \\
\text { Legal }\end{array}$ & $<30-500+$ \\
\hline
\end{tabular}

Table 3.7: Make up of Focus Groups

A difficulty with geographical accessibility arose during the selection of the South Island participants. Of the participants who were invited for the central South Island focus group location, all of those in the upper South Island areas were unable to attend due to the time and distance involved.

The applicants from the upper South Island were geographically isolated and mainly from small to medium sized employers who were under-represented in the primary focus 
groups. In discussion with my supervisors it was agreed that value would be added if an additional feedback session with those from that area was held, to confirm whether the data gathered also represented their views (see Table 3.8).

\begin{tabular}{|l|c|c|c|l|c|}
\hline & $\begin{array}{c}\text { No in } \\
\text { Group }\end{array}$ & Location & $\begin{array}{c}\text { Yrs in } \\
\text { Admin }\end{array}$ & Industry type & $\begin{array}{c}\text { Organisation } \\
\text { size }\end{array}$ \\
\hline $\begin{array}{l}\text { Additional } \\
\text { Feedback } \\
\text { Group }\end{array}$ & 5 & $\begin{array}{c}\text { Upper South } \\
\text { Island }\end{array}$ & $11-31+$ & $\begin{array}{l}\text { Construction } \\
\text { Insurance } \\
\text { Aquaculture } \\
\text { Local Govt }\end{array}$ & $<30-499$ \\
\hline
\end{tabular}

Table 3.8: Make up of additional Feedback Group

\section{Research Methods}

\section{On-line survey}

The on-line survey was developed to gain wide geographical and industry coverage and to seek demographic data plus some initial descriptive data to answer the research questions.

The survey (see Appendix H) was designed using "SurveyMonkey" (SurveyMonkey, 2008), an on-line survey package which is available in the public domain. Participants came from the AAPNZ membership with a wide geographic and industry spread. The potential numbers involved indicated that an on-line survey as a research method would be useful to allow this larger sample and spread in this initial stage of the research (Babbie, 2001, p. 238). The survey sought to; provide demographic data, gain some initial insight into administrative professionals' knowledge of and accessibility to professional development, discover whether they had professional development goals and career pathways.

The final question in the survey invited respondents to participate in one of two focus groups to be held, one in each of the North and South Islands. Those who wished to participate were required to provide personal data to enable contact after the survey period had closed. Thirty-one responded with an expression of interest in being involved in the focus groups.

An advantage of using the on-line survey was anonymity for those participating through blocking the respondents contact details. For some participants this allowed them to feel 
comfortable when answering questions which may have been perceived as critical of their employing organisation. This was a factor in providing an environment which encouraged sharing of thoughts and experiences.

Questions 1.1 - 1.7 (see Appendix H) in the survey were developed to provide demographic data relating to: length of time working in the administrative field, title of current role, location of place of work, type of industry working in, number of employees in own whole organisation, number of employees in own office, and what groups of employees receive professional development in own office.

Questions 2.1 - 2.9 (see Appendix H) were aimed at gathering information on: the respondents' knowledge of professional development, whether there are opportunities and support within their organisation, what those supports or resources might be, whether professional development is undertaken in work time and/or own time, if it is undertaken in own time what might it be, what types of professional development are known about, what professional development goals are held and why it is important to the respondent.

Questions 2.10 and 2.11 (see Appendix H) were developed to gather data on what career pathways were perceived as being available and what an ideal career would be.

Question 2.12 (See Appendix H) sought any other comments.

Question 2.13 (see Appendix H) was developed to seek volunteers to participate in the focus groups.

The final question 2.14 (see Appendix $\mathrm{H}$ ) asked if those who wished to participate in one of the two focus groups planned would provide their contact details.

The on-line survey was trialed to gain feedback on its usability, to ensure the clarity of the questions being asked (Babbie, 2001) and to confirm the length of time it may take to complete (approximately 20 minutes). This trial resulted in some minor adjustments to the wording of the questions to improve clarity and resolve initial ambiguities. 
Once all approvals had been received (Ethics Committee, AAPNZ's National Executive Committee) the survey of the AAPNZ members throughout New Zealand was conducted over a 1 week period. The survey was sent to local AAPNZ group presidents for forwarding to their own area membership databases to further enhance anonymity. Potential respondents were given 7 days in which to complete the survey. As it was possible to keep track of response totals, a reminder including a slight extension of time (3 further days), was provided to help increase the number of responses.

The second 'snowball' survey, due to the low initial response, ran over a 12 day period. However, there was no invitation to participate in a focus group included in the second 'snowball' survey as there had been sufficient responses, from the AAPNZ membership, in the first survey to develop the focus group make-up. A total of 193 completed survey forms were returned and formed the initial data for this study.

As over $50 \%$ of those who responded were from large organisations (see Table 3.5), this had a significant impact on the research findings. The 'snowball' sampling enhanced this impact as many of those contacted in the 'snowball' survey also came from large organisations. (This impact is discussed in Chapter 5 Discussion, under limitations).

\section{Focus groups}

Focus groups were used in this research to explore the experiences of the predominantly female administrative professionals, seeking their descriptive stories of those experiences. The two focus groups, one each in the North and South Islands, met twice. The first session was to gather data. The second session was to provide feedback to the participants, checking with them that the themes developed in the analysis represented their views appropriately.

Feminist research has extensively used focus group work as a research tool for providing an environment which encourages participants to share their experiences: "as a form of collective testimony, focus group participation has often been empowering for women" (Madriz, 2000, cited in Kamberelis \& Dimitriadis, 2005, p. 893). Focus groups have been used by feminist researchers to gather group resistance stories which could be used by any group that feels powerless, "to unveil specific and little-researched aspects of women's daily existences, their feelings, attitudes, hopes and dreams" (Madriz, 2000, cited in 
Kamberelis \& Dimitriadis, 2005, p. 896). While Madriz's research is about the serious social difficulties of crime and gender, administrative professionals can face potential gender stereotyping and powerlessness within the workforce. Research shows that, as the workplace replicates society (Bierema, 2001), so there is inequality in how occupations largely peopled by women, are perceived, thus suggesting focus groups as an appropriate data collection method.

Krueger and Casey (2009) identify participatory research as a recognised variation in the use of focus groups where people in the community (e.g., the workplace) recognise that the process can assist that community. The focus group process can help to clarify issues from the perspective of the participants and to identify strategies to assist in resolving those issues. Kamberelis and Dimitriadis (2005) discuss focus groups as providing a tool to assist finding solutions to 'real world' problems requiring rich and complex communal knowledge and practice rather than trying to solve those problems on an individual basis.

The administrative professionals, who participated in the focus groups for this research, while not employees of the same workplace, are a community in that they belong to the same professional body and have much in common through their work roles. Focus groups provided them with an opportunity to discuss their professional development opportunities, the effect on their career pathways and, if needed, what they might consider doing to effect change. Additionally the participants in the focus groups provided in-depth data to enrich that gathered in the on-line survey.

Focus group questions were based on the supplementary research questions. The draft questions were used at the trial focus group to see if what was planned was understood by the participants (Krueger \& Casey, 2009). The trial focus group provided an opportunity to further develop the questions, ensuring they encouraged participants to share their experiences and did not overly direct them. Only very minor adjustments were required to finalise the focus group questions (see Appendix M).

As I have a wide knowledge of those participating in the focus groups through my involvement with AAPNZ; using an independent facilitator for these was important to mitigate the possibility of bias in the data gathered. The facilitator I selected was known to me as we had worked together in previous facilitation situations. My knowledge and 
respect for the facilitator enabled the development of a very strong relationship between the needs of the study and providing the correct environment for the focus groups. A confidentiality agreement (see Appendix N) was completed and signed by the facilitator. The focus group questions and procedures were discussed with the facilitator and her input sought to ensure she was comfortable with them.

Selecting the focus group participants from survey respondents allowed the research to cover a wide range of industries in which administrative professionals work. The focus group environment encourages rich descriptions of participants' social experience to be gathered and analysed in the research process. Focus groups also contribute to participant confidentiality within the final written document through the use of pseudonyms and collective reporting.

After focus group participant selection, using the specifically developed criteria (Appendix J), had taken place a letter of invitation was sent to each participant requesting their involvement and including a consent form. Once responses from participants were received and the dates confirmed, the decision was made to hold the additional feedback session in the upper South Island. At this stage a letter of invitation and consent forms were sent to this additional group. There were eight participants in the North Island group, seven in the South Island group and five participants took part in the upper South Island feedback group.

Each focus group met twice, approximately three months apart. Each group was conducted in the evening after work and ran for approximately 2 hours. This timeframe allowed for refreshments and for the group to settle and become comfortable. The facilitator quickly established a rapport with the focus group participants through mingling with them over refreshments, many of the participants knew me and each other from being members of AAPNZ.

At the start of each focus group session I provided an overview of the research and an outline of the process of data gathering and analysis, before introducing the facilitator who led them through the questions. Timing was controlled by me and was largely adhered to. However, it was noticeable that in both focus groups no-one was in a rush to 
leave, even though some had travelled for more than an hour to attend, and that there were more stories and further discussion that could have been undertaken.

All sessions were recorded by both digital and micro cassette recorder and the facilitator also took notes on a flip chart. The facilitator regularly checked with the participants whether what she was recording on the flip chart did or did not represent the views being expressed. I sat behind those participating in the focus groups and took notes to support the recordings.

All transcription was done by me, using the skills I developed during my 30 years working as an administrative professional. This meant that a confidentiality agreement for a transcriber was not required.

It had become clear during the initial analysis using NVivo8 that there had been insufficient exploration in the focus groups around barriers to professional development experienced or observed; therefore an additional question was developed. This question was "What barriers to professional development have you experienced: Internal (self), External (environment)?"

At the feedback session (second round of focus groups), the participants were presented with the initial results of the analysis, which were primarily the demographic data plus the themes that had emerged from the survey and the first round of focus group data. After the presentation of the analysis, the facilitator led the discussion of the additional question addressing the gap found during initial analysis. The data from the discussions of the additional question were gathered and incorporated into the analysis.

These feedback sessions allowed participants to confirm that their collective voices had been heard and ensured that those participating felt their views were being appropriately represented.

\section{Data Analysis}

The survey of administrative professionals provided the demographic data for this study. The "SurveyMonkey" package provided the data in a format which enabled calculations of percentages within each question which are presented in the tables. 
After each focus group session I transcribed the recordings. While transcription was a slow process, it assisted considerably in deepening my understanding of the discussions and in analysing the data (Krueger \& Casey, 2009). All the completed survey forms plus the focus group transcriptions were imported into NVivo8, a qualitative data analysis software programme.

After gathering the survey data, initial themes were developed as a "start list" (Miles \& Huberman 1994, p. 58) for provisional coding during analysis. The 'start list' assisted with analysing the data gathered and was based on the headings of the supplementary questions of: current situation, professional development and career pathways. The themes were adjusted during the coding of the focus group data due to the frequency with which items arose. Through developing familiarity with the data the themes quickly evolved into: employment environment, personal characteristics, professional development opportunities and career pathways.

During data analysis, reviewing the coding and themes for relevance and usefulness was ongoing. This reviewing is a recognised and accepted data analysis process in qualitative research (Miles \& Huberman 1994). Where necessary the themes were refined and modified to ensure they were fit for purpose, truly reflecting what was within the data. A single piece of data might relate to more than one theme and working with NVivo8 allowed the placing of these items under more than one theme or sub-theme when appropriate. Working with the data in this way added to my deepening of knowledge of it and the initial themes evolved into a more comprehensive series of sub-themes (see Appendix O).

Analysing the data involved reading and re-reading the data as grouped under the themes and gaining an understanding of how the different pieces fitted together. (These themes are explored further in the discussion on the findings in Chapter 5, and led to the development of a conceptual framework to illustrate them).

The feedback to the primary focus groups confirmed the themes identified and the additional feedback session in the upper South Island confirmed that those same themes also represented their experiences. 


\section{Ethics}

Ethics approval for conducting this research project was gained from Victoria University Faculty of Education Ethics Committee (see Appendix P).

SurveyMonkey allows the blocking of respondents contact details which protected their privacy. Personal information was used for selecting focus group participants but was not otherwise used in the research. Pseudonyms were allocated to all who volunteered to participate in the focus groups, assisting participant confidentiality.

All information gathered about participants, transcripts from the focus groups and all research data is held securely in a locked filing cabinet. All hard copy data, and recordings, will be destroyed within 24 months from completion of this thesis.

The consent form developed and included with the letter of invitation to each potential participant in the focus groups were completed, signed and returned. The facilitator for the focus groups signed and returned a confidentiality agreement but one was not required for transcription of the recorded data as I undertook this personally.

\section{Trustworthiness of the study}

Trustworthiness in the study was supported by the use of triangulation (Krueger \& Casey, 2009) through:

1. differing data sources (on-line survey to gather data from a wide cross section of administrative professionals and focus groups to gather further in-depth descriptive data),

2. separation of the researcher from the focus group discussions through using a separate facilitator, and

3. member check (participant feedback to confirm with participants their voices were being appropriately represented).

Credibility was provided through the specifically developed participant selection process for the focus groups outlined earlier. The aim was to reduce the risk of bias by using one of my supervisors to select participants, thereby distancing me from that selection process. 
To enhance credibility the focus groups were led by an independent facilitator to ensure that my own knowledge of the administrative field and the participants did not direct or dominate the discussions (Krueger \& Casey, 2009). I was present in a supporting role, observing and recording proceedings.

Purposive sampling in the focus groups was used to provide representation from different geographical and industry areas with individually differing levels of understanding about the role of professional development and career pathways. The information to enable purposive sampling was from the on-line survey and the specifically developed focus group criteria. 'Snowball' sampling was used in a second round of the survey to increase the number of participants and therefore the amount of survey data gathered.

\section{Summary}

The purpose of this study was to discover the perceptions held by administrative professionals in New Zealand of their professional development opportunities and career pathways. The research methods used were an on-line survey to gather data from a wide range of respondents and focus groups to gather in-depth rich descriptive qualitative data.

The participants in the survey were initially from the membership of AAPNZ. Due to a low initial response the survey base was widened through the use of a 'snowball' sampling. The focus group participants were all selected from the AAPNZ membership initial survey responses.

Focus groups are valuable in feminist research where the supportive environment is conducive to sharing the experiences of the participants. As those who are involved in administrative work are primarily female, the focus group environment provided them with that same support. The focus group discussions assisted in understanding how administrative professionals see their own situation and provided rich data to build on the initial demographic information gathered for this research.

Focus groups have been used in participatory research where those participating from a community (e.g., administrative professionals) can use that experience to assist that community. In this situation administrative professionals spent time discussing their 
experiences and their participation and experiences may well contribute to the benefit of the wider administrative community.

The demographics of the participants were analysed (using Survey Monkey) and then qualitative analysis was undertaken using NVivo8 during which themes and sub-themes were developed to provide an understanding of how administrative professionals perceive their professional development and career pathways. 


\section{CHAPTER 4: RESEARCH FINDINGS}

\section{Introduction}

The purpose of this research was to investigate the perceptions of administrative professionals of their professional development opportunities and career pathways. The findings indicate that the majority of those surveyed believed they had professional development available as required, though their career pathways were less clear. In addition there were shown to be barriers to accessing professional development which meant that, while it was available, being able to actually participate in it was not always achievable.

This chapter will report on the findings in relation to each of the three foci of the research; the current situation for administrative professionals, professional development, and career pathways. It will also report some of the themes that emerged through the analysis.

Current situation: what professional development opportunities are available to administrative professionals and what they know about those opportunities, what professional development they are able to access, and what their professional development goals are.

Professional Development: who gets professional development, what support they receive both in the workplace and externally, and barriers to their undertaking professional development.

Career pathways: impacts of professional development on administrative professionals' career pathways, pathways to their current administrative roles, career pathways available to them, and their awareness of those pathways.

Emerging themes: the value of self, the value of the administrative role, gender bias and stereotyping, and others' perceptions of the administrative role.

\section{Current situation}

The initial aim of the research was to discover how administrative professionals perceived their current situation in the workplace with regard to their professional development 
opportunities, what professional development they were able to access and what their goals were.

Data to answer the research questions 'What do administrative professionals know about the professional development opportunities that are available?' and 'What are their goals?' come from questions 2.2, 2.3, 2.6 and 2.7 in the on-line survey (see Appendix H) and discussion in the focus groups primarily in response to the focus group questions 1 and 2 (Appendix M).

The majority (89\%) of survey respondents report that professional development support is available to them in their workplace (Table 4.1).

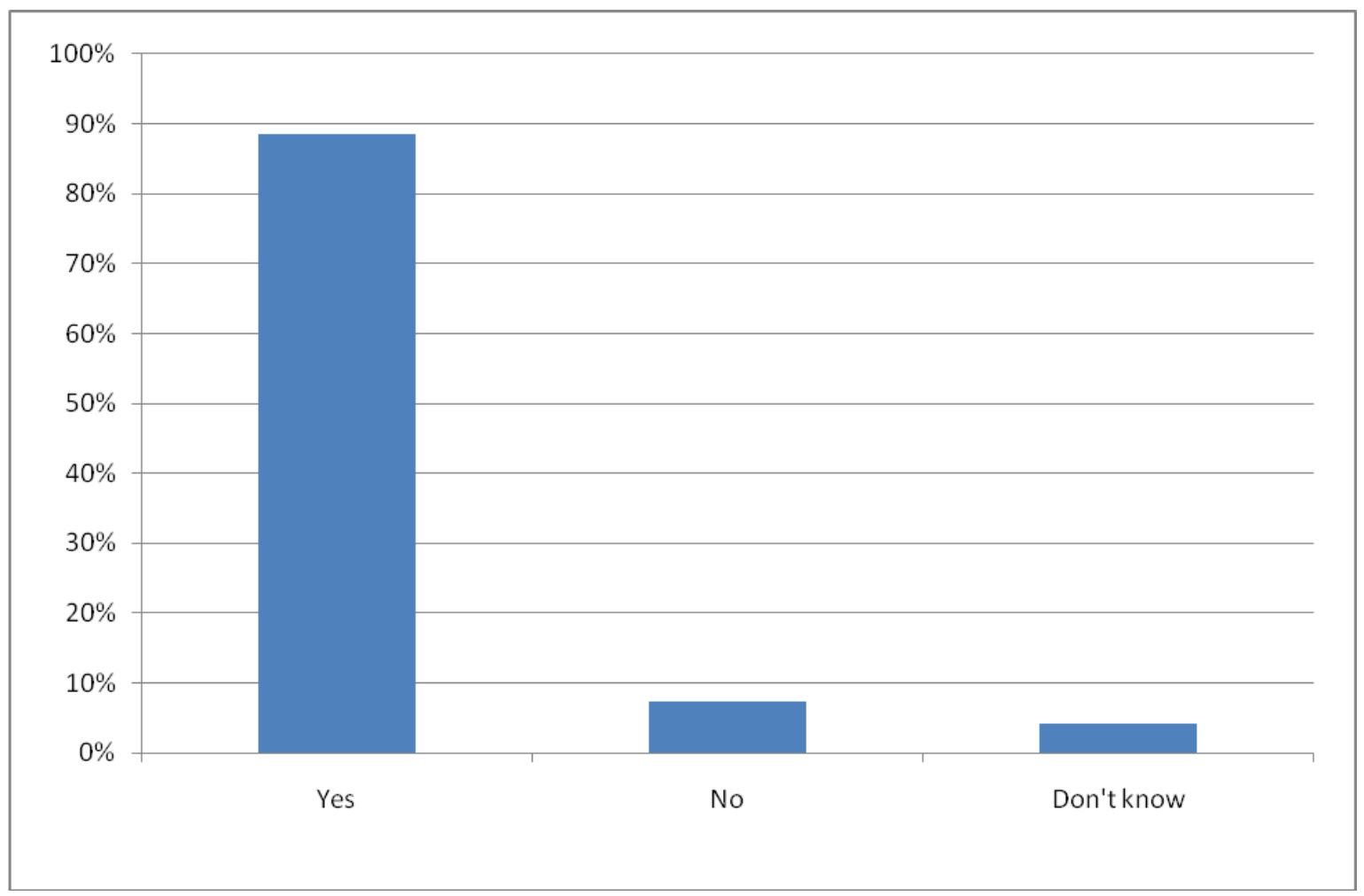

Table 4.1: Professional development support available for administrative professionals

\section{Knowledge of professional development opportunities}

Conference attendance and funding/study time/payment of memberships were noted as the most common sources of professional development available to administrative professionals (Table 4.2). 


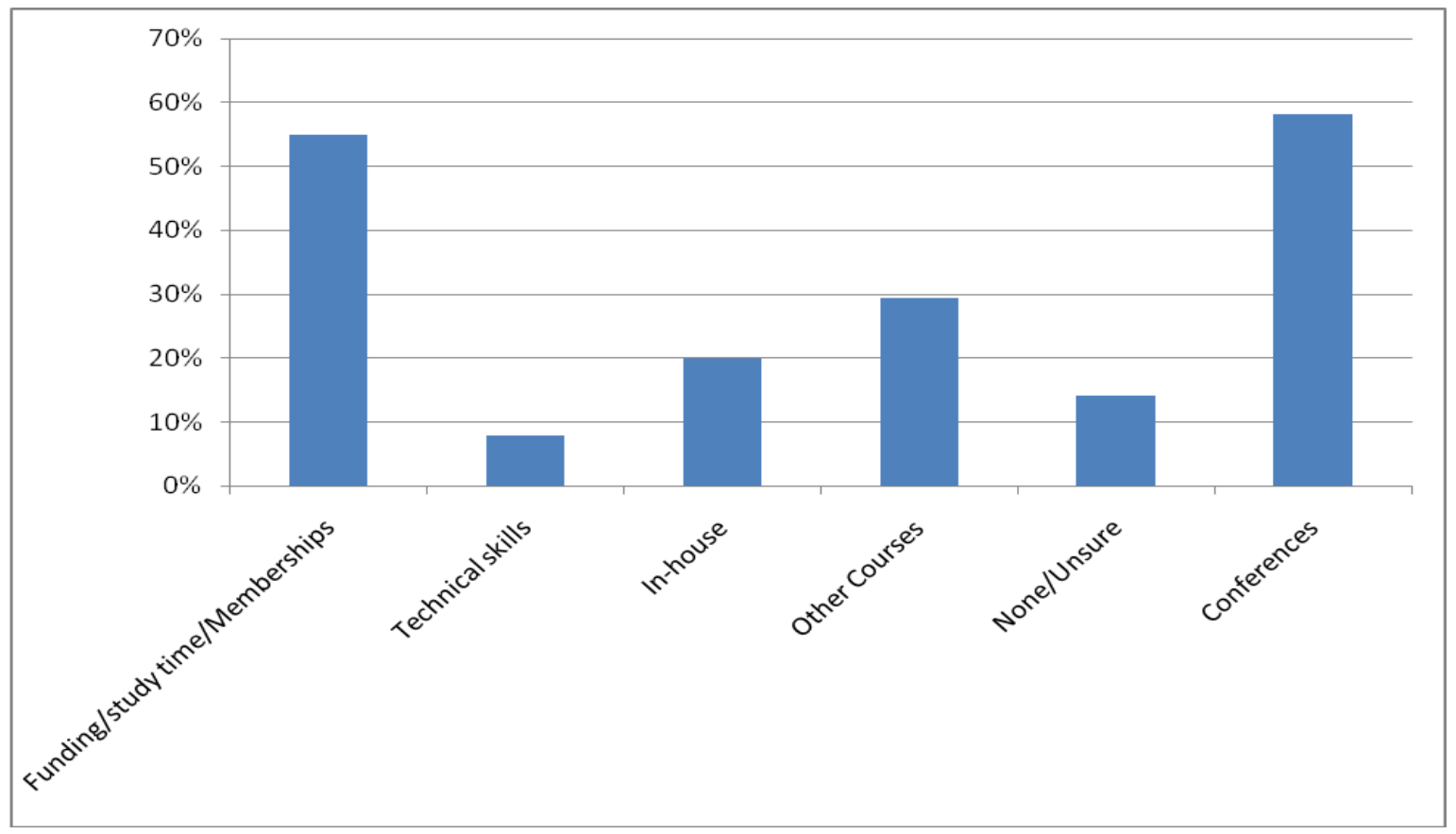

Table 4.2: Professional development opportunities available

Survey respondents were able to indicate knowledge of as many of the types of professional development options listed in the survey question 2.6 as they wished. Conferences and technical training were listed as the main forms of professional development they knew about (Table 4.3).

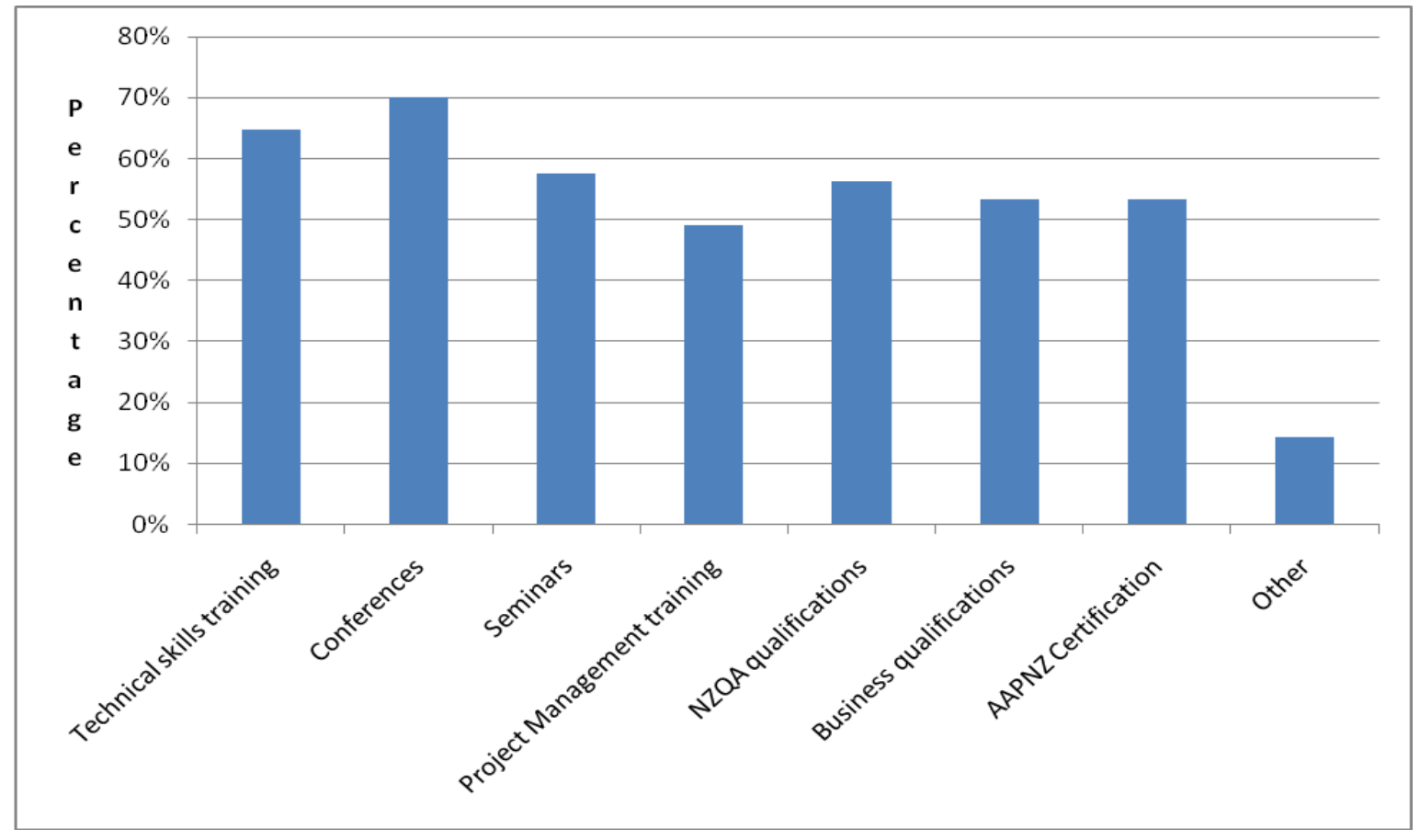

Table 4.3: Types of professional development 
The focus group discussed professional development gained through changing jobs or roles. There is a challenge in taking on a new role, in particular when an individual is sought out for a role due to recognised skill sets, as described by Brenda:

I think that's really important, and for someone to come to you and say 'I have a job that I want you to do' and I've said 'well I am not looking for a new job', 'No but this job is ... very valuable and very important to us and we need somebody we can trust and we think [you] can do [it] ...'. And that is a pathway to changing what you're doing ... because you have that support and encouragement, um maybe stepped out a little bit yourself and challenged yourself and you know that somebody had faith in you.

While the professional development generally available to administrative professionals is of value, it may not always provide the specific training or professional development required for the specialist role. For example Ursula, who works in the legal industry, is not regularly included in training opportunities offered by the Law Society to those in the legal industry. She indicates that most Law Society courses offered are aimed at the solicitors, not the non-legal staff.

The length of time administrative professionals have worked in the field may limit the perception of the variety of professional development available. For example Joanne, who has worked for 11+ yrs in these roles, said she was "running out of options of what I can and can't justify doing that are relevant to my role".

Survey respondents demonstrated a wide range of knowledge of the various options for professional development listed in the on-line survey and over $50 \%$ of the respondents noted they knew about AAPNZ Certification (Table 4.3). In addition it was interesting to note in the responses that AAPNZ was a source of many of those professional development opportunities. One respondent indicated that her manager would only approve conferences that were endorsed by AAPNZ. 


\section{Mentoring}

Mentoring, as a form of professional development which was perceived to provide considerable value, was an unanticipated topic arising from focus group discussion. The discussions covered both receiving mentoring and providing mentoring of value for others. Beverly talks about the support she has received:

Under the leadership of an amazing CE I have learnt to realize that I need to feel empowered around my decisions that I make for my future, be it within my career or personally, um I am in an environment that nurtured me towards professional development and any future training that I wished to undertake, whether it is directly towards my role or whether it's related to something that I am more interested or passionate about.

Jane talks about what she can give back through modelling and mentoring those who work for her:

But people like me whose work started out right through the industry, if we walk away what is that saying to anyone else. I would like to think that I could be a role model for someone.

One respondent highlighted a personal professional development goal of mentoring others to assist them in formulating their own professional development plan. Brenda encourages others to take on professional development opportunities in an informal mentoring role:

you take every bit of PD - you've got a lot of years to work ... don't you let anybody stop you ...”... I really encourage them because nobody ever did that for me.

There was discussion in the focus groups on the importance for some administrative professionals of 'bringing others on' in the administrative field through sponsorship/ mentoring/coaching. 'Bringing others on' is about sharing the knowledge you have gained informally on the job over time and/or through professional development opportunities. This is particularly well described by Joanne as she both wants to bring someone forward and is also having her own positive attitude reinforced in the process. 
There is one girl in reception who I actually want to train up to do my job one day and she comes into my office and she says 'how can I be like you? I want to be a PA one day. What can I do to get there?' and to me that's like 'Wow' that she wants to be in a position like me and I want to give her the help that I never had.

\section{Access to Professional Development}

While professional development was noted as being available to administrative professionals (Table 4.2), the survey responses did not differentiate between what was available and whether they had actually accessed it. The following respondent lists where she could access the types of professional development listed in the survey, if she wished to and/or was able to:

BOP Polytechnic community computing units, AAPNZ/Chamber of Commerce Business Women's Regional Conference, Chamber of Commerce/Bright Star/Conferenz, University of Waikato at Tauranga?/Chamber of Commerce, BOP Polytech/Waiariki Polytechnic(online)/MIT, Correspondence School/Open Polytechnic, [AAPNZ Certification] - not available to me at Level 4 yet but do know about it, Continuing Education classes in assertiveness training etc

For some administrative professionals, there are professional development opportunities available to them because of the organisation they work for. For example, those who work for tertiary institutions are encouraged to undertake papers or attend on-site training courses.

However, for some in some smaller regional areas, accessing professional development opportunities may be limited by geography. Mary comments that "Our population won't support professional development opportunities."

A lack of a professional development plan was discussed in the focus groups. For example Emily indicated that for her professional development was on an "ad hoc basis - 'Oh look there's a good course; I'll do that', sort of thing or someone would say 'Oh that sounds like [a good one]"'. The ad hoc nature of training and where it leads was also raised by Jillian: 
You take every opportunity you can - when you think there is something new to learn you just hop on board ... it has left me thinking "What is professional development? Where does this give me a qualification or does this just add to my [knowledge] base?

This concern about whether ad hoc training will lead anywhere also comes from Maryanne when she looks at her own training: "I enrol for a course and I do a paper so I have got a lot of papers, a lot of papers, but they don't add up to a cohesive qualification."

Some of those in the focus groups also expressed concern about whether potential employers see value in formal qualifications and if those qualifications would be recognised or seen as of value in the workplace.

\section{Current professional development goals}

Over $60 \%$ of respondents to the on-line survey had 'non-specific' ${ }^{4}$ professional development goals, or 'no' goals (Table 4.4). Thirty-four percent stated specific goals and of those, $15 \%$ noted they planned to achieve AAPNZ Certification.

Typical 'non-specific' goal responses include the wish "to be able to do my job properly and be recognised" or "to move on from my current job to a more responsible and better paid job. I wish someday to be able to run my own business."

While not all 'specific' goals were detailed in how they were to be achieved, they did cover a wide range of opportunities and indicated a clear purpose or intention.

'Specific' goals ranged from a certificate in business administration to post graduate study through to retirement plans. One specific goal was "To firstly attain AAPNZ certification this year and then to complete my Graduate Diploma in Business Management in 2011 (doing it part time)." Another goal was about using the administrative role as a 'filler' until personal circumstances changed, for example pre-school children, allowing the participant to continue in their preferred field.

\footnotetext{
${ }^{4}$ The separation of non-specific from specific goals was based on the respondent's use of language. Active positive language indicated a defined intention so was classed as a specific goal. More generalised language indicated a wish perhaps, rather than a specific intention so therefore was classed as a non-specific goal.
} 


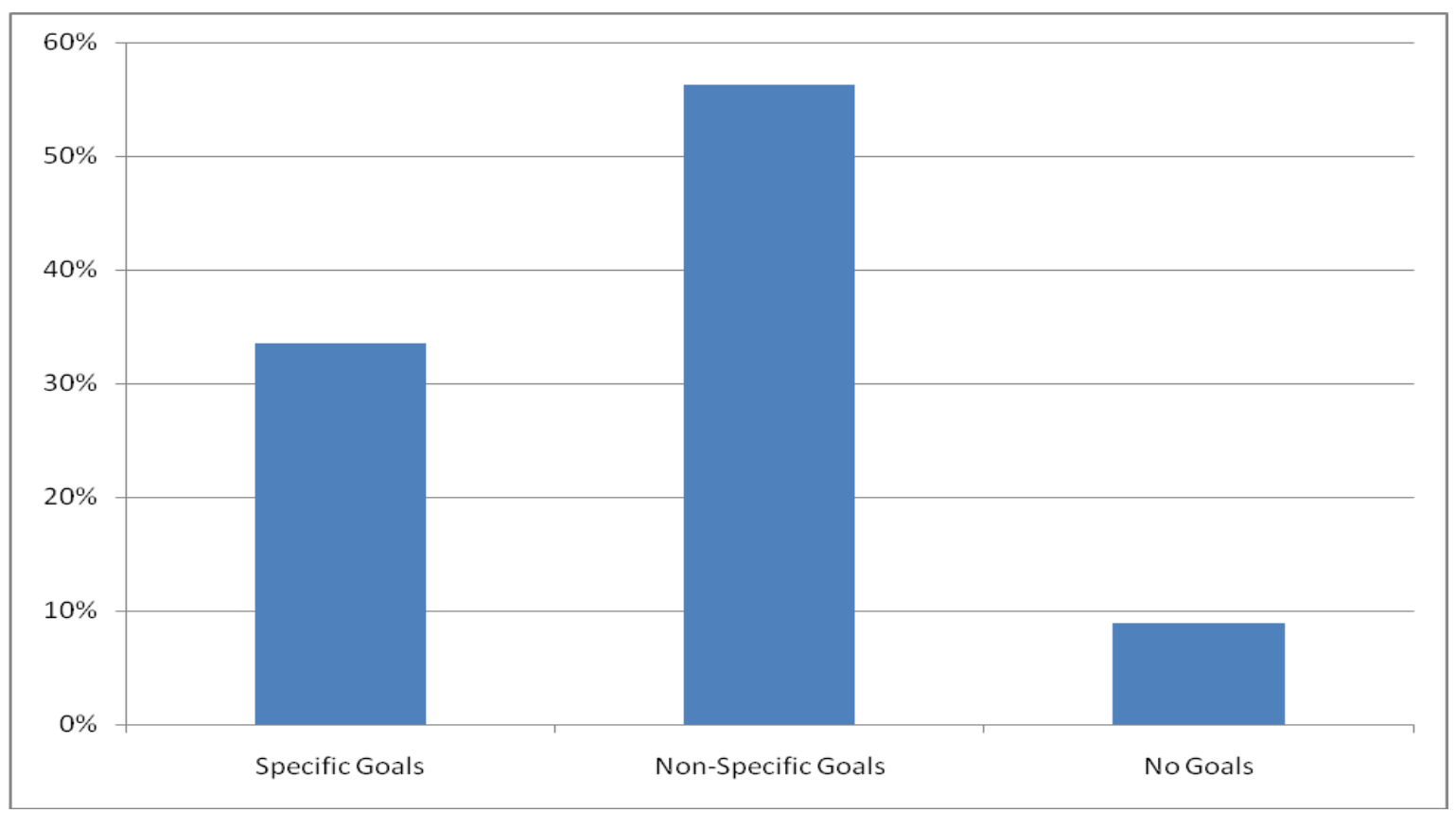

Table 4.4: Professional development goals

The findings indicate that the majority of survey respondents have access to, and support for professional development within their workplace. The majority of survey respondents have no professional development goals or non-specific goals; however over $30 \%$ do have specific professional development goals.

\section{Professional Development}

The research aimed to provide an understanding of the importance of professional development to administrative professionals and clarity about who receives professional development in the workplace. In addition, understanding what internal and external support is available to administrative professionals, and what barriers there are to their undertaking professional development was also sought.

Data to answer the questions 'How do administrative professionals perceive or experience their employing organisation's view of their professional development needs?' and 'What support, organisational or other, is there available for administrative professionals to undertake professional development?' come from the on-line survey questions 2.1, 2.4 and 2.8 (Appendix $\mathrm{H}$ ) and discussion in the focus groups primarily in response to questions 2 and 5 (Appendix H). 
Data on how administrative professionals perceive or experience their employers' view of their professional development needs are provided by identifying who receives professional development within an organisation. Administrative professionals' professional development needs and its value to them, are demonstrated by showing how important professional development is to them and the effects of positive attitudes of an individual on creating professional development opportunities.

Data on organisational or other support come mainly from the survey data. Data primarily from the focus group discussions, contributes to describing perceived barriers to gaining professional development.

\section{Who receives professional development}

For over $50 \%$ of survey respondents, the perception is that everyone within their organisations receives professional development (Table 4.5).

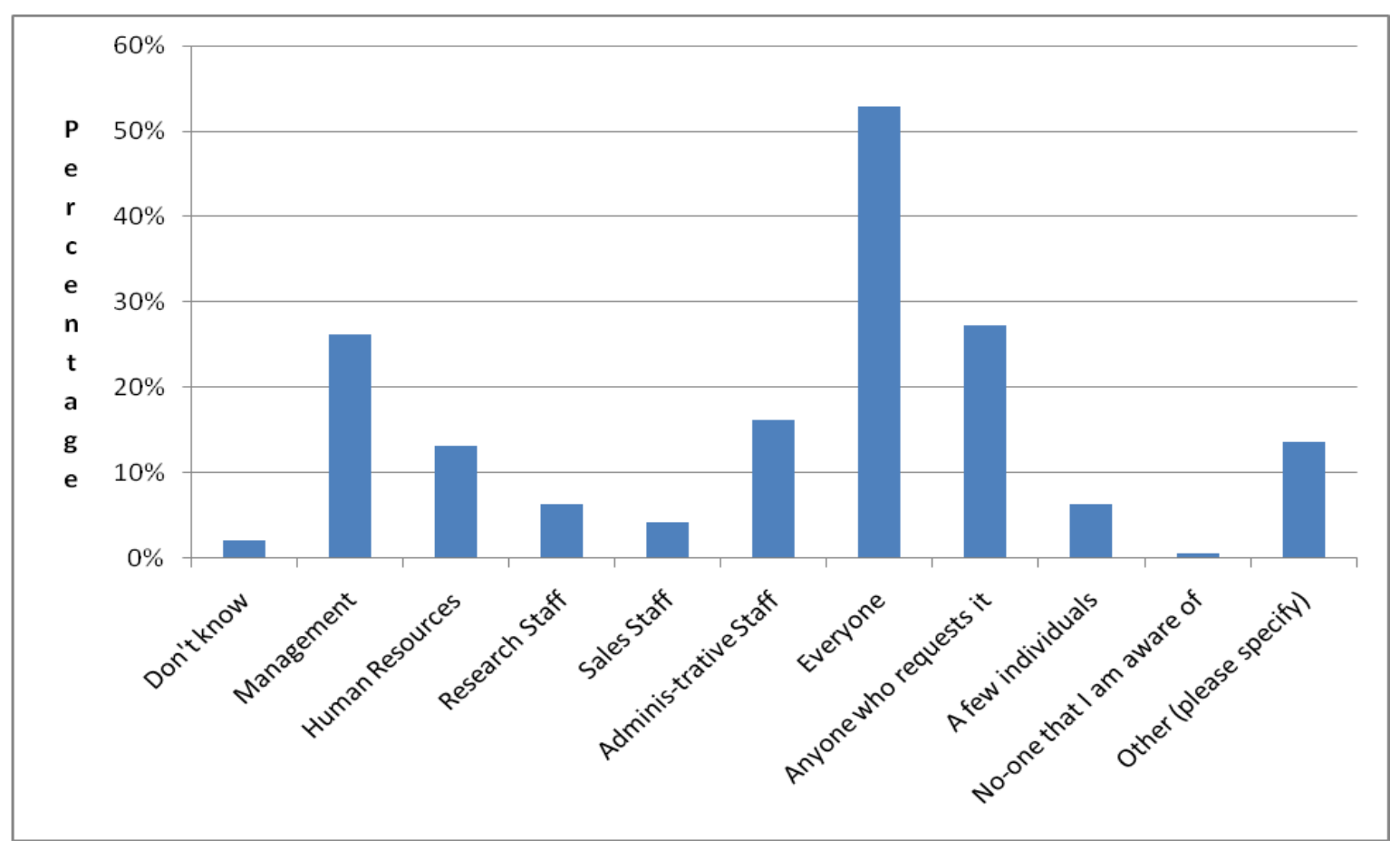

Table 4.5: Employees who receive professional development

\section{Importance of professional development}

Over $70 \%$ of survey respondents indicated that professional development was important to them (Table 4.6). 


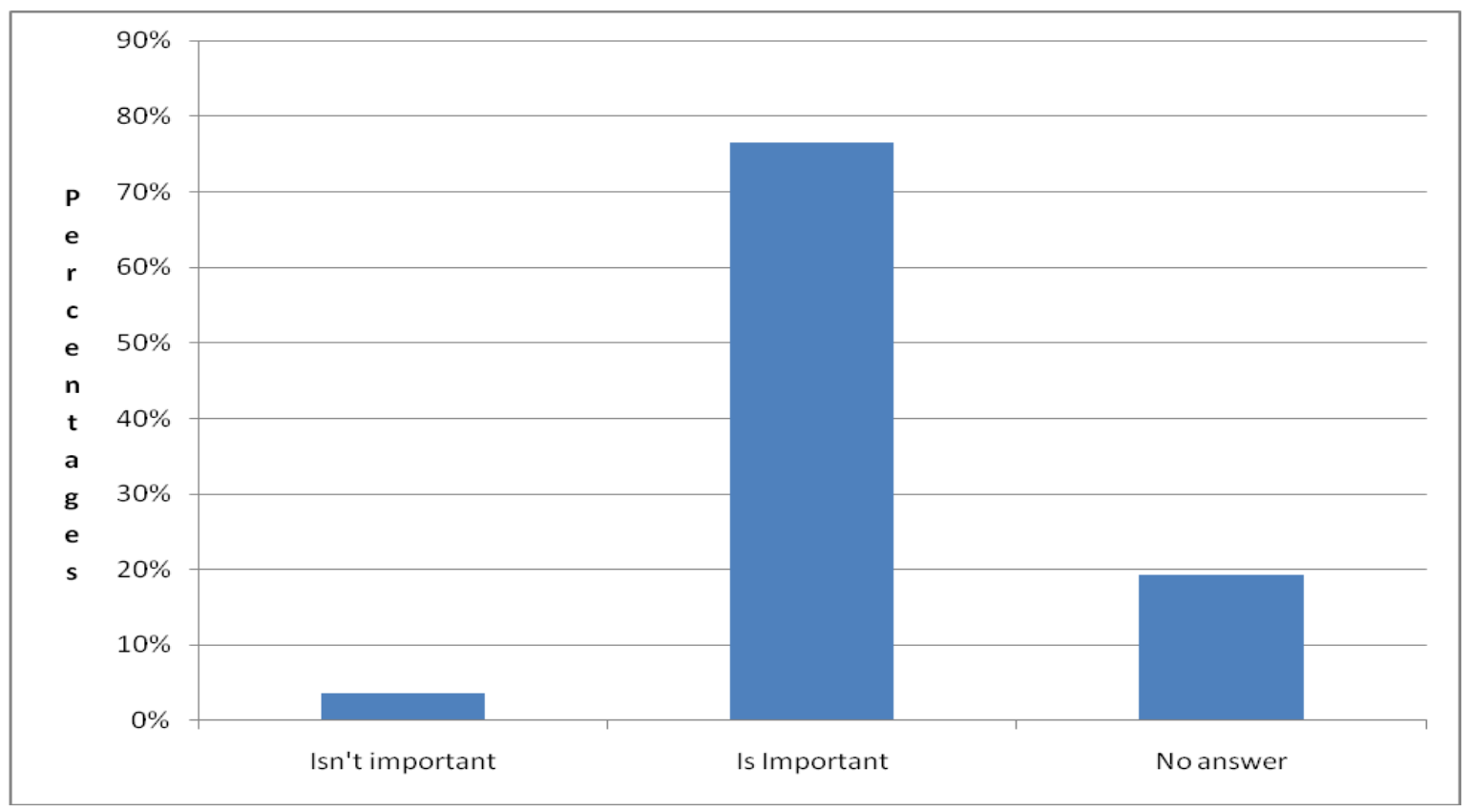

Table 4.6: Importance of professional development

The following quotes demonstrate the importance and relevance of professional development to many administrative professionals:

It is very easy as an Administrator to be stuck in a rut and just do your daily tasks as required. I'm an ambitious person and requiring opportunities to keep me motivated. It's also good for the organisation.

That's the only way to stay up-to-date with the market changes, be competitive, well qualified and wanted staff.

Life-long learner, continuing education.

\section{Positive attitudes and self motivation}

The attitudes of individuals also contribute to the importance of professional development for administrative professionals. Comments which indicated a positive attitude from the respondents ranged from those who were driven to seek every opportunity, for example Jane says:

We actually have to actively force it ourselves and I think every single one in this room is actually driven to do that and that's how you force your way up. 
To some who have developed the desire to develop professionally and now look for opportunities as highlighted by Ursula, who said:

In the last couple of years as I have become aware that I really want to have a qualification .... I want some sort of formal recognition for the knowledge and in-house training and other training that I have done.

Some administrative professionals undertook professional development themselves in their own time and at their own cost. Positive attitudes and determination, were demonstrated by Jillian who described how she undertook self-taught learning to be able to handle her role better and how that impacted on her career:

I just went away and did a lot of reading about ... budgets and talked to a lot of people and ... um that grew me too in learning about finance and I think learning about how to handle money and handling budgets and cutting budgets really set my career pathway at the same time.

\section{Workplace environment support}

The majority (79\%) of survey respondents stated that they receive full support from their employing organisation for their professional development (see Table 4.7).

The focus groups discussed that the largely supportive workplace environment for professional development may be due to their whole employment environment, or sometimes is specifically influenced by their direct manager. Alternatively for some, support was available through negotiation either at the time of employment or when required. Support can cover a wide range of areas from reimbursement, conference attendance, in-house training and time off to study. 


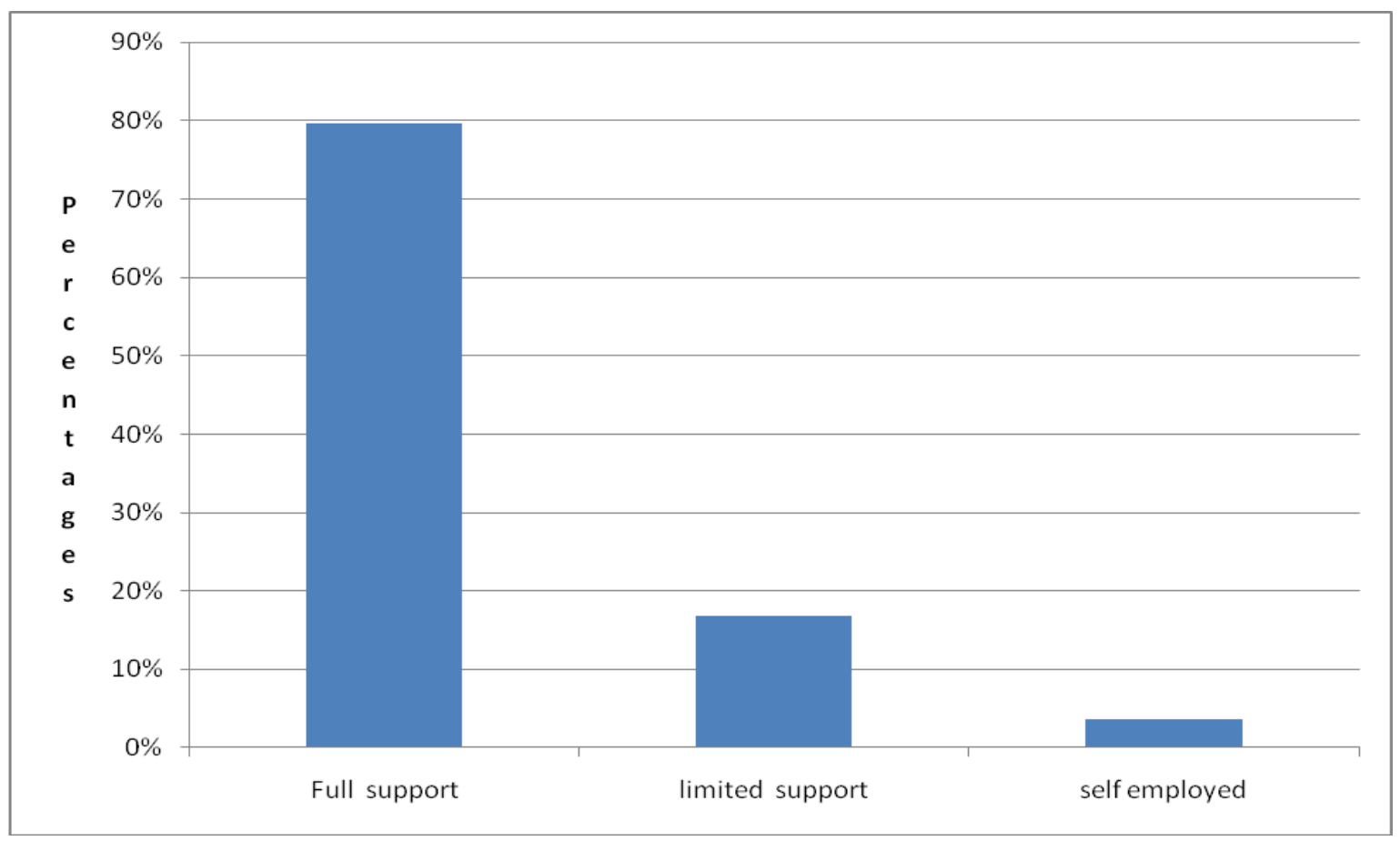

Table 4.7: Employer support

For some staff, support from their workplace is forthcoming due to their own demonstrated commitment to their profession, as explained by Joanne:

I am lucky enough to get funding to go to the AAPNZ conference. I felt I had to justify why I wanted to go again to gain funding from my employer and luckily my involvement with AAPNZ over the last two years on committees has allowed me to get funding because I am more involved in my profession.

However, while in some organisations in-house and organisation specific professional development or training is offered, there was comment that support was not readily available for other forms of professional development. This is explained in this example where the respondent indicated that "privacy workshop, industry specific software [available as in-house training but] I felt that training is really not that accessible."

Overall the majority of administrative professionals in large organisations perceive their professional development is supported by their organisation, within budget constraints, time constraints and individual managers' approval. For the small number working for smaller organisations this support may not be readily available and this is discussed later in this chapter. 


\section{Funding Support}

Funding support for professional development, where specified by the respondents, ranged from $\$ 350$ - $\$ 2000$ per annum or was a percentage of the annual salary. Many respondents did not provide a dollar range; however support was noted as ranging from 'some support' through to 'considerable support'. Some respondents described their organisation's very clear specific rules to be followed to gain approval for professional development and others described a more ad hoc approach or that it was left to the direct reporting manager or Human Resources department to make a decision.

Some comments showed a flexible approach to funding support for professional development, as Maryanne noted "obviously budget and all the rest of it, but I find that [a] budget can be elastic". However, it was noted that in tight financial times the first thing to be cut is the professional development/training budget.

Where budgetary constraints might appear to limit funding, if the professional development was deemed valuable to the organisation the money might be found as Helen explains:

Everyone is looking really closely at all professional development and I think they are not cutting out professional development as such. I think they are just looking at the different things like conferences ... and thinking actually that's not as good a value as they could be getting.

\section{Manager's support}

An important source of support for professional development in the workplace comes from the manager:

This [professional development] is manager dependent. All ... is available but will the manager say 'yes'? There is a percentage of salary which is put aside for training for each person - manager dependant to say 'yes'.

Managers supportive of individuals' professional development requirements were described by Cherrie when she discussed being well liked by her managers and that they 
saw potential in her. This led the managers to encourage her through professional development opportunities.

Joanne told of her former manager not wanting to lose the potential he had seen in her:

I had briefly worked for him and he'd recognised the potential then but couldn't do anything about it ... and they'd come up with this position because they didn't want to lose me and for me to be able to progress from the sole secretary position to a supervisor was terrific.

\section{Providing a professional development pathway}

Emily explains that in her organisation she has set up a pathway involving professional development and qualifications to assist new staff achieve the level expected for her organisation.

We've said you're coming in at ground level and you've got to have this skill, and some common sense, and you are starting from the bottom up and actually have some practical application to your knowledge, give some practical good grounding. They will only stay copying and filing, really junior things, for a short time and we know that some might stay a bit longer but it is actually building something within the organisation.

This is an example of the organisation providing the type of professional development and up-skilling that they wish their staff to participate in. There is an expectation that some of those new staff would take the training opportunity, especially the very junior staff, and move on to other employment.

\section{Administrative professionals concerns}

The importance of the organisation receiving value for money and the time used to attend professional development events was raised as a concern for the focus group participants and is demonstrated when the focus group facilitator provided a summary of shared ideas: 
External providers don't meet the needs of administrators that the time spent must be valuable - that's also in terms of getting something out of it for the time that you are putting in ... (noises of agreement).

Some participants expressed concerns about the value received by their organisation from professional development they undertake as it may not have been well thought through.

We gained some funding for eight of us to attend a three day course. It was excellent ... it was a bit wasted um ... When I think about it, most people who went on it may not have got any lasting value ... probably not enough thought really, to be honest, as to what the outcomes will be. It might have been better to have specific training targeted at people.

Administrative professionals may need to justify how financial support will provide value to their employers, as Jillian explains "now my employer is seeing that the value of my membership [paid for by the employer] with AAPNZ is actually helping the company and I've put dollar signs beside it."

The individual receiving professional development may provide additional value to their employer if they pass on the newly gained knowledge within their organisation. However the issue of time on return to work, to share the information gained was raised, as while the intent was there, the opportunity for this often did not eventuate.

Also discussed in the focus groups was how difficult it can be to put into practice, on return to the busy work environment, the learning the individual felt so enthused about at the professional development event.

\section{Limited workplace support}

In the focus groups, discussion was largely around the perception of readily available professional development in the large organisations in which most participants worked. Caroline, however, provided a different perspective from the others in these discussions. She works with administrative professionals in small industries and explains the situation: 
It is actually really common in NZ. We are one of the biggest small to medium enterprises countries and it is a huge base that AAPNZ is not really touching. They [administrators] don't think they are valued enough “Oh I couldn't do that" you know. They think if you are working in a professional industry with DHB or government departments or tertiary education you've kind of already got a certain level. But if you are working for somebody who has 20 factory workers, the culture of expectation is just so different - [professional development] is not valued or wanted.

Eighteen percent of survey respondents made comments on limited support (Table 4.7). They perceived their work environment to be unsupportive: "the facility is there on paper but in reality there is no time to undertake professional development". There was also a perception that administrative professionals were often the last employees to be considered for professional development: "I think that admin staff are always left out and then sometimes there is lesser money to support them". Some of these comments were made by those who had previously noted that professional development was available to them in the workplace.

Joanne noted that while in-house professional development was available for senior managers, there was little in-house that would suit her:

We've got a management development programme, a market leader programme and an executive development programme and a lot of those senior managers get the opportunity to go on those. ... to get on to Executive Development I would probably need to become a senior manager.

This quote provides a more in-depth general comment on the lack of support for professional development by some potential employers:

Having recently been applying for admin jobs after a period of temping, I have been surprised at the lack of interest by employers to encourage any kind of personal/professional development for their admin staff. This 
attitude in several educational organisations appears to make any real recognition of administration careers an age away yet.

Caroline commented on what she has observed working with small businesses with regard to their administrative professionals:

[To] these manufacturers it really is just somebody to get that job done and they are not respected or valued in that role. It's like having a factory worker but instead of putting something through the line, what they are doing is answering the telephone and sending out the invoices and quite often they are actually quite untrained, unskilled.

\section{External environment support}

One external supportive environment can be through involvement in the professional body for administrative professionals, AAPNZ. AAPNZ provides access to scholarships to undertake qualifications and training for professional development. Gaining or enhancing skills is the main professional development focus at AAPNZ monthly group meetings.

Demonstration of skills gained through AAPNZ membership may help when seeking or undertaking a new role. Tiri explained that writing is a big part of her current role and her involvement with AAPNZ helped to further enhance those skills. Tiri recounted her experience in the job interview for her current role when her then prospective employer asked:

\footnotetext{
'What are your writing skills like?' and I still can't believe today that I had a copy of [AAPNZ group newsletter] and a whole page in it that I had written in my role as [Group] President and I just pulled that out (laughter) and he could see that I could string two words together ... I was obviously prepared.
}

\section{Personal choice}

Focus group discussions highlighted that when opportunities become available sometimes it is not the right time to take that opportunity and sometimes it is. This is outlined in the following from Maryanne: “choices, you make a choice because you can't do all of it ... 
flag that, take that, whereby if you try to juggle everything you end up dropping the lot." She goes on to say:

I think if I was working full-time I could take on a manager role and have more say but I choose not to and we make sacrifices for what we want to do yet there have been missed opportunities because of the choices I have made.

Joanne comments further on her unsatisfactory experience in a supervisory role:

I don't like it [supervisory roles] and that's why I am happy doing what I am doing with no staff to report to me. I actually like not having that responsibility because it doesn't fit well with me.

This discussion highlights that individuals can control their own professional and personal development and take responsibility for it.

\section{Barriers to professional development}

Discussion around the barriers to receiving professional development in the focus groups provided data in response to question 5 and in open-ended responses from the on-line survey.

\section{Lack of manager's support}

The comment from Brenda: “one barrier would have to be manager(s) [who] didn't see the need" contributed to discussions on the difficulties of undertaking professional development when there was a lack of support from the manager.

Maryanne suspected that professional jealousy from her manager may have been a contributing factor to her not being able to take up a professional development opportunity:

Not because they haven't seen me as being capable of doing it, but because of the other individual's personal agenda, so I have felt that has held me back in many ways. ... I guess jealousy would be one ... I've said I want to extend myself to take on this challenge [and] my manager at the time, 
wouldn't allow me to do it, not because I couldn't do it but because [she felt] 'Oh I wouldn't mind doing that' so there was that aspect to it.

However, Joanne felt a lack of support from her manager when she was promoted to a supervisory role and was not provided with training to help her to cope with the new level of responsibility:

Supervisory role - I was pretty much just thrown into it. I wasn't taught how to do it properly. ... what I found the hardest was that I was supervising people who were older than me and who didn't feel like I had the right and that made it extremely difficult."

This led Joanne to say later on in the focus groups that she would never take on a supervisory role again as the experience was not positive for her at all.

Individual managers' responses to requests for professional development can be a barrier. It can also impact on the feelings of value of self experienced by an individual, as described by Cherrie:

[New manager] said to me in an email that because it was an expected [agreed during interview] in your new position that this time she would allow it but in future you have to remember - yes, exactly, you remember you are only level 3 [the manager said that on Level 3 no-one would be allowed to attend a conference, that was only for managers]. That's how it felt, I was quite hurt and kind of disappointed and put off - yes undervalued, not by the whole organisation, definitely that person.

On occasions after the individual has attended an agreed professional development event, comments made by senior colleagues about the course attended, may not always feel supportive as Andrea relates:

I finished one yesterday called 'Thriving under fire' and my colleagues ... asked me 'which course are you on this time?' and I told them and they burst out laughing. 


\section{Educating manager}

The importance of educating a manager about the type and level of support an administrative professional can provide was discussed in the focus groups as a method of resolving lack of manager support as a barrier.

Education of the manager may help him/her understand why professional development is important to the administrative professional and their role in the organisation. This is best described by Emily:

Part of that has been educating the managers that it [professional development] is important for their staff ... I think one of the biggest gaps is that managers don't know how to use you as an administrator or PA or whatever. They don't actually understand what you are capable of or they don't understand what they need so there is a real gap in their knowing how to use you. So you are trying to educate them. ... showing them this is what you could do, so if you gave me this development then I could help you do this. ... that allows me to take that part of your role which allows you to do what you're paid for.

\section{Time}

A barrier identified was the difficulty of finding time to undertake professional development. This difficulty occurred even though support was apparently there to undertake it as demonstrated by "All support is available in theory but in reality it is not usually possible to take up opportunities due to heavy workloads!", and

I looked at undertaking Level 5 in Administration/Business and was able to have the time off for this but had to keep up with own work which management had just restructured and it became a too heavy workload.

\section{Geography}

Some barriers relate to location which brings in an additional barrier of cost as outlined by Joanne: 
a general thing throughout the South Island um - you know we got talking to some of the people at the [AAPNZ] Conference, they are excited that it is actually going to be in the South Island next year because it gives more of them the chance to actually attend because of that cost barrier that comes into it."

\section{Transferable skills}

Lack of recognition of the transferability of administrative skills was a barrier raised in the focus group discussions. Specialisation through working in one specific industry should not limit where core administrative skills can be used as they are readily transferable and not limited to a specific industry. Tiri described the value of her wide ranging general administrative skills when she moved from an agricultural administrative support role into a new role in a health field, and how those core administration skills helped her move into a whole new area:

I had been there only about 6 months as a PA so it was a new role for me, when the health and disability standards came in, ... so I, all of a sudden, had to switch on to that. ... it was something I really enjoyed ... something I hadn't ever been involved with before but using my experience (laughter) I could swing into a completely new thing. ... due to my experience I found that I could.

Administrative professionals being classed as 'industry specific' can provide a significant barrier to finding work. Industry specific skills are often learned through informal learning in the individual's working environment. However, the perception described by Joanne that industry specialisation is a limitation applied by recruitment agencies:

Being put into boxes. I certainly found that when I was looking for employment I had only ever worked in the health sector previously or the education sector. So I found it difficult ... I think it was more recruiters - I hate to say that - it was recruiters putting me into a particular box, and trying to convince them that I can fit into any box. 
Ursula drew on her experiences in seeking a new position outside her current industry:

I did actually get my CV out there for a few EA jobs and I was pigeon holed 'Oh you've spent 20 years in a legal office, you couldn't possibly work in a different industry' and I think an issue that needs looking at is that the skills set that administrators have is transferable (murmurs of agreement)."

Professional development covers a range of activities; training and course attendance, mentoring, changing roles and the informal learning undertaken in the workplace from doing the work, self education and peers. Nearly $80 \%$ of survey respondents indicated that they received employer support in a variety of ways covering funding, time and attendance at conferences and seminars. The support of a direct manager was deemed very important.

While over $70 \%$ of survey respondents indicated that professional development was important to them, concerns were raised by administrative professionals as to whether organisations were gaining value for the money and time spent on some training courses. The only external support listed was that provided through AAPNZ in the form of scholarships available to members for professional development.

In summary, a significant barrier to undertaking professional development was lack of manager's support. However, educating a manager as to what the administrative professional could actually do to support the manager might play a big part in developing that support. Other barriers listed were time, geography and a lack of recognition of the transferability of administrative skills apparently locking administrative professionals into a specific industry area.

\section{Career Pathways}

The research aimed to explore what impacts professional development might have on the career pathways of administrative professionals, pathways to their current roles in administration, what career pathways might be available to them and their awareness of those career pathways. 
Data to provide the answers to the questions 'How do the professional development opportunities available impact on administrative professionals' career pathways?' and 'What career pathways are there available to administrative professionals?' came from the on-line survey questions 2.9 and 2.10 (Appendix $H$ ) and through discussion in the focus groups primarily from questions 3 and 4 (Appendix M).

\section{Pathways to current roles}

Discussion was held in the focus groups on pathways to their current roles. Jane talked about how her professional development opportunities moulded her current career. She said she never would have thought she would be in the type of position she currently is and of which she is proud.

Ursula indicated the pathway she undertook from her start point of 'Office Junior':

When I started I was, the politically incorrect term now, but I was the office junior and so there was a career pathway - obviously Junior, Secretary and then Secretary to the partner or what have you.

There were comments which refer to a career pathway; for example "I've been in local government for over 35 years now and have progressed from typist to Executive Assistant and Committee Advisor", and Jane comments that "they say to me if you started in reception, look at what you've done with your life". For some the pathway changes direction:

Possibly I've deviated from the administrative 'normal' path by becoming more involved in business software training and implementation, but I feel that what I do ... is still within the 'administrative professional' umbrella.

The lack of a clear pathway today is raised by Emily who explains that new staff do not always have the skills required to do the job:

You get people that either get a degree at university or they don't know what to do and they say 'Oh well I will go and be an administrator' and, 
and they are not good at it. They can do the function but there is something more to it than that.

There are informal mentoring relationships gained through membership of a relevant professional body such as AAPNZ which can assist with career decisions as described by Joanne:

My involvement with AAPNZ is really helping me think about other things. I mean a lot of what I have taken on board over the last 12 months has been due to conversations with Conny about things [career choices] I want to go for, is this the right thing I should do?

Jane described the role a mentor played in her learning her new management role:

The professional development I've had has been he has given me a mentor, a 74 yr old business man, who has seen and done just about everything I have said or done, which has just about turned whatever hair he has got left on his head white ... he has really pushed my intellect.

\section{Career pathways available}

When the survey respondents were asked what career pathways were available to them, over $60 \%$ noted that they saw career pathways available within administration and in either management or other career options (Table 4.8). However, it was notable that $27 \%$ of survey respondents recorded a perception of a limited career pathway and $5 \%$ were unsure. 


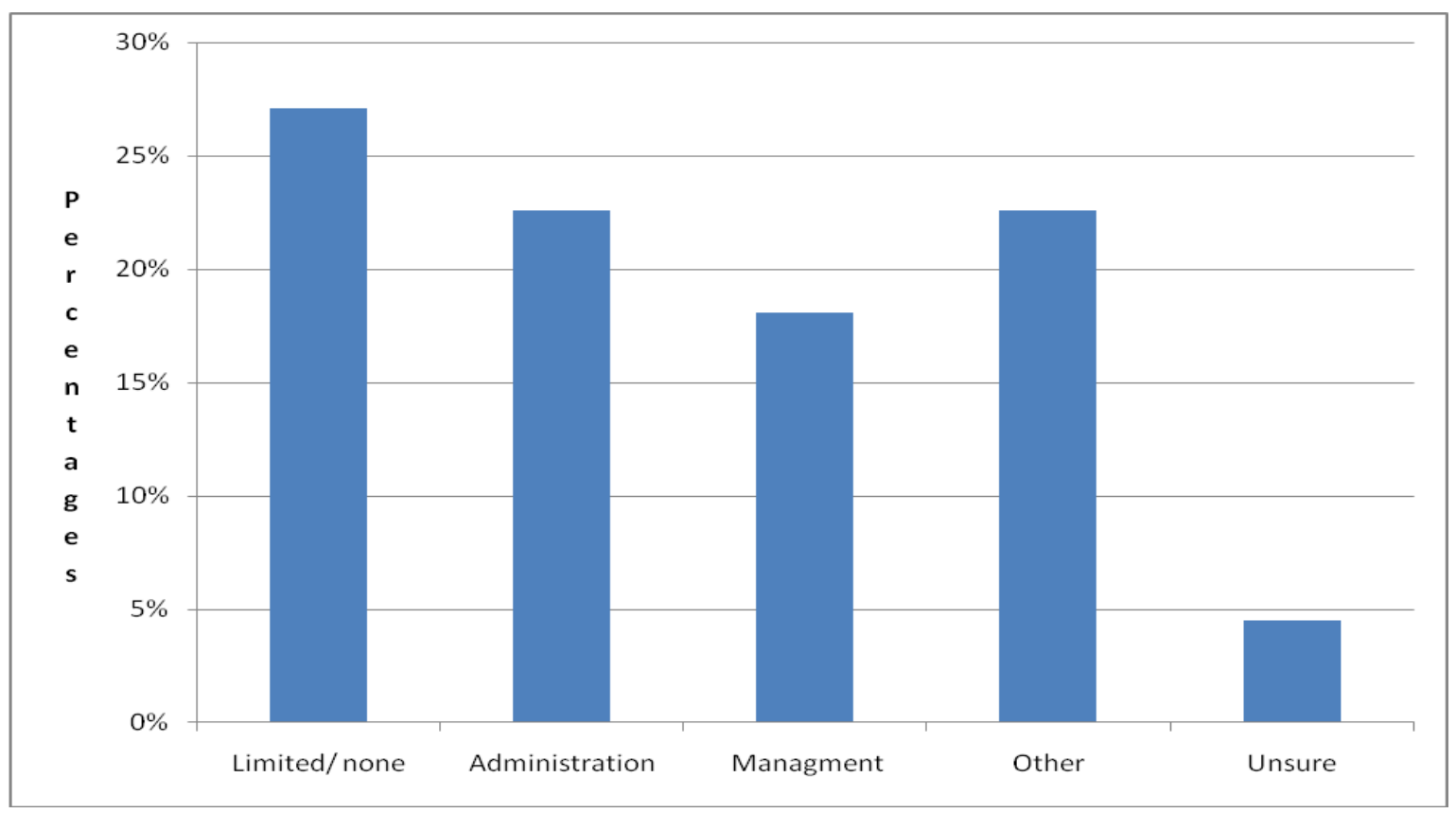

Table 4.8: Career pathways

It is interesting to note that there are differences in the percentages between career pathways that administrative professionals see for themselves and what they report as being their ideal career. Management and a variety of other careers were the ideal careers for $55 \%$ of the survey respondents. Forty-one percent considered that their ideal career was Administration (Table 4.9).

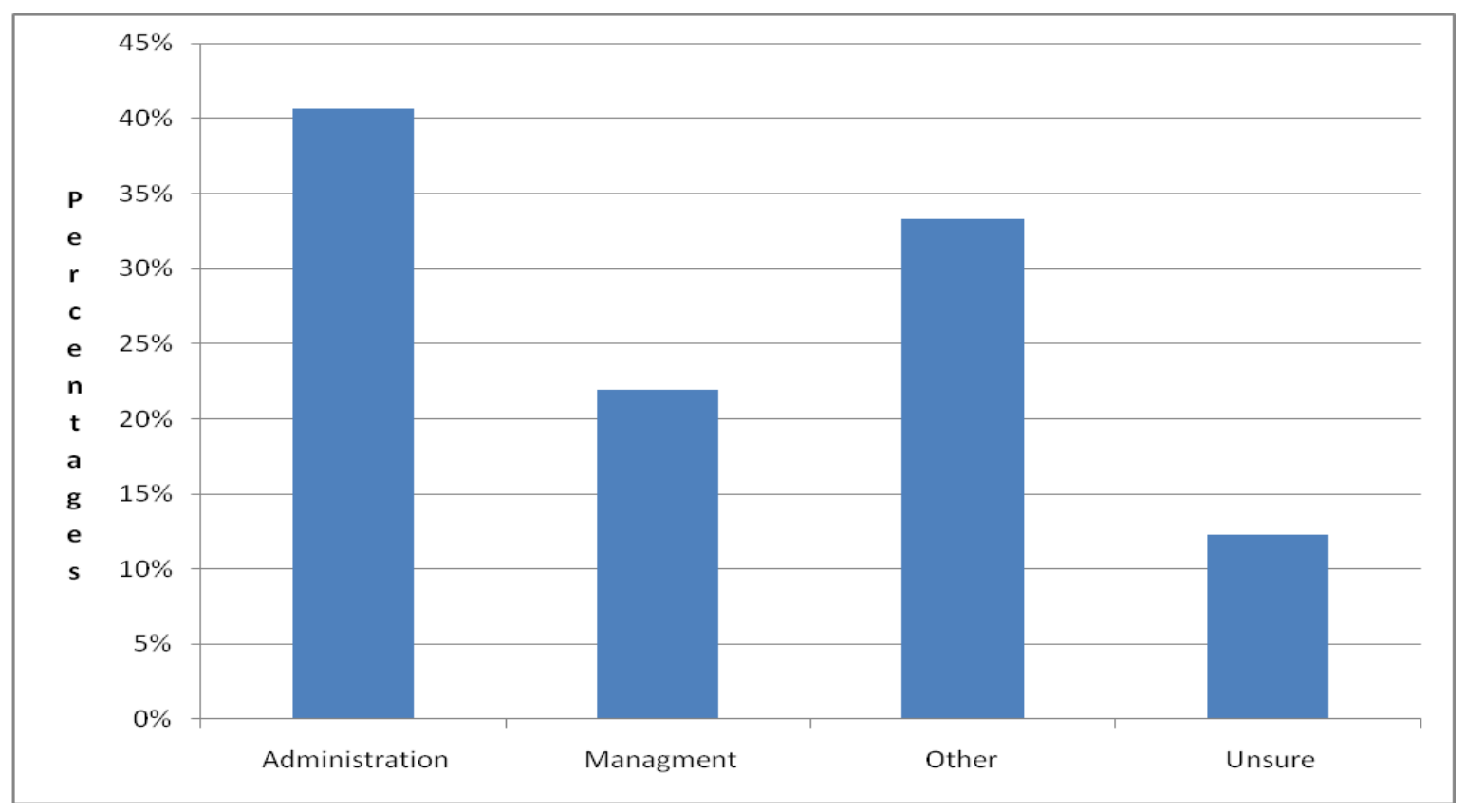

Table 4.9: Ideal career 


\section{Career pathways - Administration}

Forty-one percent of survey respondents chose administration as their ideal career. For some it was a choice from very early in life, as Brenda describes:

I have known all my life what I've wanted to do. From the time I was a little girl until the time I was an old girl (laughter) I always said that this was the career path that I wanted and I've never swayed from that.

The choice of administration as a career does not mean it was always chosen from the start but that, at some point, the individual decided they wished to continue with administrative work and to recognise it as their career. Joanne commented on her enjoyment of the administrative role and the support she received which kept her on her pathway:

I love what I do and I am glad that I took the path that I took and there have been a couple of managers along that way that have recognised my potential and allowed me to move up.

Some survey respondents wished to stay put and others had had dreams of careers they would like to follow but circumstances did not allow that to eventuate, for example:

I discovered while studying for my Diploma in Business Administration that I had a strong understanding and affinity with employment matters particularly to do with legal compliance. I found it very exciting and stimulating and although I did for a brief time consider going to law school it was not to be.

Some were still unsure but will stay with Administration as other options are not clear, Cherrie explains:

I am going to be 50 soon and I really don't think I have found my niche. I like working with people and I am sure the social work thing would have been more suited and I keep thinking back to that. 
These responses show a generally high level of satisfaction in the administrative role and a desire from some, for there to be a pathway for progression.

\section{Career pathways - 'Other'}

A wide range of ideal careers were provided by $33 \%$ of survey respondents under 'Other' (Table 4.9) covering: mother, freelance editor/proof reader, running own business (unspecified type), systems trainer, sales and marketing, air accident investigator, photographer, florist, civil engineer, to list just a few. This wide list shows the range of interests held by administrative professionals and while some may be 'dreams' that may not be attained, others were well under way in their planning to realise those dreams. Responses discussed intentions for a career pathway in other areas, for example:

At present - whatever I dream I want I can do - if I put my mind to it. I am not limited by my employer.

I believe anything is possible; up-skilling is essential and nothing is out of reach, simply set the goal and make it happen.

I am fortunate to have access to various career pathways, not only within the organisation but in the community.

Lots. As an executive assistant we are always working a range of tasks, accounting, budgets, HR, employment, facilitating... the world is your oyster!

\section{Career pathways - Management}

Management was selected by $22 \%$ (see Table 4.9) of survey respondents and covers a wide variety of management roles from project and event management to team leaders and middle management including one who wished to be a CEO. There were also several responses relating to 'running my own business'.

Some responses showed they would like career progression, either staying in the administrative field or moving into a related one; for example "I hope to move up in the administration field to either an office manager or event manager's role." 
The following are representative comments about being in management roles:

Project Management - at the moment I am only given opportunities as a Project Administrator.

I would love to work in event management, helping to organise big events such as the Rugby Sevens, international concerts, etc.

I am working towards a higher level management position within the financial side of my company.

Geography may play a part in limiting aspirations. For example, one respondent had been a Business Manager previously but has found with a move to a smaller region there is now limited availability of this type of role.

\section{Limited career options}

Twenty-seven percent of survey respondents (see Table 4.8) raised the issue of limited or no career options. The following quotes express frustration at not being sure how they can change or move on as they feel they are being kept in their position:

As an Administrator you are often stuck between a rock and a hard place. If you are very good at your job you are often taken for granted and teams are reluctant to see you move on. In many organisations advancement for Administrators is not seen as an option - once an Administrator always an Administrator. Some may be happy with this, I am not!

I'm not sure any [career pathways] are. There seems to be a problem with accepting that PAs can move into other roles. Once a PA, always a PA!

Career progression is not always seen as a clear pathway and while there may be options for other similar positions within an organisation, it is less clear how progressing would occur. One respondent indicated that progressing may require moving outside her current work environment: 
I would like to be the PA/EA for an exceptional manager. On the whole I enjoy my career but would need to look outside my current organisation to progress to a higher position as I don't have a degree or business qualification and institutional knowledge is not particularly valued.

\section{Personal choice - age and stage in life}

Some limitations in career choices listed were due to the survey respondent's time/stage of life limiting the options they see available to them. For example, "Limited now in view of age and stage" or "None - I enjoy my job but at age 60 I do not wish to acquire any further professional goals". These are perfectly appropriate choices that people make and indicate responsibility for their own choices.

\section{Awareness of career pathways}

A small number (12\%) (see Table 4) of survey respondents indicated they were unsure of what career pathways might be available and lacked clarity around any next step, or if there was a next step. This might be explained when people entered administration not necessarily as their first career choice but perhaps because they could not make up their minds as Joanne explains “I didn't want to be a secretary when I first [started work] ... I wanted to be a teacher." Emily talks about the limited options of only either commercial or professional (academic) courses that were available to young women when she was at secondary school. Some respondents indicated that their career options were limited by where they lived.

One response indicated a lack of certainty about how the role of an administrative person is perceived, that they are: "Not sure [of a career pathway] at this stage as the administrative profession still not 'recognised' as an important role."

Cherrie believes mentoring would be of value to administrative professionals:

Some of us know what we want to be and what we are and are very happy with it. But there are a lot of us out there who are still not sure if we are in the right direction or just need someone to be interested in what we are doing and ... have that knowledge base to give you that advice and to move 
in the right direction so it's a good idea if admin personnel could have a mentor.

Joanne is concerned about a lack of succession planning within her organisation for administrative work and is therefore working to bring those with less experience up to a higher standard so they can take over from her:

[What] I am more valuable doing in this organisation is mentoring so that one day they can do my job. I've got no-one, there's no succession plan in our administration area for anyone to do what we do.

A career is not only about changing or having a pathway to somewhere different. It is also about recognising that where you are is where you wish to be. It also acknowledges that sometimes where we end up is the result of others' influences which can be a very positive thing. Jane explains this:

My career choices have definitely been affected by the professional development I have had. I have been steered in a direction that maybe I never thought I would.

In summary, within administration as a career there was no clear single pathway for the participants into their current roles, though there was a perception expressed that pathways were clear in previous times when an individual started as an office junior. This lack of progression today has led to some issues of lack of skills in those new to some roles. The impact of professional development on career pathways was not clearly outlined except where a mentor was involved.

The majority of survey respondents indicated that they perceived there was a potential career pathway, with $25 \%$ of those indicating that pathway was within administration and $18 \%$ in management. However a further $27 \%$ felt the pathways were limited. There was however, some discrepancy in responses between what was perceived as a pathway available and what was described as an ideal career. There was a small number (12\%) who lacked clarity around what any next step might be. 


\section{Themes that Emerged from the Analysis}

Two themes emerged from the analysis of the open ended responses to the survey and the focus group discussions. Data on these themes were not specifically sought. There were occasions where even though the respondent in the survey indicated that there were resources and support available for administrative professionals at their place of employment, a range of barriers were noted in the comments part of other questions. This sub-text came through also in the focus group discussions and led to the development of the two interrelated themes of 'value of self' and 'value of the role'. How an individual valued their self or valued their role, impacted significantly on how they saw opportunities in professional development and career pathways that were available to them and how they reacted to those opportunities.

The influence of the environment on an individual was another significant factor in how they saw themselves and how they reacted to opportunities for professional development and career pathways. This environment can be home, work, geographical location and social environment.

\section{Value of self}

The importance of value of self was raised by many of those participating and a lack of value was perceived as a barrier to obtaining professional development and to seeing a career pathway. Value of self is perceived by administrative professionals as being influenced by the individuals' internal environments and/or by their various external environments.

Lack of value of self by administrative professionals and not seeing themselves as worthy of professional development, was described by participants as a factor at some point in their working lives, and/or their perceptions of how others see them. Eleanor describes that for her "Barriers were self esteem ... no qualifications, didn't have school certificate, wasn't bright enough".

There is recognition that low value of self can be perpetuated within the individual as raised by Helen when she discusses that "there are barriers but a lot of the barriers are psychological in telling yourself that you can't do this or that (murmurs of agreement)". 
This is supported by Beverly when she talked about how she looked at professional development:

I guess up until a couple of years ago it wasn't something I took seriously as an administrator. I think sometimes you are either overlooked or over a period of time you just feel that is not something you should be focussing on - it's something more tailored for your boss or other senior managers in your organisation.

There was discussion in the focus groups on what the participants observed in other administrative professionals; how they didn't value themselves as Brenda explains:

Sometimes I think they might not think they are worthy (murmurs of agreement).... They have put themselves on the bottom of the heap and they don't think of themselves as worthy. ... and that is why they don't seek professional development ... because they might just not think that they are actually good enough.

An individual's value of self can be reduced or enhanced depending on the experiences of the environments in which they work. This is described by Joanne: "In a couple of, like, my early roles um I was shot down for being young and intelligent and wanting to learn so much more".

A positive working environment can enhance an individual's value of self:

I am fortunate to be currently working in an organisation that values all workers including the administrators. However I know that my organisation is a minority but it does come from within. Administrators need to value themselves in order to become valued.

Depending on the experiences of the environments in which people work, an individual's value of self can be reduced or enhanced as Joanne discusses "[the difference of] being in the right space at the right time with the right people I guess." 


\section{Value of the administrative role}

The following quote outlines the vital role administrative work plays in an organisation:

Strong/sound administration is an asset in any organisation. One of the first things one notices in any organisation is when things (e.g. payments missed, overcharging, long wait for documentation) slip through the cracks resulting in bad customer service/delivery due to poor administration. A tightly administered organisation is good for both the people working in the organisation and the customers.

However, the value of administrative professionals within an organisation may not always be recognised. Although they arrange invoicing, answer the phones, organise travel, maintain the filing and keep the systems and processes flowing, they may not feel their role is valued. This is illustrated by the following comments:

Generally speaking I have noticed during my working career that administrators are not seen as professional and therefore not worthy of doing personal development. This myth is carried onto administrators themselves who don't believe PD is of any importance to them.

Administrators always seem to be forgotten about, but people sure do notice when we're not there!

I think Administration staff are often near the bottom of the [organisation] and are not truly valued as [other professional staff] are.

The first thing to cut when there is a deficit it is Administration services.

\section{Gender bias and stereotyping}

The impact of gender bias and stereotyping is described by Jane, who is a manager:

I work in an industry where [there are] very few women. It's normal that if there is a meeting and if there are two managers female and 12 male, if coffee is mentioned they [the men] will all turn around and go .... Now that 
to me, that demeans the role that we have as women but it's also an expectation that someone who is an administrator or someone in the administrative field will do it um every single time.

Barriers to professional development opportunities may be gender related and there is a perception, in some smaller organisations, that professional development may not be appropriate for female administrative professionals. Selina talks about the "new environment" she has recently moved into: "I am finding it quite tricky; my male peers are put forward for lots of professional development". Elizabeth commented that she was “working in a boy's club - they get whatever they want - I'm at the bottom of the pile".

The majority of administrative professionals are women and there may be times in their working lives where family commitments are their first priority. This is highlighted by Elizabeth who explains that her spouse is disabled and she finds it very hard to manage, being the major earner.

All of these experiences contribute to and impact the potential development of career pathways for administrative professionals.

\section{Others' perception of the role}

Respondents demonstrated an awareness of the perception of the role by others and how that perception by peers can impact on the confidence (or value of self) of administrative professionals both positively and negatively. Beverly commented on the positive effect on her by the support of her more senior colleagues:

I'm not a clinician at all but I am fortunate enough to sit in a room and get the same level of training and recognition as some very highly intelligent individuals and actually feel on par with a lot of them ... the recognition of your peers that at times their roles are more senior to you but to ... feel like you are an equal is actually quite important as well.

A positive environment can enhance an individual's value of self. The belief was expressed that it is worthwhile valuing yourself: 
I hear how other administrators are treated in organisations where they are treated as second class employees. Administrators need to value themselves in order to become valued. Once they have overcome this mindset the world is their oyster!

Brenda noted however, that it was her more senior colleagues, who commented supportively about her achievement of a diploma, not her peers who worked in the same type of role as she did. The potential for being seen as different by your immediate peers can have a negative impact and be an issue in the workplace for some as described by Cherrie:

There is a group ... who think that people like Brenda and I are very ambitious and grasp whatever we want. They actually criticise you and laugh behind your back and minimize whatever you do, I have seen it happen.

Administrative professionals may perceive they are seen by their peers in a demeaning way, as demonstrated in this comment:

From personal experience, I've seldom been taken seriously as an administrator by peers because they have had a tendency to look at the role as being nothing but a glorified tea-attendant.

Caroline talked about those in small organisations who are not valued by their workplace and who may then not value themselves either:

I work with a lot of small companies with one or two admin people and they seem to have quite a different focus, that they really are dogs-bodies and they are at the very low end of the scale and either they are not interested in having any training whatsoever and mostly its probably fear comes up, 'I will be shown up to not really know what I am doing and I'm it, so where's that going to go'. 
In summary, lack of value of self was perceived to provide a barrier to obtaining professional development and to seeing potential career pathways. Conversely value of self was seen as a motivating factor to take up opportunities in both those areas. How an individual valued their self was seen as being something that could change depending on the environment in which an individual worked.

The value of the administrative role was acknowledged; however it was noted that in some workplaces the role is not perceived as being valued. The perception of the administrative role by others within the workplace was also seen as impacting on how an individual saw themselves and their role. Gender bias and stereotyping seemed to be an issue for some and seemed to be more prevalent if the working environment was largely male, such as may occur in a smaller organisation.

\section{Summary}

The research provided a review of the current situation of professional development opportunities within the workplace, as perceived by administrative professionals. It showed that the majority believed that if required, they had support for professional development within their organisation. However, professional development was most often informal and there was no professional development plan or goal. There were also perceived to be some barriers to accessing professional development which meant that while it was available, participation in it was not always achievable.

The research also showed that the majority of administrative professionals believed that there were career pathways available to them. However a significant number did not believe this to be the case and felt frustrated at not seeing themselves as able to progress within, or to move out of, their administrative role.

The discussion on opportunities for professional development and/or career pathways noted that administrative professionals who worked for large employers had professional development opportunities available, however, it was suggested that this perhaps did not readily apply to those in smaller organisations.

There were barriers perceived which impact on administrative profess ionals' ability to access professional development opportunities. These barriers may have been within 
their own internal lack of value or the lack of value they perceive others to have of their role. Alternatively there may be barriers from the external environment, which is not limited to the workplace. Where the individual had a sense of value of self, barriers were not perceived as being blocks; instead opportunities for professional development were recognised, and career pathways were perceived as wide open.

The overarching themes that emerged from the analysis were the roles played by the value of self and the value of the role. The perceptions of the role by others, gender bias and stereotyping had an impact in a variety of ways on value of role and also contribute to value of self. 


\section{CHAPTER 5: DISCUSSION}

\section{Introduction}

This chapter will discuss the findings from this research project undertaken to investigate administrative professionals and their professional development opportunities and career pathways in New Zealand. This group of workers have been under-researched and their needs and expectations in professional development and career pathways are not well understood.

This study has explored administrative professionals' perceptions of their professional development opportunities and career pathways. While the needs of adult learners have been well researched, some principles of adult learning appear to be overlooked in the learning and professional development undertaken by this group of workers. Further, the knowledge and experience gained in the administrative professional role also appears to be undervalued, contributing to perceptions of a lack of value of self and of the role for this highly female gendered section of the workforce. This lack of value of self and of the role possibly reflects the power relationships within society.

This chapter will discuss the situation for administrative professionals with regard to their professional development and career pathway experiences, detail the conceptual framework from the research findings, outline limitations of this study, and implications for industry and for future research in this area.

\section{Professional Development}

A high percentage (88\%) of survey respondents indicated that professional development was available to them at their workplace when they need it. They indicated knowledge of a wide range of professional development opportunities, as listed in the survey, with conferences and technical training noted by $70 \%$ and $65 \%$ of respondents respectively. Conferences were reported as available through conference providers (Conferenz, Brightstar, Skill Path etc), professional bodies (AAPNZ, SOLGM) or in-house events.

Some participants were clear on where they could access the various types of professional development listed in the survey question. Some participants indicated that they had attended conferences, were currently in training to achieve qualifications or had received required technical training (e.g., updating software). Knowledge was expressed of NZQA 
and other business qualifications (e.g., NZIM certificates) and AAPNZ Certification; in addition some knowledge was indicated in relation to undertaking qualifications and achieving AAPNZ Certification. While respondents appear to recognise these wider professional development opportunities it was not clear however, whether they were generally participating in these options.

Administrative professionals' perceptions of professional development opportunities and the career pathways available to them, and their access to those opportunities and pathways, provides an interesting contrast within this study. This contrast was most noticed in the survey analysis where respondents indicated professional development as being supported which, in some cases, was contradicted elsewhere in the survey by the same participant. This confusion between availability of professional development and uptake of professional development may be due to the perception of lack of value in themselves and the role.

The data indicated that participants were aware of the professional development opportunities available but there appear to be some barriers to their accessing these opportunities, a key one of which is lack of workplace support. There are also some barriers to achieving qualifications: funding, stopping work to undertake formal education, and respondents not believing they were capable of achieving in formal learning. These barriers appear to be significantly affected by their own lack of value of themselves and of their administrative role

\section{Workplace Support}

Workplace support is very important to accessing or undertaking professional development. In the research into learning in the workplace and adult learning, the importance of workplace support is noted in particular where transfer of learning into the workplace is required (Analoui, 1993; Blanchard \& Thacker, 2004; Cheetham \& Chivers, 2001; Knowles, 1973; Noe \& Colquitt, 2002) The nature of the support available in the workplace and the impact on administrative professionals from its presence or absence was an important aspect of the findings in this study.

A supportive manager is described by respondents as being critical for administrative professionals to access professional development. Funding support in the workplace, where 
mentioned, varied widely from $\$ 350$ - \$2000 annually and, where no dollar figure was defined, support was noted as ranging from 'some support' to 'considerable support'.

Support is provided in different ways. For example, one organisation provides support to their administrative professionals through a professional development plan leading to NZQA qualifications offered from when they are first employed. This plan is for staff to gain the skills required by the organisation to be able to perform their roles effectively and is a positive step for the administrative professionals within this organisation as there is a clear professional development plan available. The professional development plan incorporates recognition of informal learning undertaken in the workplace and allows for targeting training where required. It leads to a formal qualification in business administration and is an adaptation of the modern apprenticeship model available in many other occupations (e.g., plumbers, builders, electricians).

The modern apprenticeship model suits many aspects of learning for administrative professionals who learn on the job with targeted training when required. Incorporating formal learning, if needed, to achieve a qualification would be quite straight forward. The modern apprenticeship model was developed in recognition that there is foundational knowledge required to be able to competently perform many jobs effectively and efficiently. Modern apprenticeship is a feature of today's workplace in New Zealand. Learning State, the Public Sector industry training organisation, has developed a modern apprenticeship programme for administrative professionals working in the public sector (Learning State, 2010). However, this is the only modern apprenticeship available to administrative professionals through an ITO.

Where there is limited or no support for professional development, this has a significant impact on the transfer of skills to the workplace. In addition, limited opportunity for practising and sharing that newly gained knowledge reduces the value to the organisation of the investment in the training. A lack of value for investment in training, through lack of transfer to the workplace is discussed by Analoui (1993). The lack of opportunity to transfer and share newly gained knowledge may contribute to a perception that the organisation does not really value the learning undertaken and discounts its worth. These limitations can lead to feelings of lack of value of self and of the role for the administrative professional. It is interesting to note that concern was expressed by some respondents that, 
on occasions, employers may not be receiving full value from the professional development undertaken by their staff member. One way of demonstrating the value of training received is through the administrative professional transferring their newly gained knowledge and/or sharing it with other administrative professionals within the organisation.

In organisations where a percentage of an individual's salary may be indicated as available for training, the manager of that person may have the right to agree or deny its use. This, of course, is appropriate if the decision is solely based on the relevance of the training to the position, the organisation and/or available funding. However there is potential for this power to be used in ways which may not always be of benefit to the individual or the organisation. If improperly used, this power imbalance can have a significant impact on the administrative professional. It can lead to feelings of lack of value of self and of the role and enhances feelings of powerlessness. In an organisation, where clear specific rules are defined for applying for professional development support, this possible scenario may be alleviated.

Not providing or supporting professional development when an individual is promoted or moved to a new role is another potential area for difficulty. The lack of development to meet the requirement of a new role and potentially with higher levels of responsibility may be perceived as 'setting someone up to fail' due to not having the skills or knowledge to be able to succeed. This again can lead to feelings of lack of value of self and may also reduce career options if the feelings of failure are such that an individual discounts that type of role in the future. In contrast, recognition of competency in the required skills and knowledge provides a strong motivating force for adult learners (Wlodkowski, 1999) to continue learning and thereby enhance their feeling of value of self, of the skills required for their role and provide an environment for success.

There may be an expectation by employers that all potential administrative employees already 'have' the basic skills required. This could be a continuation of the perception that these skills are intrinsic in women (Golding, 1986; Pringle, 1988; Truss, 1993) and may provide some explanation for professional development for administrative staff not being supported in some situations. However, with no required qualification it may be difficult to gauge skills and capability of a potential employee. 
A gap in some organisations between professional staff and non-professional staff (Billett, 2001) may lead to professional development being available for professional staff but not readily for others. As a specific example of this, in the legal profession, the Law Society provides frequent professional development for legal professional staff. However, there is a perception among legal administrative professionals of limited professional development offered for them which was also described in recent Australian research (Cavanagh, 2007). These limited professional development opportunities may contribute to a negative value of self due to the perception that the non-professional role is not valued sufficiently to warrant those opportunities.

While most administrative professionals coming from large organisations report support for professional development, it was raised in focus group discussions that those in small industries appear to have no expectation of being provided with professional development and may not believe they warrant it. Gender bias and stereotyping may also be factors within small organisations which are perhaps largely male dominated while the administrative professionals are predominantly female. The perception was expressed in the data that male staff are provided with professional development opportunities while the female administrative professionals do not receive those same opportunities. This gender bias may be a continuation of the "office wife" (Pringle, 1988) syndrome which has perhaps, not changed significantly within small organisations.

\section{Informal learning - on the job, ad hoc and just-in-time}

Informal learning is undertaken through a wide variety of options; conferences, seminars, AAPNZ meetings, training courses and on-the-job through communities of practice as defined by Wenger (1998). Much of the training described in this research (64\% of survey respondents) appears focussed on technical skills. Technical training was described as being accessed through training providers and in-house opportunities and these were provided to 'enable me to do my job'.

There are different ways of gaining skills and knowledge which are also considered professional development, for example, changing jobs or roles leading to a new set of skills through informal learning. With no formal qualification required for this role, informal learning may be a feature of this sector of the workforce. In addition, when there is no 
particular encouragement provided to achieve a formal qualification the perception arises that the skills held by administrative professionals are not valued. Informal learning and lack of encouragement for a formal qualification contributes to a perception of lack of value in the skills and the role, contributing to a lack of value of self for the administrative professional.

Skills learnt on the job are valuable and necessary for carrying out the work required. However, Billett (2001) also describes the perception that learning gained through informal sources is seen as less valuable than that gained through formal learning processes. To facilitate progression or movement to other roles, recognition of skills gained through formal qualifications is important (Maguire, 1996). The value of formal qualifications recognising the skills and capabilities the administrative professional has, to enable progression is clear; however it is not clear whether the value of qualifications to a career pathway is understood by administrative professionals themselves.

While $88 \%$ of respondents reported their professional development is supported by their employers there was a contradiction expressed by some that that support was there but in theory only. In addition no professional development goal or plan was developed, leading to mainly ad hoc or just-in-time training. Given that informal learning is seen to be less valuable, solely informal professional development in this role and no required qualification may be contributing factors to undervaluing of the skills held by those who work in this field and to a perception of the role being undervalued.

Another form of professional development, mentoring, is raised by administrative professionals. While it is not seen as readily available to them, where it has been accessed either formally or informally, it is perceived as very valuable. One aspect of the value of mentoring to administrative professionals is that many managers are seen to receive it and therefore it is perceived as having value. In addition, administrative professionals were keen to provide mentoring to others, which was reported as valuable to both parties involved and provided support that was seen as being previously unavailable.

\section{Formal learning}

Formal learning leading to a qualification, while known about by administrative professionals, does not appear to be as readily accessed as informal learning. The different 
methods of achieving formal qualifications do not appear to be understood by many. The inability to 'stop work and go to tech' as expressed by some, may mean that gaining a formal qualification is discounted as an option. The low number of relevant formal qualifications held by administrative professionals may, perhaps, be linked to the perception that these qualifications are not valued. This lack of value may be due to qualifications not being required to undertake the role and to limited knowledge about how they may be achieved.

Billett (2001) outlined that informal learning is not as recognised as formal learning and a qualification. Maguire (1996) recommended that administrative professionals require a formal qualification if they wish to progress into other roles and should be proactive about gaining them. The participants in this research however, indicated that they were concerned whether formal qualifications, once gained, would be recognised by current or future employers and therefore whether they were of value. These conflicting factors, that formal learning is required but may not be recognised as valuable, contribute to the perception that administrative skills are not valued. Therefore this lack of value of skills could contribute to the administrative professionals' lack of value of self (Knowles, 1973), and may lead to a 'catch-22' situation and powerlessness.

The development of AAPNZ's certification process in 2004 had the effect of raising the level of administrative professionals' knowledge about formal qualifications. Part of the criteria to achieve AAPNZ Certification requires a Level 5 or above, $120^{+}$credit qualification, listed on the NZQA Kiwi Quals register. AAPNZ has scholarship opportunities to provide support for achieving such a formal qualification and can also provide information on the different methods of gaining a relevant qualification. Achieving AAPNZ Certification results in:

1. a designation after the person's name (e.g. Eth Lloyd, AAPNZ Fellow, Cert.), 2. a formal presentation of the certificate at the AAPNZ Annual General Meeting,

3. a listing of the individual's name and a citation of how they achieved Certification on the AAPNZ Website; this list is accessible to potential employers for confirmation of achievement. 
This certification process by AAPNZ is beginning to build recognition by administrative professionals of the value of the skills and attributes they have and the value of a relevant formal qualification stating that those skills are held. This form of recognition may contribute to improving the administrative professional's value of self and of the role, promoting awareness and undertaking of professional development opportunities, and helping to develop professional development plans and goals.

\section{Value of professional development}

Professional development was seen as important to over $70 \%$ of respondents for a variety of reasons. The main reasons appear to be so they can do their job better, more effectively and efficiently, and to provide career progression either within their field or to move outside their current field into new areas.

The majority of respondents (over 60\%) in this research indicated they had non-specific goals or no goals in professional development, though $34 \%$ did have specific goals. Maguire (1996) recommends that administrative professionals need to take responsibility for their own professional development. Developing a plan for this may promote a feeling of ownership and responsibility, perhaps leading to a formal qualification as a goal. This responsibility and ownership for learning is part of Knowles' (1973) assumptions for adult learners where the adult has moved from dependency to being self-directed and takes on this responsibility.

However, confusion may exist for some administrative professionals where they believe they are not granted that responsibility for their own professional development through their work environment. That responsibility is often seen to sit with their manager or training and development personnel. The confusion comes, perhaps, from a tension between what they may wish to do and what they may be permitted to do, leading to a feeling of disengagement, a lack of ownership of their own professional development plans and potentially to a lack of value of self through their needs as adult learners not being met as suggested by Knowles (1973).

Some administrative professionals have negotiated support as part of employment contract negotiations, where organisational support is not readily available for professional development. There are other administrative professionals who do not receive any 
professional development other than what they find and pay for themselves. Among those who talked about undertaking professional development for themselves, some told stories of completing qualifications with small children at home or having to share their learning environment and technology with teenagers who also required access. Others who undertake professional development in their own time may do so through self-taught opportunities, for example, reading in the relevant area of knowledge required. These stories demonstrate how important professional development is to many administrative professionals and how they can take charge of those opportunities. These stories show the importance and positive impact of being self-directed and taking ownership and responsibility for one's own professional development, enhancing their value of self and of their role.

While professional development was important to the majority of those involved in this research, concern was expressed at its ad hoc nature. A tendency to take whatever professional development is on offer when offered; if it appears interesting 'grab it', regardless of relevance or where it might lead was also shown. The link between being self-directed with professional development and the value of self for the individual and their role seems to be apparent. For progression to a more formalised goal or career pathway, structure is required to plan professional development ensuring that what is undertaken is relevant and generally leads towards a defined and agreed goal.

\section{Career Pathways}

Truss et al. (2009) noted, in her research into secretarial staff in the United Kingdom, that career options were very limited. The present study, conducted in New Zealand into the wider grouping of administrative professionals, showed a different result with over $60 \%$ indicating that they did see a career pathway available within administration, management or other career options though it was not clear if these options were being taken up. However over $30 \%$ felt that there were limited career pathways or they were unsure if there were any options available.

A few respondents described career pathways to their current roles. These pathways may have been within the same organisation over a number of years or may have taken them away from the usual administrative roles while retaining links to the administration skills developed. Other participants alluded to a career pathway which had evolved through their 
working life though not necessarily by design or planning. Therefore while a pathway may not have been consciously determined, it occurred through recognising and taking up opportunities when they arose.

Administration was noted by $41 \%$ as being the ideal career for administrative professionals. While this may not always have been their initial career choice, those who expressed that administration was their career choice, wished to continue on in this role. Some wished to stay within administration but develop higher level skills within this area. The lack of a clear career pathway in administration today was contrasted with the former more hierarchical career pathway model of "Office Junior" progressing through one or more levels to a "Senior Secretary" often undertaken within the same organisation or by changing employers to gain progression. The generally high level of satisfaction in this career choice in administration was demonstrated though some also indicated a desire for there to be a more defined career pathway within the field. For those who sought progression, the former pathway from 'Office Junior' had made it clearer to plan their progress. For many today progression will involve undertaking higher level qualifications.

Twenty two percent of the respondents indicated that they wished to move into some form of management. Management ranged from middle management to event or project management and included team leadership. This interest to progress also showed a desire for a career pathway but acknowledged that higher level qualifications would be required. Some were unclear how they would attain higher level qualifications or whether those qualifications would be sufficient to enable a move into management. This lack of clarity and lack of confidence may be consistent with a lack of value of self and the role.

However, a significant number $(27 \%)$ of respondents felt they did not have career pathways available to them. This reflects that some administrative professionals in this study believe they are trapped in the role once they are in it confirming other earlier research (Kennelly, 2006; Maguire, 1996; Pringle, 1988; Truss, et al., 2009). This is the glass ceiling effect of this role. A lack of value of self and a lack of value for the role contributes to the inability for some administrative professionals to see that they have options and choices, that they must take responsibility for their decisions and be self directed. However, for some, a lack of a career pathway may be a choice due to age and 
stage of life or a choice to stay in the current situation both of which are actually career decisions.

There are some other factors which impact on perceptions of career pathway options and these include blurring of position titles and tasks and a lack of clarity over whether administrative skills are readily transferrable between industries, both of which impact on the value of self and the value of the role.

\section{Position titles}

Blurring of the roles and position titles for administrative professionals with the change from the former title of secretary to a very wide variety of titles has made it very difficult for administrative professionals to gauge whether there is a career pathway. This was initially seen as being a relatively small issue but as this research progressed it became a much larger issue in the discussion due to the potential impact on value of self and value of the role for the administrative professional.

Administrative professional is an overarching title used internationally covering work roles that were previously and variously referred to as clerical, secretarial, receptionist, personal assistant and executive assistant, to name a few. Some of these position titles are still used, often in combinations of titles as positions have changed and merged. The extremely wide variety of titles for those in administrative professional roles is demonstrated in the responses to the survey where 19 titles were provided to select from and yet respondents added a further 29 titles under the option of "other" in the survey.

This wide variety of titles is confirmed internationally through research in the United Kingdom (Truss, et al., 2009) and the United States of America (IAAP, 2009). However, these studies were aimed at secretaries and it was noted that in both studies very few respondents had the word secretary incorporated into their job title and that many other titles were also provided. A recent New Zealand recruitment agency survey ${ }^{5}$ undertaken into executive (primarily Chief Executives) support in Wellington, shows that there were 10 different titles being used for this role alone, in this one city.

\footnotetext{
${ }^{5}$ This was a survey undertaken only in Wellington by K. Groombridge of Hudson Office Support, however it demonstrated the wide range of position titles within only one role, that of senior executive support.
} 
Restructuring in many workplaces has led to confusion with many different administrative support roles merged and reformed during that process, often with new titles or combined titles. Another impact of such a wide variety of position titles is that, with no recognised hierarchy the variations in titles and tasks that relate to them, can lead to considerable blurring of roles.

The commonly accepted pathway of administrative assistant progressing to personal assistant and then to executive assistant has been partially reversed in a recent trend in some government departments in New Zealand. Previously the normal position expectations were that an executive assistant provided administrative support a Chief Executive or General Manager, and a personal assistant provided administrative support to managers below that level, either one or a group of managers. The new trend has defined a personal assistant as providing administrative support to only one manager, therefore generally a CEO or General Manager. An executive assistant has then been defined as providing administrative support to more than one manager therefore lower level managers. This recent reversal of two administrative roles, in two government departments, does not appear to be replicated in the international experience from recent research in the United Kingdom (Truss, et al., 2009).

A flow-on effect from this recent trend for those who apply for roles with the reversed titles is that task expectations may be incorrect for what the role might entail. Also potential employers for those roles may not get applicants of the type or calibre or remuneration levels they expect. In addition, determining a career pathway becomes increasingly difficult for administrative professionals when it is unclear what titles relate to which tasks and at what level within any organisation.

A further impact for administrative professionals occurs in defining pay scales when there is such a wide array of titles and no generally accepted hierarchy. The pay range for administrative professionals, as a generic title, ranges from $\$ 28,000$ p.a. to $\$ 75,000$ p.a. ${ }^{6}$ (J. Fanselow, personal communication, May 17, 2010). When the pathway is not defined and titles are varied and even interchanged it can become much more difficult to define the pay range for any particular role.

${ }^{6}$ confirmed by J. Fanselow FRCSA (Life), Director, CareerDynamix Group 
The large number and lack of clarity of position titles and roles, and the tasks required within them makes it difficult for the administrative professional to understand or see career pathways that may be available and also impacts on their perceptions of the value of the role and of themselves.

\section{Transferable Skills}

A lack of recognition in some situations of core administrative skills (see Appendix C) as transferable was raised as a barrier to being able to change employment or even to change roles within the same employment. The lack of recognition of these core transferable skills was described as an issue with recruitment agencies who categorise administrative professionals as 'belonging' to a specific industry. There does not appear to be recognition that industry, organisation or department specific knowledge, outside of core administrative skills, is a routine process of informal learning on the job, often through communities of practice within the workplace for all employees. Lack of recognition of skills and experience held by adults is referred to by Knowles (1973) in his assumptions of adult learning and the role of experience in the adult learners' value of self. This lack of recognition may be perceived by the adult learner as a rejection not only of their experience but also of his/herself. This perception of rejection of self may contribute to a lack of value of self, skills and role for an administrative professional.

\section{Value of Self/Value of Role - Conceptual Framework}

Through the data, two major themes emerged which were: value of self and value of the role, impacting on how administrative professionals see and react to opportunities for professional development and career pathways. The conceptual framework developed from this research reflects the perceptions as explained by the participants (see Figure 1).

The framework displays a background of the external environment which can enable the administrative professional or present barriers to opportunities for professional development and career pathways. The environments that administrative professionals live, socialise and work in, including their geographical location, can impact significantly on their value of self, the value of their role and how they react to professional and career development opportunities. The comment from one participant of "self and environment are barriers" outlines the impact of both the environment and self. 


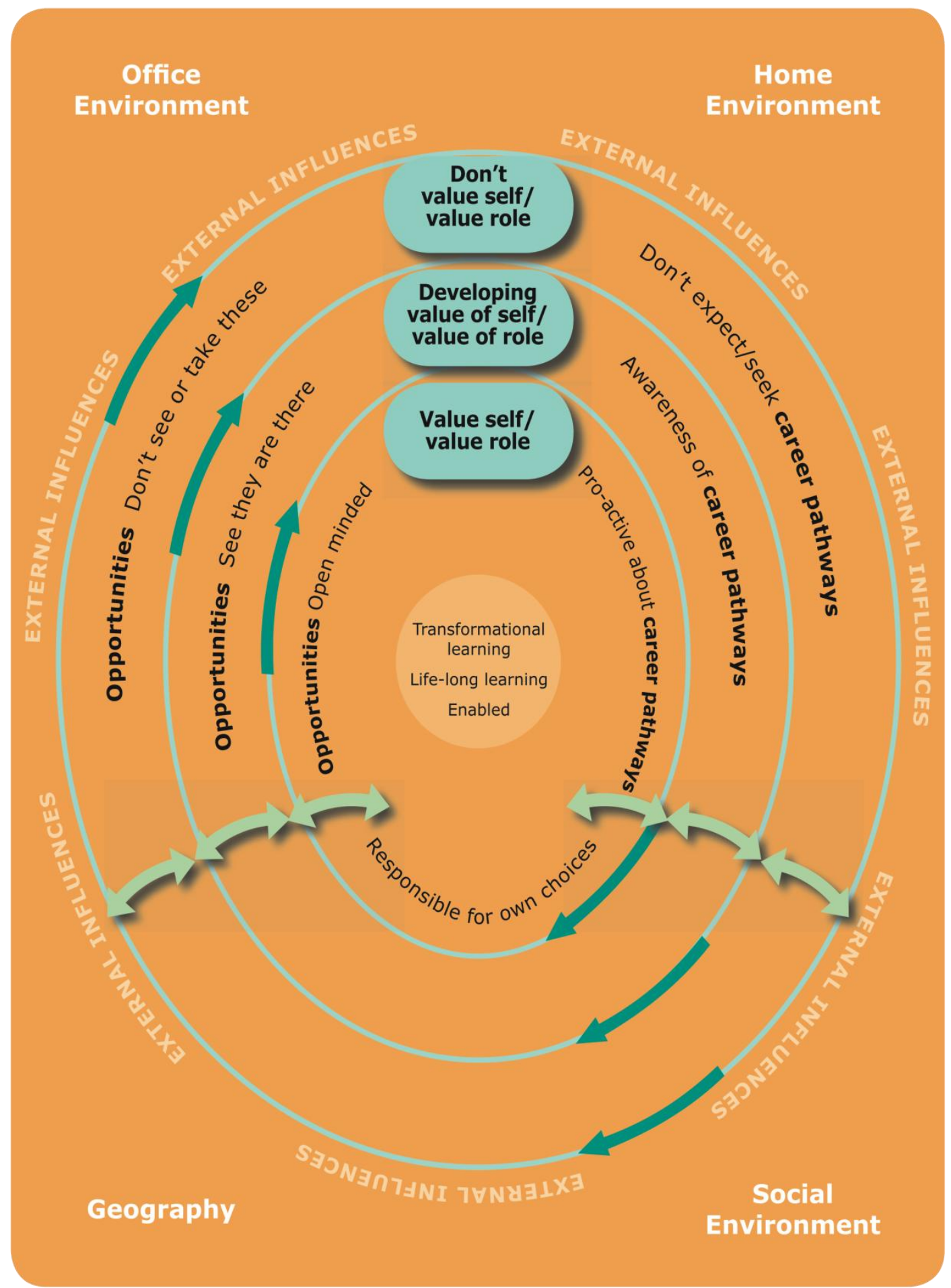

Figure 1: Conceptual framework of the interrelationship between value of self/value of role, professional development and career pathways 
Barriers may also be seated in their own internal lack of value and/or the lack of value they have or perceive others to have of their role. However, where the individual has a sense of value of self, barriers may not be perceived as being blocks; they may be recognised as opportunities and career pathways may be seen as wide open.

\section{External environment - home, social, work, geographical}

The conceptual framework displays a background of the environment which can enable the administrative professional or provide barriers to opportunities for professional development and career pathways. The external environments that administrative professionals are in can impact significantly on their professional development opportunities and career pathways, on their value of self and their value of the role, both positively and negatively.

As administrative professionals are primarily female there is always the potential for their careers to be interrupted or delayed. These family responsibilities may contribute to the environment when timing may be appropriate or not so appropriate in which to take on professional development opportunities. Recognising these and acting accordingly is an appropriate option for these workers to take and will differ according to the individual making that choice. Appropriate decisions at this stage may indicate that the individual is self-directed and willing to take responsibility for their future.

Home and social environments may affect administrative professionals' ability to be able to take up professional development opportunities or career pathways where there is limited support or their family responsibilities preclude it. This is a common factor in the lives of working women and for many may influence their decision making. Where there is a lack of support or perhaps events which are life changing, these situations can impact on the individual's value of self which may well determine how they react to opportunities.

The work environment can be either negative or positive and links very strongly with the value of the role as perceived by those in the administrative professional's workplace. Encouragement and support within a workplace environment can enhance the administrative professional's sense of value of self and value of the role which in turn may impact positively on their reaction to opportunities. Alternatively a work environment which does not encourage and/or support will act as a deterrent and demotivating force. 
The geographical environment has both a positive and negative impact. Smaller geographical areas may well have limited options available in both professional development and career pathways, which may negatively impact on opportunities available. Conversely, larger or city environments will open those opportunities wider and the individual's value of self will therefore likely be the determinant of the reaction to those opportunities. However, limited options may, over time, impact negatively on an individual's value of self as they feel that their skills and knowledge are not valuable or valued.

Value of self may be demonstrated through the participants' awareness of availability and opportunity for professional development and career pathways, which impact on their experiences. Those who value themselves may recognise the opportunities available for professional development and career pathways leading to potential life-long learning and continuing education. It may be simplest for an administrative professional to do the work only to the standard required. However, if the administrative professional has a positive value of self and seeks out opportunities for professional development then development may occur which has benefits both for the individual and the organisation. Those who have low value of self do not readily see these opportunities or career pathways and their value of self and lack of qualifications provide barriers to their progressing.

In summary, recognition of the importance of professional development is linked to value of self for the individual; if it is positive the individual is likely to see and consider the opportunity. Alternatively the professional development opportunity may contribute to the process of developing positive value of self, potentially leading to further opportunities.

\section{Positive belief - internal}

A positive value of self provides an internal positive belief which can lead to others valuing you and the role; this is demonstrated in the findings of this study. This value of self is shown through comments where one focus group participant talks of an opportunity to 'bring someone on' as that person had indicated they wished 'to be like you'. The effect that opportunity had on the participant was to provide positive reinforcement of her role and also herself which, she indicated, made her feel good about both. 
Internal positive belief is further demonstrated through comments where the individuals feel that their options are wide open and that it is up to them to take charge of their situation with words such as 'the world is our oyster'. These feelings of value of self may contribute to being open to opportunities and encourage the administrative professional to take control and responsibility for their choices, becoming self-directed thus enhancing their value of self (Knowles, 1973).

\section{Barriers - internal}

While there was wide acknowledgement that those who worked for large employers have greater access to professional development or career opportunities, barriers exist that impact on administrative professionals' ability to access these opportunities. These barriers were often perceived to be internal and stem from a lack of value of self held by the individual and a lack of value of the role.

An individual's attitudes may come from one's value of self and are important in providing motivation in learning (Billett \& Somerville, 2004) and if the individual is not open to professional development opportunities or proactive in seeking professional development those attitudes may act as a barrier to receiving it. It must also be recognised that while there are some aspects of the environment which also act as barriers, individuals themselves may create or add to those barriers. This may be demonstrated by an administrative professional wishing to attend a professional development event, but deciding, through their lack of value of self, that it would not be approved and therefore not asking, thereby reinforcing their own lack of value of self.

\section{Support factors - external}

A supportive environment, especially the work place, supports and enhances the value of self which appears to promote openness to opportunity for professional development and possible career pathways. This openness to opportunity may positively influence the situation within which the administrative professional works such that value of the role is also enhanced. This situation was raised within the survey where some respondents commented on their very supportive environment while acknowledging that this might not be the same for all administrative professionals. 
Other supporting factors from the external environment are provided by the professional body of AAPNZ through opportunities for achieving qualifications or undertaking professional development through scholarships and their certification process. Winning a scholarship or achieving AAPNZ Certification provides an external recognition of value both of the role and of self which may flow through many aspects of the administrative professionals working situation.

\section{Barriers - external}

External barriers to accessing or undertaking professional development were noted. These included: a lack of workplace or manager support, insufficient time to undertake professional development including receiving value for time and money spent. In addition a further barrier was geography where limited professional development is available and added cost of travel and accommodation highlights 'value for money' concerns.

Additionally limited availability of relevant professional development, where one has worked in the administrative field for a significant period of time, can lead to a feeling of 'there is not much out there for me'. These factors can enhance lack of value of self or role where the administrative professional may feel they are the only ones not receiving professional development therefore they and their role are not valued.

Making the time to undertake professional development was a barrier that occurred even though the professional development was apparently supported. This may indicate a time management problem for the individual and/or a problem in managing the administrative professional. It can also be a 'priority' issue both for the individual and for management.

\section{Limitations}

The findings and implications from this study need to be considered in light of several limitations.

The respondents to the on-line survey were primarily (over 50\%) employed by large organisations $\left(500^{+}\right.$employees) from mostly government, local government, education and the health sectors (see Table 3.5) with a further $22 \%$ from organisations of $100^{+}$ employees. Large organisations are not representative of businesses in New Zealand where 99\% are small to medium enterprises (SMEs) with fewer than 100 employees. However, only $30 \%$ of all workers are employed by SMEs (Massey University, 2010). This make-up 
of respondents had an impact on the research findings as larger organisations are more likely to have policies and funding available for professional development for all staff and at a greater level than an SME. The snowball approach to increase the number of respondents heightened this impact, as many of those contacted in the snowball survey also came from those same sectors.

Despite piloting the survey, responses to some of the questions did not provide the type of information sought. There was some confusion over use of the words professional development and participants' understanding of what the question was asking. For example, in many cases the same answer was given to the question on 'what are your professional development goals' as was provided to 'what is your ideal career' so the wording was not precise enough to ensure differentiation. Also the question on types of professional development known about by administrative professionals did not also ask whether this professional development was actually being accessed by them.

The use of the membership of AAPNZ may have created a bias in the research sample as those members already have an interest in professional development, demonstrated by joining their professional association. It may also be considered a limitation. It is not clear how many of the snowball respondents had a particular interest in professional development as it is presumed most of these were not AAPNZ members.

The potential pitfalls of my own knowledge of the administrative profession and the members of AAPNZ are recognised. I had to be very aware to allow the data to speak for itself. However, my knowledge of the administrative profession is also a strength as it provided me with the ability to gain the trust of those participating and my own knowledge readily allowed me to become immersed in the data gathered.

\section{Implications for the workplace/providers}

One of the major impacts of improving the recognition of administrative professionals as contributors to the work place and with valuable skills, would be for all industry training organisations to support administrative professionals in their industry area to gain relevant qualifications. 
Tertiary providers could assist the administrative professional to attain qualifications if they were able to provide access to single module learning opportunities which are unit standard based. This provision would enable the administrative professional to undertake formal learning for a specific area where a gap in knowledge is identified. Filling this gap in knowledge would allow completion of a higher level qualification (e.g., National Diploma Business Administration L5) where the qualification is being undertaken primarily through workplace recognition of current competency.

Workplace support by encouraging professional development and growth of administrative professionals would provide recognition of the value of the role and skills held. Discussion on career pathway options and future plans, without prejudice for their current role, would enhance the value of self for the individual. It would recognise the skills they have and the role they fulfil in the workplace and where those plans might lead, if the administrative professional wishes to take advantage of that opportunity.

\section{Implications for further research}

The knowledge that participants expressed of professional development opportunities was an unexpected finding in the research. However, an area for further research would be whether that knowledge of professional development opportunities also leads to participation in those opportunities.

The management of administrative professionals and their professional development are potential areas for further study. One area might be whether they seek and are provided with appropriate training when promoted (i.e., into a supervisory role). Another might be management of availability of support in the workplace to facilitate transfer of learning in the workplace. This should include the management of time to facilitate the sharing of recently acquired relevant knowledge with other administrative professionals within the organisation to enhance the value to the organisation of the training received.

As administrative employees of SMEs were not well covered in this study, they may be the hidden employees in this field. Therefore hearing their voices would add considerable depth to the knowledge of their professional development opportunities and career pathways and is an area where further research would be of value. 
Informal training (ad hoc, on the job, just-in-time) as the main source of professional development available for administrative professionals may also contribute to a lack of clarity as to future career pathways as there is no professional development plan or structure. This is another area where further study would be of value.

The concern expressed by some respondents about whether recognition and value was placed by employers on a formal qualification is an area which could benefit from further research, investigating the employers' perspective.

Due to the proliferation of position titles and some changes in the accepted informal hierarchy, there would be considerable value in research into the relationship between position titles, expected tasks and anticipated pay ranges.

Further research could also help understand the perception that administrative professionals do not have a career pathway (the glass ceiling effect). Such research could assist in identifying what causes this barrier and what would help to break through it.

\section{Conclusion}

This study has shown that there is strong support generally available for professional development within the workplace for administrative professionals which is largely informal (ad-hoc, just-in-time or on the job) to enable them to do their job appropriately. However the lack of a professional development plan and goals further promotes informal training and development limiting career pathway options for administrative professionals.

A lack of value of self and the role by administrative professionals promotes barriers to accessing professional development and also to seeing career opportunities when they arise. The various environments within which the administrative professional lives, socialises and works significantly impacts on the value of self and the value of the role. Historical gender bias and stereotyping of the administrative professional role and its highly female gendered workforce is still present today, perhaps most especially in SMEs.

However, administrative professionals can take control of their professional development, become self directed adult learners and choose whether to accept the perceived lack of 
value of the role. Administrative professionals can become pro-active in seeking formal qualifications and develop professional development and career plans to which they work.

If the administrative professional is starting from a base of a lack of value of self, becoming pro-active with professional development plans is not an easy option and is only suggested for those who wish to do so. What is important is that administrative professionals do give consideration to their situation and make a decision for themselves as to how they wish their working life to be and to progress, and value themselves and their skills and knowledge. 


\section{REFERENCES}

Analoui, F. (1993). Training and transfer of learning. Aldershot: Ashgate Publishing Limited.

Association of Administrative Professionals New Zealand Inc. (2010a, 5 July 2005).

Background and history. Retrieved 28 March, 2010, from

http://www.aapnz.org.nz/History-and-Background.92.0.html

Association of Administrative Professionals New Zealand Inc. (2010b, 12 June 2009).

Certification. AAPNZ certification - your professional development goal. Retrieved

$28 \mathrm{March}, 2010$, from http://www.aapnz.org.nz/Certification.77.0.html

Association of Administrative Professionals New Zealand Inc. (2010c, 30 August 2009).

Gallery of certificated members. Retrieved 28 March, 2010, from

http://www.aapnz.org.nz/Gallery-of-Certificated-Members.298.0.html

Association of Administrative Professionals New Zealand Inc. (2010d). Welcome to AAPNZ. Retrieved 28 May 2010, from http://www.aapnz.org.nz/

Babbie, E. (2001). The practice of social research (9th ed.). Belmont:

Wadsworth/Thomson Learning.

Bandura, A. (1977). Social learning theory. Englewood Cliffs: Prentice-Hall Inc.

Bierema, L. L. (2001). Women, work, and learning. New Directions for Adult and Continuing Education, Winter 2001(92), 53 - 62.

Billett, S. (2001). Learning in the workplace: Strategies for effective practice. Crows Nest: Allen \& Unwin.

Billett, S., \& Somerville, M. (2004). Transformations at work: identity and learning. Studies in Continuing Education, 26(2), 17.

Blanchard, P. N., \& Thacker, J. W. (2004). Training design. In Effective training: systems, strategies, and practices (pp. 179-231). New Jersey: Pearson/Prentice-Hall.

Blaxter, L., Hughes, C., \& Tight, M. (1998). Education, work and adult life: How adults relate their learning to their work, family and social lives. In P. Sutherland (Ed.), Adult learning: A reader (pp. 135-147). London: Kogan Page.

Bowerman, J., \& Peters, J. (1999). Design and evaluation of an action learning plan - a bilateral view. Journal of Workplace Learning, 11(4), 131-139.

Career Services (2007). Select a job summary. Retrieved 22 May 2008, from http://www.careers.govt.nz/default.aspx?id2=1\&id1=A\&id0=3

Cavanagh, J. (2007). Women, work and learning. Unpublished Doctoral dissertation, Griffith University, Brisbane, Queensland, Australia.

Cheetham, G., \& Chivers, G. (2001). How professionals learn in practice: An investigation of informal learning amongst people learning in professions. Journal of European Industrial Training, 25(5), 247-292.

Department of Women's Affairs. (2003). Next steps to pay equity: submissions report. Wellington: Dept. of Women's Affairs.

Dilbert (1999). Retrieved 12 April, 2010, from http://www.dilbert.com/strips/2010-04$11 /$ ? $\mathrm{F}=1 \&$ CharIDs $=13 \&$ ViewType $=$ Full $\&$ NoDateRange $=0 \&$ SingleDate $=\&$ Order $=\mathrm{s}$ . DateStrip \&PerPage $=5 \&$ After $=04 \% 2 \mathrm{~F} 16 \% 2 \mathrm{~F} 1989 \&$ Before $=04 \% 2 \mathrm{~F} 12 \% 2 \mathrm{~F} 2010 \&$ CharFilter $=$ Any $\& x=28 \& y=14 \&$ Page $=13$

Fenner, S. (2004). How to obtain the proper training. IAAP research and trends web page Retrieved December, 2004, from http://www.iaap-hq.org

Fenwick, T. (1998). Women's development of self in the workplace. International Journal of Lifelong Education, 17(3), 18.

Fenwick, T. (2002). Lady Inc.: Women learning, negotiating subjectivity in entrepreneurial discourses. International Journal of Lifelong Education 21(2), 15. 
Fenwick, T., \& Tennant, M. (2004). Understanding adult learners. In G. Foley (Ed.), Dimensions of adult learning. Maidenhead: Open University Press.

Golding, J. (1986). Some problems in the concept of secretary. International Studies of Management and Organisation, XVI(1), 17.

Industry Training Federation. (2010). List of ITOs. Retrieved 27 May, 2010, from http://www.itf.org.nz/list-of-itos.html

International Association Administrative Professionals (2008). About IAAP. Retrieved 28 May, 2010, from http://www.iaap-hq.org/aboutus/

International Association Administrative Professionals (2009). Research/trends. Retrieved 27 March, 2010, from http://www.iaaphq.org/newsroom/journalistresources/2009survey.html

International Association of Administrative Professionals (2010). Advanced skills admins need to excel in today's workplace. Research/trends Retrieved 28 May, 2010, from http://www.iaap-

hq.org/resources/keytrends/advanced_skills_admins_need_to_excel.html

Kamberelis, G., \& Dimitriadis, G. (2005). Focus groups strategic articulations of pedagogy, politics, and inquiry. In N. K. Denzin \& Y. S. Lincoln (Eds.), The sage handbook of qualitative research third edition (pp. 887-907). Thousand Oaks: Sage Publications Ltd.

Kennelly, I. (2006). Secretarial work, nurturing and the ethic of service. NWSA Journal, $18(2)$.

Knowles, M. (1973). The adult learner: A neglected species. Houston: Gulf Publishing Company.

Kostos, C. (2006). Learning in the knowledge age, where the individual is at the centre of learning strategy and organisation success. Australian Journal of Adult Learning, 46(1), 74-83.

Krueger, R. A., \& Casey, M. A. (2009). Focus groups: A practical guide for applied research (4th ed.). Thousand Oaks: Sage Publications

Lave, J., \& Wenger, E. (1991). Situated learning: Legitimate peripheral participation. Cambridge: Cambridge University Press.

Learning State. (2010). Modern Apprenticeship Programme. Retrieved 23 April, 2010, from http://www.learningstate.govt.nz/display/document.asp?navid=402

Lloyd, E. (2003). Valuing ourselves so others value us. Paper presented at the 5th International Secretarial Summit, London, United Kingdom.

Lloyd, E. (2004). AAPNZ certification - launched and ready to go! admiNZ, 14.

MacDonald, C. J., Gabriel, M. A., \& Cousins, J. B. (2000). Factors influencing adult learning in technology based firms. Journal of Management Development, 19(3), 220-240.

Maguire, H. J. (1996, December). Just a sec! A comparative study of the changing role of secretarial staff in Australia and New Zealand. Paper presented at the Australia New Zealand Academy of Management (ANZAM) 1996, Woolongong, Australia

Martin, A. (2000, October). Training day. Office Pro, 6-8; 10-11.

Martin, A. (2002, April). Management skills that matter. Office Pro. Retrieved December, 2004, from http://www.iaap-hq.org

Massey University. (2010). NZSMERC Retrieved 23 April, 2010, from http://smecentre.massey.ac.nz/

Merriam, B. S., Caffarella, R. S., \& Baumgartner, L. M. (2007). Learning in adulthood: A comprehensive guide (3rd ed.). San Francisco: Jossey-Bass.

Miles Matthew B., \& Huberman A. Michael (1994). Qualitative data analysis (2nd ed.). Thousand Oaks: SAGE Publications Inc. 
New Zealand Qualifications Authority. (2010a). Accredited industry training organisations. Retrieved 27 May, 2010, from http://www.nzqa.govt.nz/providers/results.do?regionCode=0\&typeCode=ITO\&na meQuery=

New Zealand Qualifications Authority (2010b). Sub-field business administration. Retrieved 10 April, 2010, from http://www.nzqa.govt.nz/framework/explore/subfield.do?frameworkId=75271

Noe, R. A., \& Colquitt, J. A. (2002). Planning for training impact: principles of training effectiveness. In K. Kraiger (Ed.), Creating, implementing, and managing effective training and development (pp. 53-79). San Francisco: Jossey-Bass.

Pringle, R. (1988). Secretaries talk: sexuality, power \& work. Sydney: Allen \& Unwin.

Salas, E., \& Cannon-Bowers, J. A. (2001). The science of training: A decade of progress. Annual Review of Psychology, 52, 471-499.

Sanghera, S. (2009, 2 November 2009). PAs could be taking their work too personally. Times online. Retrieved 24 November, 2009, from http://business.timesonline.co.uk/tol/business/columnists/article6898680.ece

Statistics New Zealand. (2010a). Classification code hierarchy occupation - Australia and New Zealand standard classification of occupations. Retrieved 11 March, 2010, from http://www.stats.govt.nz/methods_and_services/accessdata/ClassificationCodeFinder/ClassificationCodeHierarchy.aspx? classification $=37$ $81 \&$ code $=5 \&$ action $=$ expand $\&$ scrollLeft $=0 \&$ scrollTop $=0$

Statistics New Zealand. (2010b). Clerical-Administrative workers - statistics. Retrieved 11 March, 2010, from http://wdmzpub01.stats.govt.nz/wds/TableViewer/tableView.aspx

Statistics New Zealand. (2010c). Clerical-Administrative workers definitions. Retrieved 19 March, 2010, from http://www.stats.govt.nz/methods_and_services/accessdata/ClassificationCodeFinder/ClassificationCodeHierarchy.aspx? classification $=37$ $\underline{81 \& \text { code }=52 \& \text { action }=\text { show } \& \text { scrollLeft }=0 \& \text { scrollTop }=475}$

SurveyMonkey (2008). Retrieved 3 October, 2008, from http://www.surveymonkey.com/

Truss, C. (1993). The secretarial ghetto: Myth or reality? A study of secretarial work in England, France and Germany. Work, Employment \& Society, 7(4), 23.

Truss, C., Goffee, R., \& Jones, G. (1995). Segregated occupations and gender stereotyping: A study of secretarial work in Europe. Human Relations, 48(11), 24.

Truss, C., Rosewarne, A., Alfes, K., \& Parr, R. (2009). Secretarial work, skills and careers. Kingston, UK: Kingston University and Global PA Network.

Wenger, E. (1998). Communities of practice: Learning, meaning, and identity. New York: Cambridge University Press.

Wlodkowski, R. J. (1999). What motivates adults to learn. Enhancing adult motivation to learn (pp. 67-88). San Francisco: Jossey-Bass. 


\section{APPENDICES}

\section{APPENDIX A}

Australia New Zealand Standard Classifications of Occupations (ANZSCO) used by Statistics New Zealand. Website reference, accessed 11/3/10 and expanded: http://www.stats.govt.nz/methods_and_services/accessdata/ClassificationCodeFinder/ClassificationCodeHierarchy.aspx ?classification $=3781 \& \mathrm{co}$ $\underline{\mathrm{de}}=5 \&$ action $=$ expand \&scrollLeft $=0 \&$ scrollTop $=0$

\section{Definition and Position Titles}

CLERICAL AND ADMINISTRATIVE WORKERS provide support to Managers, Professionals and organisations by organising, storing, manipulating and retrieving information.

\section{Clerical and Administrative Workers}

51 Office Managers and Program Administrators

511 Contract, Program and Project Administrators

5111 Contract, Program and Project Administrators

511111 Contract Administrator

511112 Program or Project Administrator

512 Office and Practice Managers

5121 Office Managers

512111 Office Manager

5122 Practice Managers

512211 Health Practice Manager

52 Personal Assistants and Secretaries

521 Personal Assistants and Secretaries

5211 Personal Assistants

521111 Personal Assistant

5212 Secretaries

521211 Secretary (General)

521212 Legal Secretary

53 General Clerical Workers

531 General Clerks

5311 General Clerks

531111 General Clerk

532 Keyboard Operators

5321 Keyboard Operators

54 Inquiry Clerks and Receptionists

541 Call or Contact Centre Information Clerks

5411 Call or Contact Centre Workers

541111 Call or Contact Centre Team Leader

541112 Call or Contact Centre Operator

5412 Inquiry Clerks

541211 Inquiry Clerk

542 Receptionists

5421 Receptionists

542111 Receptionist (General) 
542112 Admissions Clerk

542113 Hotel or Motel Receptionist

542114 Medical Receptionist

55 Numerical Clerks

551 Accounting Clerks and Bookkeepers

5511 Accounting Clerks

551111 Accounts Clerk

551112 Cost Clerk

5512 Bookkeepers

551211 Bookkeeper

5513 Payroll Clerks

551311 Payroll Clerk

552 Financial and Insurance Clerks

5521 Bank Workers

552111 Bank Worker

5522 Credit and Loans Officers (Aus)/Finance Clerks (NZ)

552211 Credit and Loans Officer (Aus)/Finance Clerk (NZ)

5523 Insurance, Money Market and Statistical Clerks

552311 Bookmaker

552312 Insurance Consultant

552313 Money Market Clerk

552314 Statistical Clerk

56 Clerical and Office Support Workers

561 Clerical and Office Support Workers

5611 Betting Clerks

561111 Betting Agency Counter Clerk

561112 Bookmaker's Clerk

561113 Telephone Betting Clerk

561199 Betting Clerks nec

5612 Couriers and Postal Deliverers

561211 Courier

561212 Postal Delivery Officer

5613 Filing and Registry Clerks

561311 Filing or Registry Clerk

5614 Mail Sorters

561411 Mail Clerk

561412 Postal Sorting Officer

5615 Survey Interviewers

561511 Survey Interviewer

5616 Switchboard Operators

561611 Switchboard Operator

5619 Other Clerical and Office Support Workers

561911 Classified Advertising Clerk

561912 Meter Reader

561913 Parking Inspector

59 Other Clerical and Administrative Workers

591 Logistics Clerks

5911 Purchasing and Supply Logistics Clerks

591111 Code retired 
591112 Production Clerk

591113 Purchasing Officer

591114 Code retired

591115 Stock Clerk

591116 Warehouse Administrator

591117 Order Clerk

5912 Transport and Despatch Clerks

599 Miscellaneous Clerical and Administrative Workers

5991 Conveyancers and Legal Executives

599111 Conveyancer

599112 Legal Executive

5992 Court and Legal Clerks

599211 Clerk of Court

599212 Court Bailiff or Sheriff (Aus) / Court Collections

Officer (NZ)

599213 Court Orderly (Aus) / Court Registry Officer (NZ)

599214 Law Clerk

599215 Trust Officer

5993 Debt Collectors

599311 Debt Collector

5994 Human Resource Clerks

599411 Human Resources Clerk

5995 Inspectors and Regulatory Officers

599511 Customs Officer

599512 Immigration Officer

599513 Motor Vehicle Licence Examiner

599514 Noxious Weeds and Pest Inspector

599515 Social Security Assessor

599516 Taxation Inspector

599517 Train Examiner

599518 Transport Operations Inspector

599521 Water Inspector

5996 Insurance Investigators, Loss Adjusters and Risk Surveyors 599611 Insurance Investigator

599612 Insurance Loss Adjuster

599613 Insurance Risk Surveyor

5997 Library Assistants

599711 Library Assistant

5999 Other Miscellaneous Clerical and Administrative Workers 599911 Code retired 599912 Production Assistant (Film, Television, Radio or Stage)

599913 Proof Reader

599914 Radio Despatcher

599915 Clinical Coder

599916 Facilities Administrator 


\section{APPENDIX B}

Australia New Zealand Standard Classifications of Occupations (ANZSCO) used by Statistics New Zealand. Website reference, accessed 19/3/10 and expanded: http://www.stats.govt.nz/methods_and_services/accessdata/ClassificationCodeFinder/ClassificationCodeHierarchy.aspx? classification $=3781 \&$ co $\underline{\mathrm{de}}=52 \&$ action $=$ show $\&$ scrollLeft $=0 \&$ scrollTop $=475$

\section{Definition, Skill level and Tasks}

CLERICAL AND ADMINISTRATIVE WORKERS provide support to Managers, Professionals and organisations by organising, storing, manipulating and retrieving information.

Indicative Skill Level:

Most occupations in this major group have a level of skill commensurate with the qualifications and experience outlined below.

\section{In New Zealand:}

NZ Register Diploma, or at least three years of relevant experience (ANZSCO Skill Level 2); or

NZ Register Level 4 qualification, or at least three years of relevant experience (ANZSCO Skill Level 3); or

NZ Register Level 2 or 3 qualification, or at least one year of relevant experience (ANZSCO Skill Level 4); or

NZ Register Level 1 qualification, or compulsory secondary education (ANZSCO Skill Level 5)

In some instances relevant experience and/or on-the-job training may be required in addition to the formal qualification. In the case of some Skill Level 5 occupations, a short period of on-the-job training may be required in addition to or instead of the formal qualification, or no formal qualification or on-the-job training may be required.

Tasks Include:

administering contracts, programs and projects;

setting, reviewing and controlling office functions;

performing clerical, secretarial, organisational and other administrative functions;

entering, processing and editing text and data;

greeting clients and visitors, and responding to inquiries and requests for information; producing, recording and evaluating financial, production, stock and statistical information;

receiving, processing and sending mail, documents and information.

Occupations in this major group are classified into the following sub-major groups:

51 Office Managers and Program Administrators

52 Personal Assistants and Secretaries

53 General Clerical Workers

54 Inquiry Clerks and Receptionists

55 Numerical Clerks

56 Clerical and Office Support Workers

59 Other Clerical and Administrative Workers 


\section{Definition, Skill level and Tasks}

PERSONAL ASSISTANTS AND SECRETARIES perform organisational, clerical, secretarial and other administrative tasks in support of Managers and Professionals.

Indicative Skill Level:

Most occupations in this sub-major group have a level of skill commensurate with the qualifications and experience outlined below.

\section{In New Zealand:}

NZ Register Level 4 qualification (ANZSCO Skill Level 3)

At least three years of relevant experience may substitute for the formal qualifications listed above. In some instances relevant experience and/or on-the-job training may be required in addition to the formal qualification.

Tasks Include:

liaising with other staff about a range of matters relating to the organisation's operations; drafting and preparing documents such as briefing notes, memoranda and correspondence; maintaining appointment diaries and making travel arrangements; processing mail, filing correspondence and maintaining records; answering telephone calls and inquiries; taking and transcribing dictation of letters and other documents.

Occupations in this sub-major group are classified into the following minor group: 521 Personal Assistants and Secretaries 


\section{BUSINESS ADMINISTRATION SERVICES \\ Demonstrate knowledge of management administrative services}

level:

credit:

4

final date for comment:

September 2009

expiry date:

December 2010

sub-field:

Business Administration

replacement information:

This unit standard and unit standard 21863 replaced unit standard 124.

purpose:

People credited with this unit standard are able to examine a role that provides management administrative services within an organisation, and identify and assess management administration service strategies in relation to an organisation.

entry information:

accreditation option:

moderation option:

special notes:
Open.

Evaluation of documentation and visit by NZQA and industry.

A centrally established and directed national moderation system has been set up by NZQA.

1 This unit standard relates to roles that provide administrative support services to management. Job titles vary greatly but may include - administrator, personal assistant/executive assistant, secretary, office manager. No one set of functions can be ascribed to any one job title.

2 Legislation relevant to this unit standard includes but is not limited to: Health and Safety in Employment Act 1992, Copyright Act 1994, Human Rights Act 1993, Privacy Act 1993, and their subsequent amendments. 


\section{Elements and Performance Criteria}

\section{element 1}

Examine a role that provides management administrative services within an organisation.

\section{performance criteria}

1.1 The role is identified, and described in terms of links and working relationships within the organisation.

1.2 The role is examined in terms of management expectations in relation to at least four primary responsibilities.

Range: $\quad$ may include but is not limited to - running meetings, making presentations, providing management reports and statistical information, conducting interviews, organising functions or conferences, arranging travel and accommodation, development of guidelines, assessing and implementing administration systems, assessing equipment requirements.

1.3 Organisational policies and legislation that affect the role are identified, and assessed in terms of implications for the provision of management administrative services.

1.4 Professional and ethical practice in the provision of management administrative services is described in terms of the role, and explained in terms of the need for confidentiality, discretion, and judgement skills.

\section{Element 2}

Identify and assess management administration service strategies in relation to an organisation.

\section{performance criteria}

2.1 Strategies are identified, and assessed in terms of how they can assist in the effective provision of management administrative services in the organisation.

Range: $\quad$ may include but is not limited to strategies relating to - building and maintaining links and working relationships, workflow, staff supervision, delegation, motivation, conflict resolution; evidence of four is required.

2.2 Strategies for providing effective client liaison are identified, and assessed in terms of how they can assist in the effective provision of management administrative services in the organisation. 
Range: $\quad$ may include but is not limited to strategies relating to - screening calls and callers, scheduling and managing appointments, meeting visitors, completing client requests and meeting client requirements;

evidence of three is required.

2.3 Time management strategies are identified, and assessed in terms of how they can assist in the effective provision of management administrative services in the organisation.

Range: $\quad$ may include but is not limited to - analysing activities, prioritising tasks, budgeting time, identifying time-wasters, reviewing use of time, meeting deadlines;

evidence of three is required.

\section{Comments on this unit standard}

Please contact NZQA National Qualifications Services nqs@ nzqa.govt.nz if you wish to suggest changes to the content of this unit standard.

\section{Please Note}

Providers must be accredited by the Qualifications Authority or a delegated interinstitutional body before they can register credits from assessment against unit standards or deliver courses of study leading to that assessment.

Industry Training Organisations must be accredited by the Qualifications Authority before they can register credits from assessment against unit standards.

Accredited providers and Industry Training Organisations assessing against unit standards must engage with the moderation system that applies to those standards.

Accreditation requirements and an outline of the moderation system that applies to this standard are outlined in the Accreditation and Moderation Action Plan (AMAP). The AMAP also includes useful information about special requirements for providers wishing to develop education and training programmes, such as minimum qualifications for tutors and assessors, and special resource requirements.

This unit standard is covered by AMAP 0113 which can be accessed at http://www.nzqa.govt.nz/site/framework/search.html. 


\section{APPENDIX D}

These roles titles and task lists are taken from the Career Services website (Career Services, 2007).

Administration officer/Team administrators may do some or all of the following and may specialise in some areas:

- co-ordinate office correspondence, including large mail-outs

- type letters, reports, memoranda, agendas, minutes and other documents

- maintain equipment and stationery supplies

- carry out receptionist duties such as greeting visitors and answering telephone calls

- undertake research for management staff

- assist with records management and filing.

- data entry

- travel planning, including arranging staff travel itineraries and accommodation

- assets supervision and bookkeeping, including budgeting, bill payments, banking and invoicing

- project or database management and meeting organisation (including tele- and videoconferences)

- training and supervising new administration staff

- health and safety, which includes making staff aware of building safety procedures and safe work practices.

Personal assistants may do some or all of the following:

- help managers organise their time effectively

- prepare travel itineraries for managers

- answer, screen and make telephone calls on behalf of managers

- prioritise incoming correspondence, including letters, memos and emails

- filter requests for appointments and arrange internal and external meetings and conference calls

- provide support at meetings including keeping minutes and follow-up actions

- type letters, reports, presentations and other documents

- co-ordinate filing and general administrative work for managers

- greet visitors

- take dictation (using shorthand, digital voice recorders or dictaphones)

- provide assistance to other staff.

Executive assistants may do some or all of the following:

- co-ordinate and prepare monthly reports, financial data and presentations

- organise meetings and conferences

- respond to and write letters, memos and emails

- take minutes and dictation

- take messages, answer queries and screen telephone calls

- maintain diaries, and make appointments and travel arrangements

- have responsibility for budgets and financial planning

- co-ordinate, assist, train and supervise other administration staff 
- compile statistics and other information

- undertake and manage projects

Administration/Office managers may do some or all of the following :

- supervise, evaluate and plan the work of other administrative staff

- interview and train staff

- manage facilities including vehicles and equipment

- ensure office meets health and safety requirements

- schedule events and projects

- liaise with administrative, technical and management staff, facilities contractors and building managers

- provide secretarial services, such as note taking, for committees

- maintain computer files, directories, databases and websites

- prepare correspondence

- manage records

- prepare financial and data reports. 
Sue Westbrook (AAPNZ Assoc, Cert)

National President

Association of Administrative Professionals New Zealand Inc

P O Box 5453

Wellesley Street

Auckland

\section{Re: Request for support to contact the AAPNZ membership with an opportunity to participate in a study of Administrative Professionals in New Zealand; their professional development opportunities and career pathways.}

Researcher: Eth Lloyd: School of Education, Victoria University of Wellington

\section{Dear Sue,}

I am writing to request the National Executive Committee's support for me to approach the membership with a request for them to participate in the above study. As you all know when I was National President of AAPNZ (2002 - 2004) I was instrumental in developing the AAPNZ Certification process and that I am currently Chairman of the national Professional Development sub-committee (PDSC) which administers Certification. Through this process I have developed a deep interest in, and concern about the professional development opportunities and career pathways available to administrative professionals i.e. the membership of AAPNZ.

Many of you may also know that I am now a full-time Masters student in Education at Victoria University of Wellington. As part of this degree I am undertaking a research project leading to a thesis. The project I am undertaking leads out of my interest, expressed above, examining the perceptions of professional development opportunities and career pathway options of administrative professionals in New Zealand. Ethics approval for conducting this research project has been gained from Victoria University College of Education Ethics Committee.

I would like to contact all AAPNZ members by email through their Group Presidents to invite them, as administrative professionals, to participate in this study. Participation will be through initially completing an on-line survey, and for those interested, involvement in focus group discussions. The information being asked of the membership is as in the attached questionnaire and, from those who request to be participants 16 - 20 will be selected.

As I know many of the AAPNZ members, selection of participants will be undertaken by my thesis supervisor Dr Liz Jones as my involvement in this could contribute to a criticism of bias in the study. However, should any participants feel the need to withdraw from the project, they may do so without question at any time until the data is analysed. They just let me know at the time. 
These focus groups, each with approximately 8 participants will be held one each in the North Island and the South Island. Participants in the focus groups will be discussing various aspects of their own professional development opportunities and their perceptions of the career pathways available to them personally.

The two focus groups will each meet twice over a four month period, once for gathering information and the second time to report back research findings to the group.

Information will be gathered at the focus groups by audio recording which will later be transcribed by me. The transcribed data will be analysed to develop any common themes or issues which will then be included in the final report. A video recording may also be used purely as an 'aide memoire' for me during transcription.

Response to the on-line survey provides consent for the information gathered to be used as part of this research project. Written informed consent is required for participation in the focus groups. This consent extends to the information provided by participants to be used in the project.

All potential participants in the focus groups will be given a pseudonym as soon as their application is received. All material collected will be kept confidential. No other person besides me and my supervisor, Dr Liz Jones will see the selection questionnaires. Only I and one of the facilitators will hear or see any of the other data collected. Generally grouped responses will be presented in this report. However, individual quotes may be used and identity will be protected through the use of a pseudonym. All questionnaires and data will be destroyed two years after the end of the project.

The thesis will be submitted for marking to the School of Education and deposited in the University Library. It is intended that articles will be submitted for publication in journals, e.g. admiNZ, the Human Resources (HRINZ) magazine Human Resources, the Recruitment Consultants (RCSA) magazine Recruitment, IAAP magazine OfficePro, and the AIOP magazine Leading the Way.

I hope that this involvement will be mutually beneficial for all who are involved and that together we all make a contribution to the understanding of administrative professionals' professional development opportunities and career pathways

If you have any questions or would like to receive further information about the project, please contact me at ethelwyn.lloyd@vuw.ac.nz or my supervisor, Dr Liz Jones, at the School of Education at Victoria University, P O Box 600, Wellington, phone (04)463 5939.

I look forward to hearing from you.

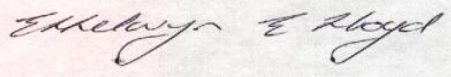

Signed:

Eth Lloyd

Masters Student

Victoria University of Wellington 


\section{APPENDIX F}

\section{National President}

AAPNZ

PO Box 1300

Rotorua 3040

Phone: (07)349-7858

Mobile: (021)239-9454

Email: president@aapnz.org.nz

Eth Lloyd

Masters Student

C/- School of Education

Victoria University of Wellington

PO Box 600

Wellington

Email: ethelwyn.lloyd@vuw.ac.nz

Kia ora Eth

\section{Re: AAPNZ membership opportunity to participate in a study of Administrative Professionals in New Zealand; their professional development opportunities and career pathways}

Thank you for your letter dated 22 April 2009, requesting support from the National Executive Committee (NEC) of the Association of Administrative Professionals New Zealand - Te Kawarangi (AAPNZ) to invite participation for your study, from our membership.

NEC congratulates and supports your purpose and objectives in undertaking this research project towards completing your thesis. We appreciate your commitment and interest in professional development opportunities and career pathways for administrative professionals, and especially our AAPNZ membership.

As outlined in your letter, you will make contact with AAPNZ members through their group presidents to invite administrative professionals to participate in this study. Participation will initially be through completing an on-line survey, with further opportunity of involvement in focus group discussions. NEC encourages all Group Presidents to share this information and support its membership to participate.

Also acknowledged is that the selection of AAPNZ participants in the group forums will be undertaken by your thesis supervisor, Dr Liz Jones, to avoid any bias of this study. Response to the on-line survey provides consent from individuals to use their information as part of your research, and all questionnaires and data will be destroyed two years after the end of the project. 
NEC sees this research as very valuable to our association, and for those in an administrative role looking to further their career ambitions. After your thesis has been marked by the School of Education, Victoria University of Wellington, NEC would be delighted to see your final Thesis or receive a copy for AAPNZ. As advised in your letter (22 April 2009), administrative professionals will have the opportunity to see articles submitted from your thesis in 'admiNZ'; the Human Resources (HRINZ) magazine 'Human Resources'; the Recruitment Consultants (RCSA) magazine 'Recruitment'; IAAP magazine 'OfficePro'; and the Australian Institute of Office Professionals (AIOP) magazine 'Leading the Way'.

Again Eth, congratulations. I look forward to your research with interest.

Naku noa, na

Association of Administrative Professionals New Zealand Inc - Te Kawarangi

Sue Westbrook AAPNZ Associate, AAPNZ Cert.

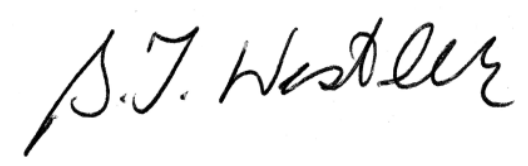

AAPNZ National President

cC: AAPNZ National Executive Committee

AAPNZ Group Presidents

Dr Liz Jones, School of Education, Victoria University of Wellington

"Excellence in Motion" 


\section{APPENDIX G}

24 April 2009

\section{Participant Information Sheet/Invitation to participate in an on-line survey for a study of Administrative Professionals; their professional development opportunities and career pathways in New Zealand}

Researcher: Eth Lloyd: School of Education, Victoria University of Wellington

\section{Dear AAPNZ Member}

I am a Masters student in Education at Victoria University of Wellington. As part of this degree I am undertaking a research project leading to a thesis. The project I am undertaking is examining the professional development opportunities and career pathways of administrative professionals in New Zealand. Ethics approval for conducting this research project has been gained from Victoria University College of Education Ethics Committee.

I am inviting members of the Association of Administrative Professionals New Zealand Inc to participate in this study. Initial participation will be through following this link https://www.surveymonkey.com/s.aspx?sm=nukj6vqtI4TUjZ3MJDtf3g_3d_3d and completing the on-line survey. Completing the survey should take you no more than 20 minutes. The survey will be open for only one week, until Friday $1^{\text {st }}$ May at 5 p.m.

This is a unique opportunity for you all to have your voices heard in the research and your responses will provide me with the material to undertake this research. To date I have found only two pieces of research relating to those who work in administration, one in California in 1959 and the other, which is Australian based in 2007. This means that the results of this research will provide a foundation for future work into the administrative field in the workforce.

As part of the survey you will be asked if you wish to participate in a focus group discussion. Two focus groups are being held, one in the North Island and one in the South Island; you will be invited to participate in one of these. Actual location of the focus groups will be determined after all applications have been received and will be on either a weekday evening, a Saturday or a Sunday. These focus groups will each meet twice over a four month period, once for gathering information and the second time to report back research findings to the group. Participants in the focus groups will be discussing various aspects of their own professional development opportunities and their perceptions of the career pathways available to them personally.

If you do then respond "yes" to the question in the survey about focus group participation, you will be requested to complete the information required. From the 
information supplied, up to 20 participants will be selected with $~ 10$ participants in each group. As I know many of you, selection of participants will be undertaken by my thesis supervisor, Dr Liz Jones. Those selected will be invited to attend the focus group closest to them. A $\$ 20$ petrol voucher will be offered as a contribution to travel for involvement in the nearest focus group.

The first focus groups will be held prior to June 2009 and the second focus group meetings will be held during August, each should take no more than two hours. As noted above, these will be to initially gather research data and then to report back to the group on the findings to date.

If you would like to be considered for selection as part of this research you will need to complete the on-line survey and to be able to commit to the two focus group sessions. However, should you feel the need to withdraw from the project, you may do so without question at any time before the focus group data is analysed. Just let me know at the time. Each applicant will be provided with a pseudonym as soon as their survey form is received and this pseudonym will be used at all times from that point on.

During the focus group the whole session will be audiotaped. The data will be analysed to develop any common themes or issues which will then be included in the final report. All research findings will be on an anonymous basis and through the use of pseudonyms will not be associated with the names of participants.

By responding to this on-line survey, you are providing your consent for the information gathered to be used as part of this research project. All material collected will be kept confidential. No other person besides me, my supervisor, Dr Liz Jones and one of the two focus group facilitators will see any of the other data collected. All survey forms and data will be destroyed two years after the end of the project.

The thesis will be submitted for marking to the Faculty of Education and deposited in the University Library. It is intended that one or more articles will be submitted for publication in various journals, e.g. the Association of Administrative Professionals New Zealand Inc (AAPNZ) magazine admiNZ, the Human Resources magazine Human Resource or the Recruitment Consultants (RCSA) magazine Recruitment.

I hope that this involvement will be a mutually beneficial time for us all. We will all have a better understanding of administrative professionals' professional development opportunities and career pathways.

If you have any questions or would like to receive further information about the project, please contact me at ethelwyn.lloyd@ vuw.ac.nz or my supervisor, Dr Liz Jones, at the School of Education at Victoria University, P O Box 600, Wellington, phone (04)463 5939.

Signed:

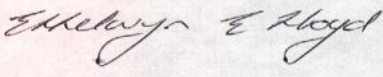

Eth Lloyd

Masters Student

Victoria University of Wellington 


\section{APPENDIX H}

\section{Demographic information}

This survey is to gather information about you, the industry sector you work in, the size of your organisation and its geographical location.

I also wish to gather information about your understanding and perception of professional development or training in your workplace. Professional development or training is usually undertaken to help you to do your job and to assist your career pathway plans.

The information gathered in this survey will be used as part of a research project for a Masters by Thesis being undertaken by Eth Lloyd through Victoria University.

Full information about this research has been provided in the covering email which included the link to this on-line survey.

\section{How many years have you worked as an administrative professional:}
O $1-5$
6-10
$11-20$
$21-30$
$31+$

\section{What is the title of your current position?}
Office Manager
$\bigcirc$ Administrative Support Supervisor
Personal Assistant
Office Administrator
Administrator
Receptionist
Administrative Assistant
Executive Assistant
$\bigcirc$ Project Support Officer
Administration officer
Executive Secretary
Business Administrator
Administration Manager
Legal Secretary
$\bigcirc$ Team Administrator
Administration supervisor
Hospital Administrator
Administration Team Leader
Secretary
Other (please specify)

\section{Where is your place of work located?}
Auckland
$\bigcirc$ Palmerston North
Nelson
$\bigcirc$ Hamilton
Napier
Blenheim
Tauranga
Hastings
christchurch
Rotorua
Masterton
west coast
Taupo
porirua
Timaru
New Plymouth
Hutt Valley
$\bigcirc$ Dunedin
wanganui
wellington
Invercargill

Other (please specify) 

4. What type of industry do you work in?
insurance
Engineering
Not-for-Profit
Health
Manufacturing
communications
Pinance
Education
Project Management
Accountant
Marketing
Retail
Legal
Government
$\bigcirc$ Medical
Local Government
other (please specify)

5. How many employees are there in your whole organisation?
○-5
○- 10
$11-25$
$26-60$
○1-99
$100-499$
○00+

6. How many employees are there in your office/workplace?
O $1-5$
6- 10
$11-25$
$26-60$
$61-99$
$100+$ 


\section{Professional Development/Training \& Career Pathways}

Professional development is the training that you are provided with, or select and choose to undertake, which will help you to do your job better. It can also be the training you undertake to move you along a career pathway for the future.

1. What groups of employees get professional development at your workplace? (Tick all relevant boxes)
$\square$ Don't know
$\square$ Management
Research Staff
Sales Staff workplace?
Yes
No
Don't know

$\square$ Administrative Staff

$\square$ Everyone

$\square$ Human Resources

$\square$ Anyone who requests it

A few individuals

No-one that I am aware of

Other (please specify)

2. Are there professional development opportunities/resources (e.g., funding, time to study, conference attendance) available for administrative staff at your

3. What professional development support/resources (e.g., funding, time to study, conference attendance) are available to you at your workplace?

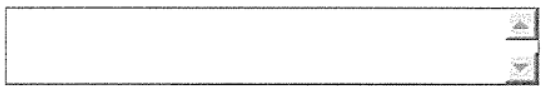

4. Do you undertake your professional development in work time?

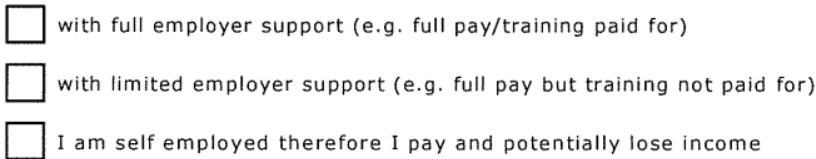

\section{Do you undertake your professional development in your own time?}

with employer support (e.g. employer pays for training costs)

with no employer support

I am self employed therefore I pay

Comment

6. If you undertake professional development in your own time, what sort of development do you do? 
7. What professional development opportunities do you know about and do you know how or where you can get them?

(Respond to as many of those listed below as you wish)
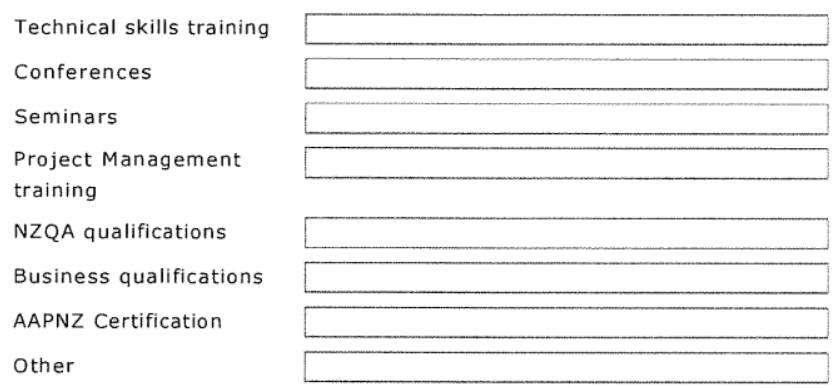

8. What professional development goals/desires/dreams do you have?

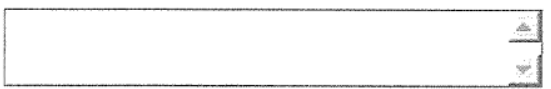

9. Why is professional development important to you?

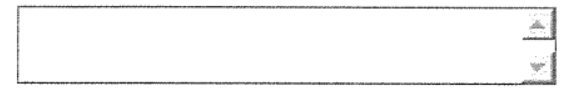

10. What career pathways do you believe are available to you?

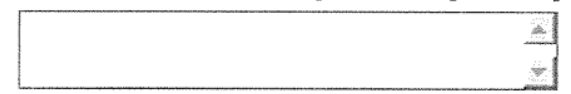

11. What would your ideal career be?

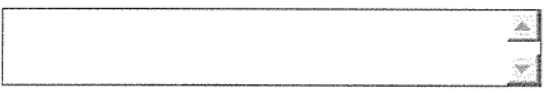

12. Please feel free to make any other comment

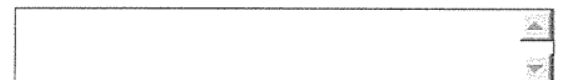

13. Would you like to participate further in this research through a focus group discussion on these issues?
$\bigcirc$ res
No

14. If you answered "Yes" to the question above, please provide the following information so that we can contact you.

Name:

Gender:

Email Address:

Phone Number:

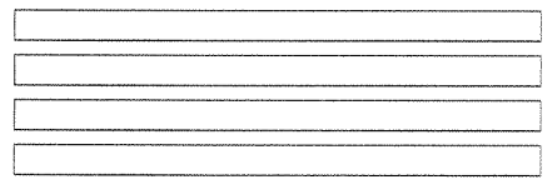

I would like to thank you very much for your contribution to this research. In gathering this information I will be able to undertake some basic analysis which will provide the background to my thesis. Your contribution is very important and valued. 


\section{APPENDIX I}

Other position titles from the survey

\begin{tabular}{|l|l|}
\hline Academic Officer & Centre Coordinator \\
\hline Executive PA & Administration Consultant \\
\hline Tutor in Business Administration & Business Manager \\
\hline Legal Executive & Executive Manager \\
\hline Revenue Team Leader & Operations Manager \\
\hline Customer Services and Democracy & Administration Secretary \\
\hline Manager & \\
\hline Judge's Associate & Customer Services Manager \\
\hline Lecturer & Human Resource Administrator \\
\hline Tutor & Administration Co-ordinator \\
\hline Senior Academic Staff Member & Software training and implementation \\
\hline Administration Consultant & Communications Assistant \\
\hline Sales \& Marketing Coordinator & Executive Personal Assistant \\
\hline Coordinator & Procurement Advisor \\
\hline General Manager & Administration Manager \\
\hline Administration Support & \\
\hline
\end{tabular}




\section{APPENDIX J}

\section{Selection Criteria for Focus Group Participants in a study of Administrative Professionals in New Zealand; their professional development opportunities and career pathways.}

\section{Researcher: Eth Lloyd: School of Education, Victoria University of Wellington}

Focus groups each require $\sim 8$ participants.

Information gathered on survey forms will include: gender, years working in administration, geographical area of work, type of industry in which working, title of current position, professional development opportunities provided and taken, and career pathway options available and/or wanted.

I would be looking for $~ 8$ each from the listed areas with the following ideal make-up:

\begin{tabular}{|c|c|c|c|}
\hline Geographic & \multicolumn{3}{|l|}{ Make-up: } \\
\hline $\begin{array}{l}\text { North Island } \\
\text { Q3 }\end{array}$ & $\begin{array}{l}\text { Large corporate (Q5) } \\
\text { Local govt or govt (Q4) } \\
\text { Small business or Not-for- } \\
\text { Profit (Q4) }\end{array}$ & $\begin{array}{l}4 \text { of } 8 \\
3 \text { of } 8 \\
1 \text { of } 8\end{array}$ & $\begin{array}{l}\text { Wide industry coverage (Q4) } \\
\text { Values PD (Q10-15) } \\
\text { Unaware/Aware of PD (Q16,17) } \\
\text { Unaware/Aware Career Path } \\
(\mathrm{Q} 16,17)\end{array}$ \\
\hline $\begin{array}{l}\text { South Island } \\
\text { Q3 }\end{array}$ & $\begin{array}{l}\text { Small business or Not-for- } \\
\text { Profit (Q4) } \\
\text { Local govt or govt Large } \\
\text { corporate }(Q 4,5)\end{array}$ & $\begin{array}{l}4 \text { of } 8 \\
3 \text { of } 8 \\
1 \text { of } 8\end{array}$ & $\begin{array}{l}\text { Wide industry coverage (Q4) } \\
\text { Values PD (Q10-15) } \\
\text { Unaware/Aware of PD(Q16,17) } \\
\text { Unaware/Aware Career Path } \\
(\mathrm{Q} 16,17)\end{array}$ \\
\hline
\end{tabular}

- The number of years working will have an impact on the make-up of the applicant's knowledge. Older workers often know less of what is available in professional development and often have lower expectations of what they could aspire to. Younger workers appear clearer about what they want and what is available, whether they actually have the knowledge or get what they want is not clear.

- It would be good to have a mix as above so that all views can be represented.

- I would anticipate some would know what professional development is available.

- I would anticipate that of those wanting professional development some were getting what they wanted or at least they knew what was available and how to get it.

- I would anticipate a significant number to not know either what they wanted or what was available. 


\section{APPENDIX K}

\section{Focus Group Participant Invitation for a Study of Administrative Professionals in New Zealand; their professional development opportunities and career pathways.}

Researcher: Eth Lloyd: School of Education, Victoria University of Wellington

\section{Dear}

Thank you for completing the survey and offering to participate in a Focus Group as part of the research for my Masters degree in Education at Victoria University of Wellington. The project I am undertaking is examining the professional development opportunities and career pathway options of administrative professionals in New Zealand.

This letter is to invite you to be part of the focus groups to be held in Christchurch on Tuesday $26^{\text {th }}$ May, 2009. Each focus group will take no more than 2 hours. A second focus group will be held in each location to report back to you all.

Ethics approval for conducting this research project has been gained from Victoria University College of Education Ethics Committee. I am enclosing a Consent form with this letter of invitation, which you will need to sign and bring with you when you attend the focus group. However, should you feel the need to withdraw from the project, you may do so without question at any time before the data is analysed.

Each focus group will have approximately 10 participants and will be held in two geographical locations, one in the North Island and the other in the South Island on either a weekday evening or a weekend day. While I will be present at the sessions to support the facilitator, each focus group will be run by a facilitator other than myself to ensure that my potential personal knowledge of many of the participants will not impact on the data being collected. Location and time of the focus group has been determined after receipt of applications for involvement. Your Focus Group facilitator is Wendy Rapana.

As a participant in the first focus group you will be discussing various aspects of your own professional development opportunities and your perceptions of the career pathways available to you personally.

At the second focus group meeting to be held in August, I will be reporting back to your group on the findings to date. I will be seeking confirmation from you all that your collective views have been properly represented. If the representation isn't accepted then further discussion will be held at that time to clarify.

Information will be gathered at the focus groups by audio recording which will later be transcribed by me. The transcribed data will be analysed to develop any common themes or issues which will then be included in the final report. Generally only grouped responses will be presented in this report. If any specific quotes are considered for use, identity 
would be protected by using a pseudonym which was allocated to you at the receipt of your survey form.

As noted above informed consent is required for your participation in the research project and a consent form is included with this letter. This consent extends to the information provided by you to be used in the project. All material collected will be kept confidential. No other person besides me, my supervisor Dr Liz Jones and one of the two focus group facilitators will see any of the personal data collected. All questionnaires and data will be destroyed two years after the end of the project.

The thesis will be submitted for marking to the School of Education and deposited in the University Library. It is intended that one or more articles will be submitted for publication in various journals, e.g. the AAPNZ magazine admiNZ, the Human Resources magazine Human Resource or the Recruitment Consultants (RCSA) magazine Recruitment.

If you have any questions or would like to receive further information about the project, please contact me at ethelwyn.lloyd@ vuw.ac.nz or my supervisor, Dr Liz Jones, at the School of Education at Victoria University, P O Box 600, Wellington, phone (04) 4635939.

I really look forward to meeting you on Tuesday $26^{\text {th }}$ May at $5.30 \mathrm{pm}$ and to working with you in the focus group sessions. I will separately confirm the venue to you by email as this is still being arranged.

Again I thank you for your willingness to participate in this research study. I hope that this involvement will be a mutually beneficial time for us and that together we may contribute to understanding administrative professionals' professional development opportunities and career pathways.

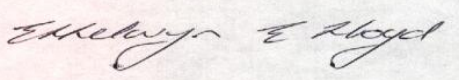

Eth Lloyd

Masters Student

Victoria University of Wellington 


\section{S9MICTORIA \\ UNIVERSITY OF WELLINGTON}

\section{APPENDIX L}

\section{Consent form for Focus Group Participants in a Study of administrative professionals, their professional development opportunities and career pathways in New Zealand}

\section{Researcher: Eth Lloyd: School of Education, Victoria University of Wellington \\ Consent}

To satisfy the ethics requirements of Victoria University it is necessary that you give consent to the following statements. Please tick all boxes you consent to:

I . agree to participate in the study of administrative professionals, their professional development opportunities and career pathway options in New Zealand, and give my consent freely.

$\square$ I understand the project will be carried out as described in the information sheet and the letter of invitation, a copy of which I have retained.

I realise that whether or not I decide to participate is my decision, and will not affect my role or my treatment within my workplace or my treatment by the researcher.

I also realise that I can withdraw from the project at any time before the data is analysed, and that I do not have to give any reasons for withdrawing. I have had all questions answered to my satisfaction.

I understand that the focus group discussions will be audiotaped and transcribed.

I understand feedback will be provided at the second focus group meeting and that our collective approval for representation of our views will be sought.

$\square \quad$ I also understand that all information held about me (survey information), all recordings and whiteboard/flip chart notes will be destroyed two years after the end of the study.

$\square \quad$ Due to the use of pseudonyms I understand I will not be identifiable in the final report.

I further understand that all information provided will be treated with the utmost confidentiality which will be maintained at all times.

Signatures:

Researcher Date

Participant

Date

I would like a copy of the summary of findings at the conclusion of this research project. 


\section{APPENDIX M}

\section{Focus Group Questions for a study of Administrative Professionals in New Zealand; their professional development opportunities and career pathways}

Researcher: Eth Lloyd: School of Education, Victoria University of Wellington

\section{Focus Group Questions}

How do administrative professionals in New Zealand perceive the effects of their professional development opportunities on their career pathways?

\begin{tabular}{|l|l|}
\hline Question & Time \\
\hline Opening: & 10 mins \\
$\begin{array}{l}\text { Everyone here today works in the administrative professional field. } \\
\text { Can you each briefly introduce yourself; give your job title, the } \\
\text { industry that you work in and what professional development means } \\
\text { to you. }\end{array}$ & 15 mins \\
\hline $\begin{array}{l}\text { 1. I would like you to think about your own professional } \\
\text { development opportunities. } \\
\text { Can you please describe some opportunities you have had in your } \\
\text { working life? }\end{array}$ & 25 mins \\
\hline $\begin{array}{l}\text { 2. Given your current workplace what is your perception of how } \\
\text { professional development opportunities for you are seen by your } \\
\text { employers? What is that like for you? }\end{array}$ & 15 mins \\
\hline $\begin{array}{l}\text { 3. Do you believe your career choices have been affected by the } \\
\text { professional development opportunities that you have received? }\end{array}$ & \\
\hline $\begin{array}{l}\text { a) Can you tell us what effect that was and how that was for } \\
\text { you? }\end{array}$ & 25 mins \\
\hline $\begin{array}{l}\text { a) What professional development do you believe might help } \\
\text { you and how might you achieve that? }\end{array}$ & 15 mins \\
describe what you think are available to you? & \\
\hline $\begin{array}{l}\text { Closing: } \\
\text { Any other questions, thoughts or something that you haven't had an } \\
\text { opportunity to share which you feel will add value to this discussion }\end{array}$ & \\
\hline
\end{tabular}




\section{APPENDIX N}

Confidentiality form for Focus Group Facilitators in a study of Administrative Professionals; their professional development opportunities and career pathways in New Zealand

Researcher: Eth Lloyd: School of Education, Victoria University of Wellington

\section{Confidentiality Agreement for Focus Group Facilitators}

To satisfy the ethics requirements of Victoria University and the Privacy Act it is necessary that you sign a confidentiality agreement prior to facilitating the focus groups planned for the above study.

I agree that all information about the participants in the focus groups which reveals details of identity, location they live in, name of their employer, place of work, etc will be maintained confidentially. All notes and papers to do with the focus groups will returned to the researcher after the debrief session.

Signatures:

Researcher Date




\section{APPENDIX 0}

\section{Data analysis themes}

Employment environment:

what manager does,

budget,

organisation view,

educating your manager (i.e. showing what you can do to help and therefore the value of professional development).

Personal characteristics:

open to opportunities,

attitudes - valuing self,

mentoring,

blocks.

Professional development opportunities:

past,

present,

value,

changing jobs is professional development,

blocks.

Career pathways:

what they might be,

clarity about what is available,

how to achieve/get there. 
TE WHARE WANANGA O TE ÜPOKO O TE IKA A MĀUI

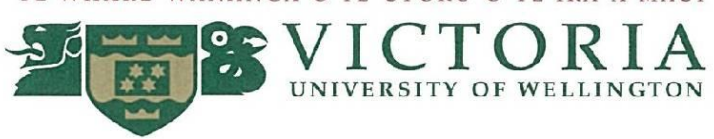

22 April 2009

Ethelwyn Lloyd

164 Weggery Drive

Waiakane 5036

Dear Eth

\section{RE: Ethics application SEPP/2008/14, RM 16442}

I am pleased to advise you that your ethics application 'Administrative Staff in New Zealand: their professional development opportunities and career pathways' with the requested amendments, has been approved by the Victoria University of Wellington College of Education Ethics Committee. Please note that the approval for your research to commence is from the date of this letter.

Good luck with your research.

Yours Sincerely
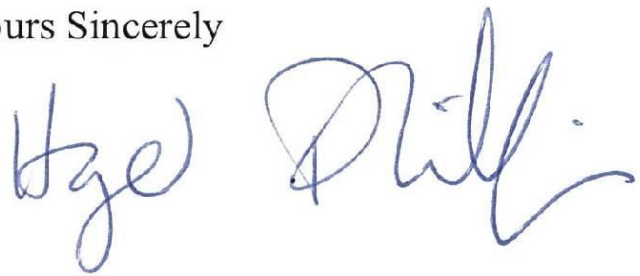

Hazel Phillips

Co-Convener

Victoria University of Wellington College of Education Ethics Committee 